\title{
Las razas de maní de Ecuador
}

\author{
The peanut landraces from Ecuador
}

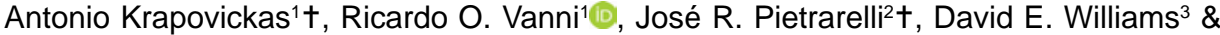 \\ Charles E. Simpson ${ }^{4}$
}

\begin{abstract}
Resumen: En este estudio para maní, se diferencian para Ecuador 51 razas de maní cultivados, de las cuales 18 pertenecen a Arachis hypogaea subsp. hypogaea var. hypogaea, una Arachis hypogaea subsp. hypogaea var. hirsuta, 13 a Arachis hypogaea subsp. fastigiata var. fastigiata, 10 a Arachis hypogaea subsp. fastigiata var. peruviana, 9 a Arachis hypogaea subsp. fastigiata var. aequatoriana; la var. aequatoriana, es casi exclusiva de la República del Ecuador, lo que indica otro genocentro importante.
\end{abstract}

Palabras clave: Arachis hypogaea, biodiversidad, Ecuador, razas cultivadas de maní.

\begin{abstract}
Summary: In this peanut study, 51 races of cultivated peanuts are distinguished for Ecuador, of which 18 belong to Arachis hypogaea subsp. hypogaea var. hypogaea, 1 to Arachis hypogaea subsp. hypogaea var. hirsuta, 13 to Arachis hypogaea subsp. fastigiata var. fastigiata, 10 to Arachis hypogaea subsp. fastigiata var. peruviana, 9 to Arachis hypogaea subsp. fastigiata var. aequatoriana; var. aequatoriana is almost exclusive to the Republic of Ecuador, which indicates another important genocenter.
\end{abstract}

Key words: Arachis hypogaea, biodiversity Ecuador, cultivated races, peanut.

\section{Introducción}

Hasta el año 1983, en el banco de germoplasma de maní (Arachis hypogaea L.) que se mantiene de la Estación Experimental Agropecuaria de Manfredi INTA (provincia de Córdoba, Argentina), existía una única introducción originaria de Ecuador, procedente de la localidad de Zaruma, provincia de El Oro, ubicada en las sierras, en el sur de dicho país.

Dicha introducción, enviada por el Sr. Polobio A. Romero y recibida a través de la División de Exploraciones e Introducción de Plantas (DEIP) en 1948, se distinguía de la generalidad de las muestras de maní procedente de los genocentros andinos de Bolivia y Perú, por diversos caracteres botánicos, especialmente por el color morado intenso de su corola, lo cual hacia presumir la existencia en Ecuador de otro centro importante de variabilidad de la especie.

En diciembre de 1976 se inició un ambicioso plan de recolección de maníes silvestres y cultivados. Ese plan fue subvencionado por el IBPGR (International Board for Plant Genetic Resources, nowadays Bioversity International) y las primeras expediciones fueron organizadas y lideradas por el Dr. Walton C. Gregory,

\footnotetext{
${ }^{1}$ Instituto de Botánica del Nordeste (UNNE-CONICET), F.C.A., Casilla de Correo 209, 3400 Corrientes Argentina. E mail: gvanni@agr.unne.edu.ar

${ }^{2}$ Estación Experimental INTA, Manfredi, Córdoba, Argentina.

${ }^{3}$ System-wide Genetic Resources Programme (SGRP), c/o Bioversity Internacional, Rome, Italy.

${ }^{4}$ Texas A\&M AgriLife Research,Texas \& University, Stephenville, Texas 76401, USA.
} 
del North Carolina State University, Raleigh (USA). Este investigador invitó a participar en las recolecciones a técnicos de diversas instituciones y países.

Después de integrar y liderar los equipos de las diferentes prospecciones llevadas a cabo desde 1976 a 1980, el Dr. Gregory se retiró como jefe del proyecto, quedando en su cargo el Dr. Charles E. Simpson, investigador de la Texas Agricultural Experiment Station en Stephenville, Texas (USA). Por lo tanto, el proyecto de colecciones en Ecuador correspondió a este último, quien invitó a los siguientes técnicos para realizar el trabajo de campo:

Banks, Donald J., United States Department of Agriculture and Oklahoma State University, Stillwater, Oklahoma, USA.

Pietrarelli, José R., Estación Experimental Agropecuaria de Manfredi- Instituto Nacional de Investigaciones Agropecuarias (INTA), Manfredi, provincia de Córdoba, Argentina.

Zurita, Hebert O., Estación Experimental de Saavedra, Centro de Investigaciones Agrícola Tropical (CIAT), Santa Cruz de la Sierra, Bolivia.

El 11 de mayo de 1983, los tres participantes (Banks, Pietrarelli y Zurita), procedentes cada uno de su propio país, se reunieron en Quito (Ecuador) e inmediatamente comenzaron a realizar contactos con el objeto de obtener información y cooperación en diferentes aspectos como transporte, asesoramiento y guía para recorrer las áreas de mayor concentración de cultivos de maní.

El contacto de mayor relevancia fue con el Dr. Julio C. Delgado, Director General del Instituto Nacional de Investigaciones Agropecuarias (INIAP). En primer lugar, facilitó transporte y chofer (guía al mismo tiempo) para coleccionar en la provincia de Pichincha. Posteriormente, indicó el personal de su organización que colaboraría. Entre estas colaboraciones se destaca el aporte, al éxito de la recolección en Ecuador, del Ing. Agr. Eduardo Calero H., subdirector General del INIAP, con asiento en la ciudad de Guayaquil y la del Ing. Agr. Saúl Mestanza, Director de la Estación Experimental "Boliche", los que proveyeron al equipo coleccionista, de información, técnicos guías y transporte.
En esa Estación Experimental fueron recogidas muestras de semillas de maní que corresponden a tres cultivares que tienen un cierto grado de difusión en el área manisera de Ecuador, conservándose la pureza de los mismos en la institución mencionada.

"Boliche” (selección de la población Tarapoto, originaria de Perú).

"Santa Rosa” (cultivado principalmente en la provincia de El Oro).

“Rojo de Oriente” (muestra original procedente de la región amazónica).

Tomando como base la información recibida se planificó coleccionar en las provincias con mayor superficie cultivada con maní; Manabí: 5.500 hectáreas, Loja: 4.600 hectáreas y El Oro: 950 hectáreas.

Lamentablemente, no se pudo visitar la provincia de Manabí debido a que los caminos de acceso estaban intransitables por las inundaciones. Afortunadamente, varias muestras originarias de esa provincia pudieron ser obtenidas en un almacén de la plaza San Francisco de la ciudad de Quito.

En línea general, todos los cultivos visitados, aún en las provincias más productoras, eran muy pequeños, no superando en ningún caso la hectárea. Esta observación hizo pensar que cultivos pequeños se podían encontrar en todas las provincias, por lo cual se realizaron breves incursiones en las provincias de Pichincha, donde se hallaron pequeños sembradíos de la var. hirsuta, y en la de Guayas.

Cabe mencionar que además del inconveniente de las inundaciones, se presentó el de los derrumbes que bloqueaban los caminos, lo cual impidió una exhaustiva exploración de las diferentes provincias visitadas. De todas maneras, por la gran variabilidad de las muestras coleccionadas, se opina que el material estudiado en Manfredi representa la mayor parte del panorama varietal del maní en Ecuador.

\section{Detalle sobre las recolecciones}

El personal técnico y transportista que colaboró en las recolecciones, fue el siguiente: Ing. Agr. Luis Haro N., técnico de la Estación Experimental “Boliche”, Ing. Agr. Vicente Azules, Técnico Extensionista del área de Loja y Sr. Francisco Valenzuela, chofer de la 
Dirección General del INIAP, en Quito y guía en el área de Pichincha.

Las colecciones se llevaron a cabo en pequeños cultivos (que en ese momento se estaban cosechando), en algunos almacenes y mercados. La prospección duró 13 días, desde el 11 al 24 de mayo de 1983. Fueron coleccionadas 53 muestras de maníes cultivados, desde el número US 681 al 733. No fueron localizados maníes silvestres. En 7 pequeños cultivos fueron coleccionadas otras tantas muestras de Rhizobium, desde el Vial 500 al 506.

Antes de que el equipo se disolviera se procedió, al igual que con las colecciones realizadas en otros genocentros, a dividir cada muestra en partes iguales. En este caso para Estados Unidos, Argentina, Bolivia y Ecuador.

Según provincias, la cantidad de muestras coleccionadas en cada una de ellas fueron las siguientes:

Pichincha: 10 (4 Manabí, 2 de la costa), Guayas: 10 (1 de Manabí, 1 de Amazonas y 1 de Perú), El Oro: 9, Loja: 23 y Los Ríos: 1.

\section{Materiales y Métodos}

Manejo del material durante varias campañas agrícolas en Manfredi

En la Estación Experimental de Manfredi, tras un primer análisis, las 53 muestras originales se transformaron en 98 al dividir cada una de ellas por el color de grano. Por ejemplo, la muestra US 693 tuvo que ser divida en 6, por estar integrada por granos colorados, morados de punta clara, violáceos, pálidos salmón, overo (colorado y albo) y jaspeado (pálido con líneas longitudinales violáceas).

En el mes de noviembre de 1983 fueron sembradas esas 98 muestras agrupadas según el color del grano observado.

A campo fueron tomadas observaciones sobre tipo de planta, porte, ramificación, grado de desarrollo del eje central, color del tallo, del brote, del clavo y de la flor, presencia o ausencia de cerdas en las estípulas.

En todas las parcelas se individualizaron las plantas de tipo diferente, para cosecharlas por separado.
Realizada la cosecha fueron analizados los frutos (cajas), agrupándolos según tamaño (largo y ancho de 10 cajas), presencia y relevancia de nervaduras, pico y joroba, número de granos, color y tamaño de éstos (largo y ancho de 10 granos) y peso de los 100 granos (P100S).

Se correlacionaron los datos de cosecha con las observaciones realizadas en el cultivo a fin de uniformar cada parcela de la colección viva, con el objeto de simplificar el muestreo y para que la comparación fuera más sencilla, dando como resultado la percepción de afinidades en forma más evidente.

Este proceso de selección en las parcelas se repitió en las campañas 83/84, 84/85, 85/86, 88/89, hasta conseguir una uniformidad morfológica satisfactoria, formándose en muchos casos, verdaderas líneas puras.

En cada campaña se sembró la colección viva tratando de agrupar las parcelas por sus características de ramificación, tipo de planta y forma de fruto.

La primera clasificación se realizó sobre la base del tipo de ramificación, separando las muestras pertenecientes a las dos subespecies, hypogaea y fastigiata y dentro de éstas se las fue agrupando por otras características.

Por ejemplo, se detectó en varias muestras pertenecientes a la subespecie fastigiata, la presencia de pelos de 1-2 mm long. en el envés de los folíolos, por lo cual todas ellas se sembraron juntas. De esta manera se puede apreciar que dicho carácter estaba asociado con otros caracteres como color del follaje y ramificación, que de otra manera hubiera sido difícil de apreciar. En toda la colección viva se destacaban estas parcelas por una tonalidad especial de verde y por el destacado desarrollo del eje central.

La constancia de estas características permitió distinguir a este grupo de razas como una variedad botánica, la var. aequatoriana, casi exclusiva a la República del Ecuador.

Para denominar las razas se respetaron los nombres locales de las muestras. De no ser así, se asignaron nombres según la región de cultivo o en otros casos remarcando algún carácter exomorfológico distintivo de la planta, porte, tipo de caja o color del tegumento de la semilla. 
La formación de esta importante colección de razas de maní de Ecuador, que enriqueció este banco de germoplasma, fue posible gracias al apoyo de las siguientes instituciones, IBPGR (FAO), USDA (EE.UU.); INTA e IBONE (UNNE-CONICET).

Las siguientes siglas corresponden a los integrantes de los equipos que coleccionaron en Ecuador:

$\mathrm{B}=$ Banks, D. J. USDA, Oklahoma, State University, Stillwater, Oklahoma, USA. $\mathrm{Ha}=$ Haro, Luis. E. E. Boliche, Ecuador. $\mathrm{P}=$ Pietrarelli, José R., Instituto Nacional de Tecnología Agropecuaria (INTA), Manfredi, Argentina

$\mathrm{S}=$ Simpson, Charles E., Texas Agricultural

Experiment Station, Texas USA.

$\mathrm{T}=$ Tapia, Cesar (INIAP-DENAREF)

Ecuador.

$\mathrm{Va}=$ Valenzuela, Franco E. E. Santa Catalina, Quito, Ecuador.

$\mathrm{W}=$ Williams, David E. (IPGRI-Americas)

W= Williams, Karen A. (USDA-ARS).

$\mathrm{Z}=$ Zurita, Hebert, Centro de Investigaciones

Agrícolas Tropicales (CIAT), E. E. Saavedra, Santa Cruz, Bolivia.

\section{Clave para distinguir los taxones infraespecíficos de Arachis hypogaea de Ecuador}

A. Eje central sin flores, ramas $\mathrm{n}+1$ en las que alternan dos ramas vegetativas $\mathrm{y}$ dos reproductivas (ramificación alternada). subsp. hypogaea

B. Folíolos con el envés glabro o con algunos pelos sobre el nervio medio. var. hypogaea

B'. Folíolos con el envés con pelos de 1 a $2 \mathrm{~mm}$ long., esparcidos en toda la superficie. var. hirsuta

$\mathrm{A}^{\prime}$. Eje central con flores y ramas laterales en las que las ramas reproductivas y vegetativas no se presentan en ningún orden (ramificación secuencial). subsp. fastigiata

C. Folíolos con el envés glabro o con pelos solamente sobre el nervio medio.

D. Frutos con retículo suave o marcado, sin que se destaquen las costillas longitudinales. Ramas reproductivas por lo general breves y delgadas. var. fastigiata

D'. Frutos siempre con retículo muy marcado y con costillas longitudinales sobresalientes. Ramas reproductivas por lo general largas y robustas. var. peruviana

$C^{\prime}$. Folíolos con el envés con pelos de 1-2 mm long. esparcidos en toda la superficie. Ramas reproductivas largas y robustas. var. aequatoriana

\section{Clave para las razas de maní de Ecuador}

\section{Arachis hypogaea subsp. hypogaea var. hypogaea}

A. Granos overos (colorado y albo).

B. Plantas rastreras, estípulas sin setas.

1. Caramelo

B'. Cojines, estípulas con setas.

C. Planta pequeña. Eje central no aparente.

2. Overo enano

C'. Planta más grande. Eje central algo aparente.

3. Overo compacto

A'. Granos de un solo color.

D. Cajas con 2-1(-3) granos.

E. Hojas con folíolos plegados. Estípulas con setas. Cojín pequeño.

F. Granos salmón.

4. Folíolos plegados salmón

F'. Granos colorados.

5. Folíolos plegados colorado

E'. Hojas con los folíolos extendidos.

G. Granos rosados. Frutos redondeados. Plantas con setas.

H. Plantas rastreras

6. Pepón rastrero

H'. Cojines.

7. Pepón cojín 
G'. Granos colorados.

I. Plantas rastreras con setas.

8. Colorado rastrero

I'. Cojines.

J. Con setas. Cojín semirastrero

9. Higuerilla

J'. Sin setas.

K. Cojín semirastrero.

10. Cultivar Santa Rosa

K'. Cojín pequeño.

11. Cojín pequeño colorado

G". Granos salmón.

L. Rastrero.

12. Rastrero salmón

L'. Semirastrero.

13. Semirastrero salmón

D'. Cajas con hasta 4 granos.

M. Planta verde claro.

N. Caja lisa, pequeña, granos pálidos.

14. Caja fastigiata, pálido, 3-4 granos

N'. Caja reticulada.

O. Cajas con costillas longitudinales más prominentes.

(tipo peruviana). Granos salmón.

15. Caja peruviana, salmón, 4 granos

O'. Cajas con retículo uniforme (tipo hirsuta).

P. Granos pálidos.

16. Caja reticulada, pálido 3-4 granos

P'. Granos negros.

17. Negro cojín

M'. Plantas verde oscuro.

Q. Granos negros.

R. Cajas tipo peruviana. Granos negros.

18. Cojin negro

R'. Retículo uniforme.

S. Cajas tipo hirsuta.

18'. Reticulado, violáceo

S'. Cajas retículo fino.

$18 "$. Cajas retículo fino

Q'. Granos salmón. Semirastrero.

18 "'. Semirastrero salmón

Arachis hypogaea subsp. hypogaea var. hirsuta

19. Maní de la mitad del mundo

\section{Arachis hypogaea subsp. fastigiata var. fastigiata}

A. Planta compacta, ramificada; eje central no aparente.

B. Granos colorados.

C. Planta pequeña, deja espacio entre los surcos.

D. Planta erecta. Cajas grandes, 4,6 cm long. $\times$ 1,4 cm lat. P100S 64 grs. ..... 20. Colorado caja grande

D'. Planta muy pequeña. Cajas menores.

E. Muy precoz. Cajas muy angostas, 3,03 cm long. $\times 1,10 \mathrm{~cm}$ lat. P100S 34-48 grs.

21. Colorado precoz

E'. Algo más tardía. Cajas algo más gruesas, $3,40 \mathrm{~cm}$ long. × 1,43 cm lat. .. 22. Colorado pequeño

C'. Planta bien desarrollada, cubre el surco.

F. Cajas lisas, sin pico ni carena.

G. Frutos mayores.

23. Colorado Portoviejo

G'. Frutos menores.

24. Colorado Sargentillo

F'. Cajas reticuladas con costillas longitudinales algo más marcadas, con pico y carena. 
H. Frutos menores 25. Colorado chico

H'. Frutos mayores. Cajas 3,44 cm long. $\times 1,40 \mathrm{~cm}$ lat. P100S 50-68 grs. 26. Rosita B'. Granos pálidos.

I. Planta bien desarrollada. Cajas 3,33 cm long. $\times 1,48 \mathrm{~cm}$ lat., con pico. 27. Rosita pálido

I'. Planta menor, bien erecta. Cajas gruesas, 3,34 cm long. $\times 1,57 \mathrm{~cm}$ lat., sin pico. .. 28. Rosita sin pico B". Granos violáceos. Planta mediana. 29. Negro planta compacta

A'. Planta poco ramificada; eje central aparente.

J. Granos colorados. Planta grande abierta. P100S 72-88grs. 30. Colorado de Piñas

J'. Granos pálidos. Planta pequeña. P100S 50-64 grs. 31. Pálido de Sargentillo

J". Granos violáceos. P100S 60-72 grs.

32. Zapotepamba

\section{Arachis hypogaea subsp. fastigiata var. peruviana}

A. Granos bicolores, pálido y morado.

B. Granos pálidos con líneas cortas violáceas. Clavo verde. 33. Tingo María

B'. Granos violáceos a pálidos, con manchas apicales más oscuras (la intensidad y extensión del violáceo varía). Clavo morado.

C. Estípulas con setas. Eje central poco aparente, ramas casi erectas. Cajas con frecuencia hasta $5 \mathrm{~cm}$ long. (raro hasta $7,5 \mathrm{~cm}$ ), con pico y jorobas. 34. Jaspeado con setas

C'. Estípulas sin setas. Eje central aparente, ramas decumbentes. Cajas por lo común hasta $4 \mathrm{~cm}$ long. (raro hasta $4,5 \mathrm{~cm}$ ), sin pico y sin joroba.

35. Jaspeado sin setas

A'. Granos con un solo color.

D. Frutos de hasta 4 granos, por lo común no pasan de $4 \mathrm{~cm}$ long. (raro hasta $5 \mathrm{~cm}$ ) y 1,5 a $2 \mathrm{~cm}$ de diámetro; con jorobas dorsales y carena, sin pico.

E. Granos violáceos.

F. Granos violáceos.

G. Planta poco ramificada, eje central aparente.

H. Planta muy chica. Tallo, brotes y flores moradas. 36. Morado de Catacocha

H'. Planta mayor, tallo violáceo. Brotes y pecíolos verdes. Flor anaranjada.

37. Verde de Cotacocha

G'. Planta bien ramificada, compacta, eje central apenas aparente.

I. P100S 59-67 grs.

38. Negro criollo

I'. P100S 45-55grs.

39. Criollo

F'. Granos morados con tintes rojizos. 40. Morado rojizo

E'. Granos pálidos. 41. Peruano pálido

D'. Frutos de hasta 4 granos, por lo común de $5 \mathrm{~cm}$ long. (hasta 7,5 cm) y 1,5 hasta algo menos de $2 \mathrm{~cm}$ de diámetro. Granos morados. Clavo violáceo. 42. Catalán

\section{Arachis hypogaea subsp. fastigiata var. aequatoriana}

A. Frutos por lo común menores de $4 \mathrm{~cm}$ long. (raro hasta $5 \mathrm{~cm}$ ) y de 1,5 a $2 \mathrm{~cm}$ de diámetro, con carena y sin pico (raro con pico apenas insinuado). Ramas de posición variable.

B. Flor con alas anaranjadas, siempre con mancha morada; estandarte desde anaranjado a morado. Brote violáceo.

C. Granos violáceos con punta clara (extensión e intensidad del violáceo variables). Fruto sin pico......

43. Zaruma

C'. Granos negros.

44. Zaruma negro

C". Granos pálidos con tinte violáceo. Estandarte anaranjado. Fruto con pico algo marcado. 
B'. Flor con alas amarillas, sin manchas. Estandarte anaranjado. Brote verde. Fruto sin pico.
D. Granos pálidos.
46. Zaruma pálido
D'. Granos rosados. 47. Zaruma rosado
D". Granos colorados.
48. Zaruma colorado

A'. Frutos con frecuencia hasta $7 \mathrm{~cm}$ long. y menores de 1,5 cm de diámetro, con pico marcado. Ramas casi rastreras.

E. Granos violáceos a negros.

49. Huasquillo

E`. Granos pálidos. 50. Huasquillo pálido

E". Granos violáceos con punta clara. 51. Huasquillo punta clara

\section{Enumeración de las razas}

Arachis hypogaea subsp. hypogaea var. hypogaea (Fig. 1A)

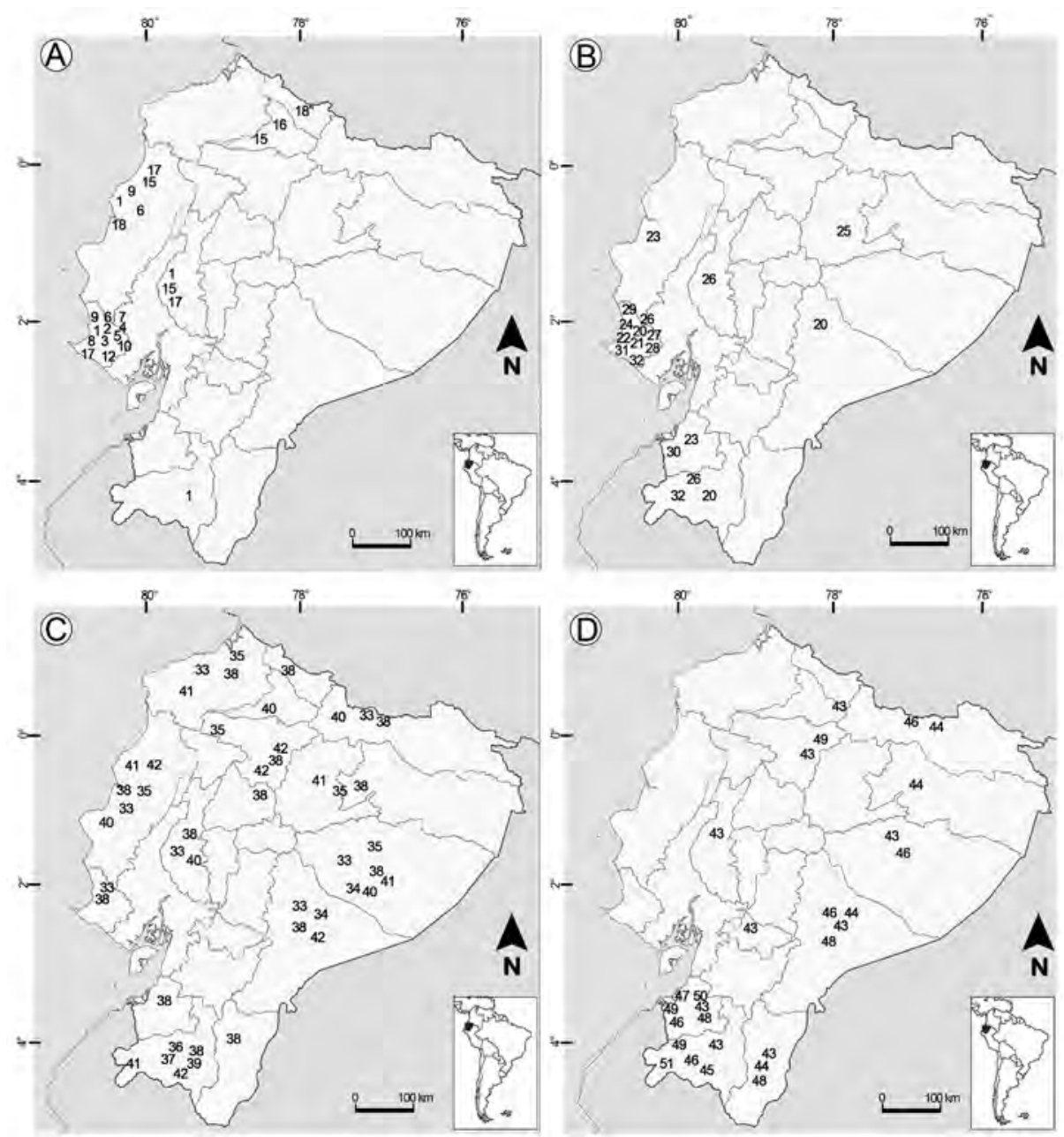

Fig. 1. Mapa de distribución de las razas en Ecuador. A: Arachis hypogaea subsp. hypogaea var. hypogaea. B: Arachis hypogaea subsp. fastigiata var. fastigiata. C: Arachis hypogaea subsp. fastigiata var. peruviana. D: Arachis hypogaea subsp. fastigiata var. aequatoriana

Fig. 1. Race distribution maps in Ecuador. A: Arachis hypogaea subsp. hypogaea var. hypogaea. B: Arachis hypogaea subsp. fastigiata var. fastigiata. C: Arachis hypogaea subsp. fastigiata var. peruviana. D: Arachis hypogaea subsp. fastigiata var. aequatoriana. 


\section{Caramelo}

Planta de porte rastrero, poco extendida; eje central poco aparente; ramas reproductivas muy cortas, no más de $2 \mathrm{~cm}$ de longitud. Tallo verde. Sin cerdas. Estandarte con aro (arco rojo en la base del estandarte). Clavo morado.

Cajas casi lisas, con algo de carena (vena media de la caja) y sin pico, con 2-1 granos de color overo (colorado con muy poco de albo).

\section{9/10 1392 WWT 1373 Grif 12595 Manabí, Corre Agua, 5 m s.n.m.}
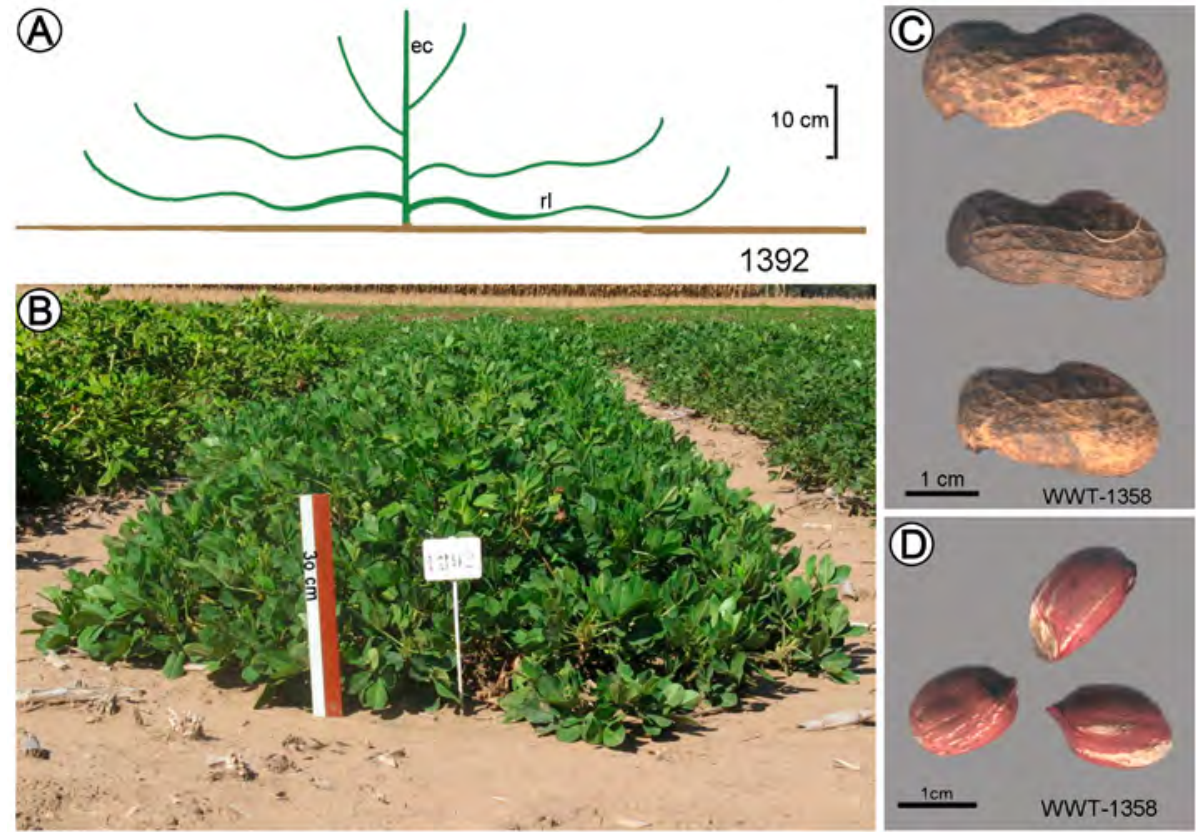

Fig. 2. Caramelo, 1392. A: Esquema de la planta. B: Planta. C: Fruto. D: Semillas.

Fig. 2. Caramelo, 1392. A: Plant outline. B: Plant. C: Fruit. D: Seeds.

Mdi.

US

687 (1) $86 / 2762$

97/98 1501

687

97/98 1503

98/99 2596

98/99 2597

98/99 2598

98/99 2599

98/99 2602

98/99 2603

98/99 2604

98/99 2605

98/99 2742

98/99 2762

731-2

WTS 24 Grif 13808

WTS 52 Grif 13833

WTS 67 Grif 13848

WTS 90 Grif 13871

WTS 69 Grif 13850
Leg. Nombre original

BPZ Higuerilla

WWT 1358 Grif 12578

WWT 1373 Grif 12595

WWT 1374 Grif 12597

WWT 1375 Grif 12598

WWT 1376 Grif 12601

\section{Procedencia}

Pichincha, Quito, almacén

Pichincha, Quito, almacén

Loja, Sacapianga, 1140 m s.n.m.

Manabí, CorreAgua, 5 m s.n.m.

Manabí, Charapotó

Manabí, Charapotó

Esmeraldas, Rosa Zárate, 240 m s.n.m.

Manabí, Tosagua, 240 m s.n.m.

Guayas, Babahoyo, 140 m s.n.m.

Los Ríos, Quinsaloma, 320 m s.n.m.

Manabí, Charapotó, 10 m s.n.m.

Guayas, Jujan, 140 m s.n.m. 


\section{Overo enano}

Planta pequeña, compacta, de porte erecto, con ramificación alternada; eje central no aparente. Estípulas con cerdas. Ramas reproductivas alargadas, hasta $5 \mathrm{~cm}$ long. Tallo verde.

Cajas más o menos pequeñas, muy poco estranguladas, con carena, con algo de pico; con 2-1 granos overos (colorado y albo en las mismas proporciones).
2009/10 1368
US 693 (4)
BPZHa
Guayas, Pedro Carbo
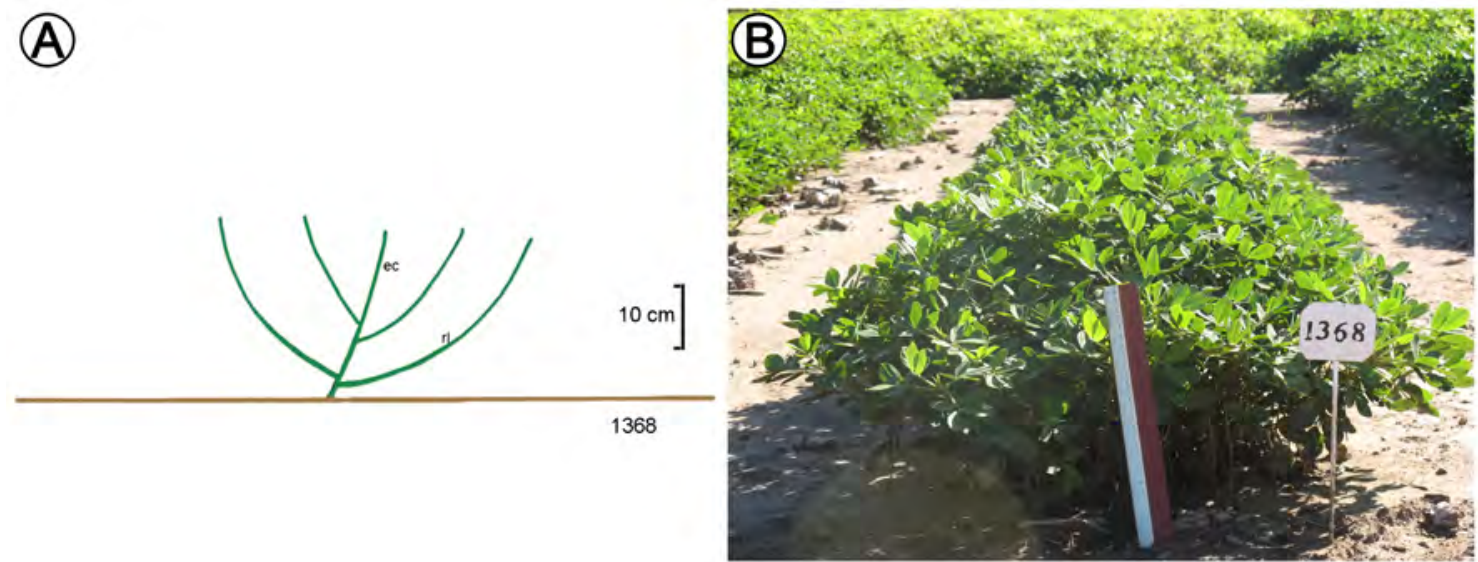

Fig. 3. Overo enano, 1368. A: Esquema de la planta. B: Planta.

Fig. 3. Overo enano, 1368. A: Plant ouline. B: Plant.

$\begin{array}{lllll}\text { Mdi. } & \text { US } & \text { Leg. } & \text { Nombre original } & \text { Procedencia } \\ \text { 86/2744 } & 693(6) & \text { BPZHa } & \text { Charapotó } & \text { Guayas, Pedro Carbo, almacén } \\ 97 / 981502 & 693(4) & & & \text { Guayas, Pedro Carbo }\end{array}$




\section{Overo cojín compacto}

Planta cojín compacto (tipo Virginia Bunch); eje central casi no aparente. Estípulas con cerdas. Ramas reproductivas por lo común de $4-5 \mathrm{~cm}$ long.; suelen presentarse algunas reproductivas alargadas hasta $15 \mathrm{~cm}$ long. con hojitas después de los $11 \mathrm{~cm}$.

Cajas similares a las del Overo enano, con leve estrangulamiento, con carena un poco más marcada y algo de pico, con 2-1-3 granos overos (colorado y albo en las mismas proporciones).
2009/10 1366
US 686(2)
BPZ Pepón
Pichincha, Quito

(A)
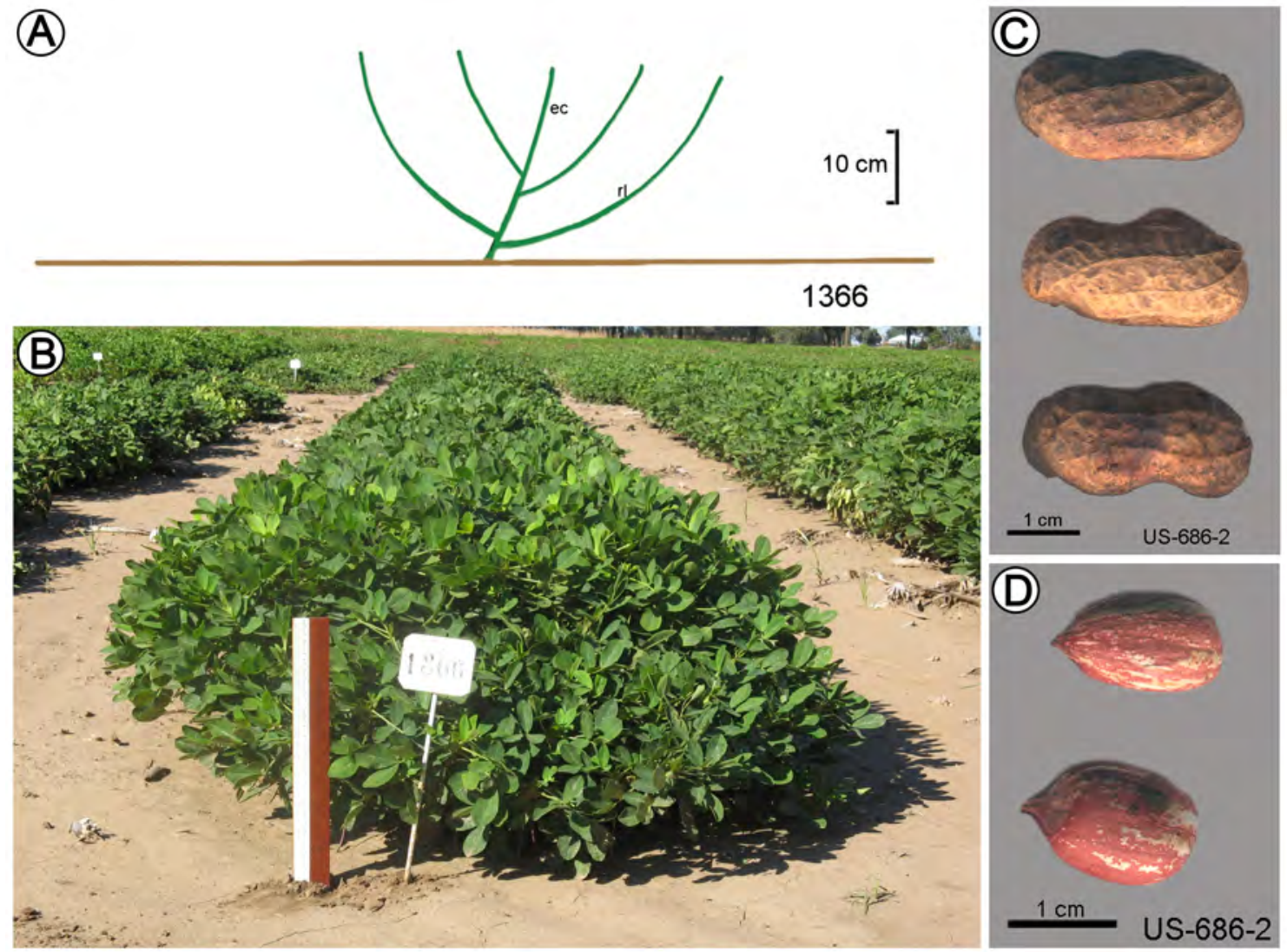

Fig. 4. Overo cojín compacto, 1366. A: Esquema de la planta. B: Planta. C: Fruto. D: Semillas. Fig. 4. Overo cojín compacto, 1366. A: Plant outline. B: Plant. C: Fruit. D: Seeds.

$\begin{array}{lllll}\text { Mdi. } & \text { US } & \text { Leg. } & \text { Nombre original } & \text { Procedencia } \\ \text { 86/2746 } & \text { 687(1) } & \text { BPZ } & \text { Higuerilla } & \text { Pichincha, Quito, almacén } \\ \text { 86/2747 } & 731(1) & \text { BPZHa } & \text { Criolla E. E. } & \text { Guayas, Guayaquil } \\ & & & \text { Boliche (2) } & \end{array}$




\section{Folíolos plegados, salmón}

Planta pequeña, compacta chata, forma un cojín pequeño; eje central no aparente. Folíolos plegados; estípulas con cerdas. Ramas reproductivas breves.

Cajas de medianas a grandes, con carena y algo de pico; con 2-1 granos de color salmón.
2009/10 1369
US 695 (2) BPZHa
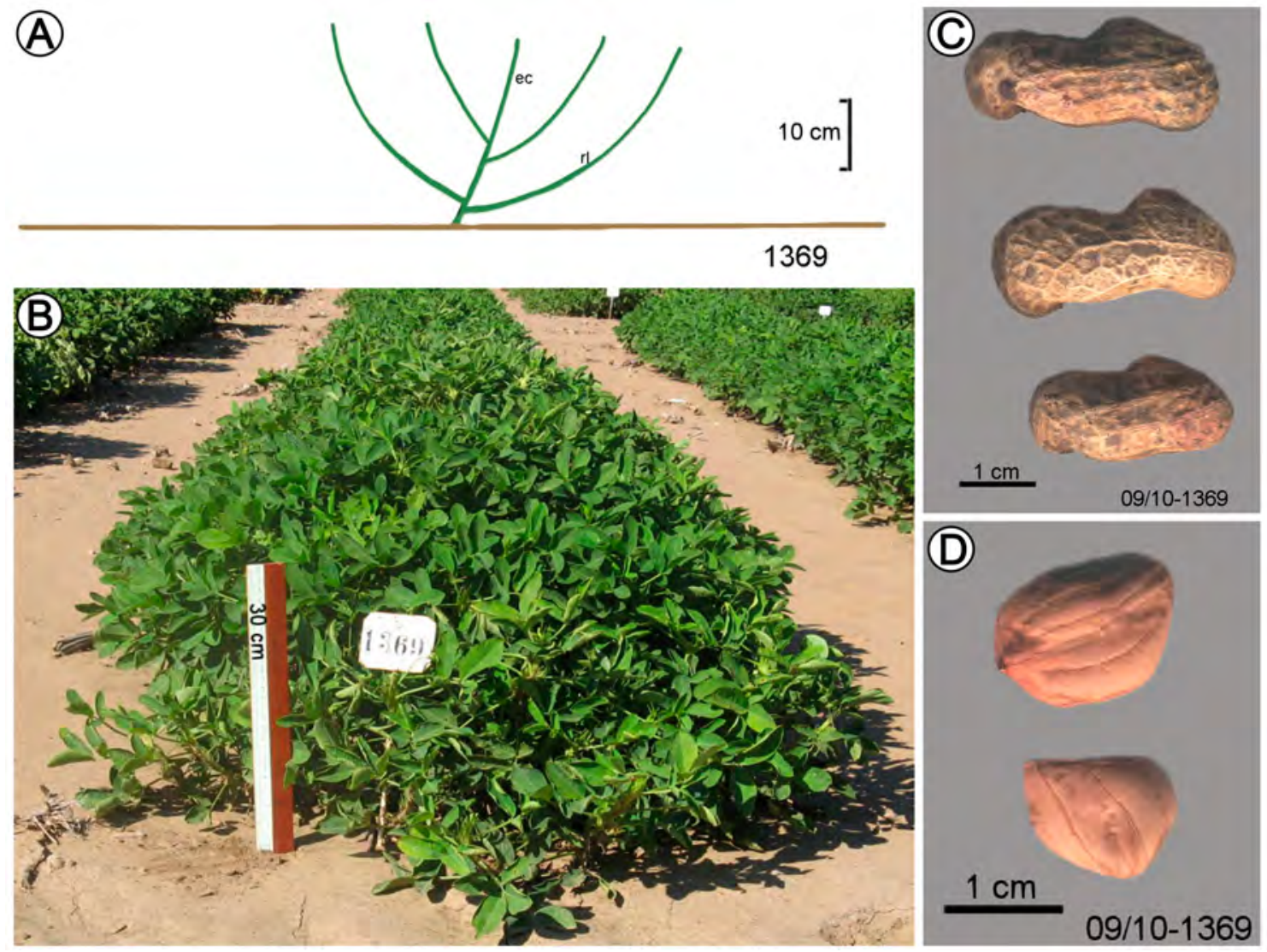

Fig. 5. Folíolos plegados salmón, 1369. A: Esquema de la planta. B: Planta. C: Fruto. D: Semillas. Fig. 5. Folíolos plegados salmón, 1369. A: Plant outline. B: Plant. C: Fruit. D: Seeds.
Mdi.
US
Leg.
Nombre original
Procedencia
$86 / 2752$
695 (2)
BPZHa
Pepón
Guayas, Pedro Carbo, almacén 


\section{Folíolos plegados, colorado}

Planta similar a la anterior. Tallo verde. Estandarte con aro.

Cajas algo más uniformes que el anterior y con granos colorados.
Mdi. 2015/207
US 695 (2)

\section{(A)}

(B)
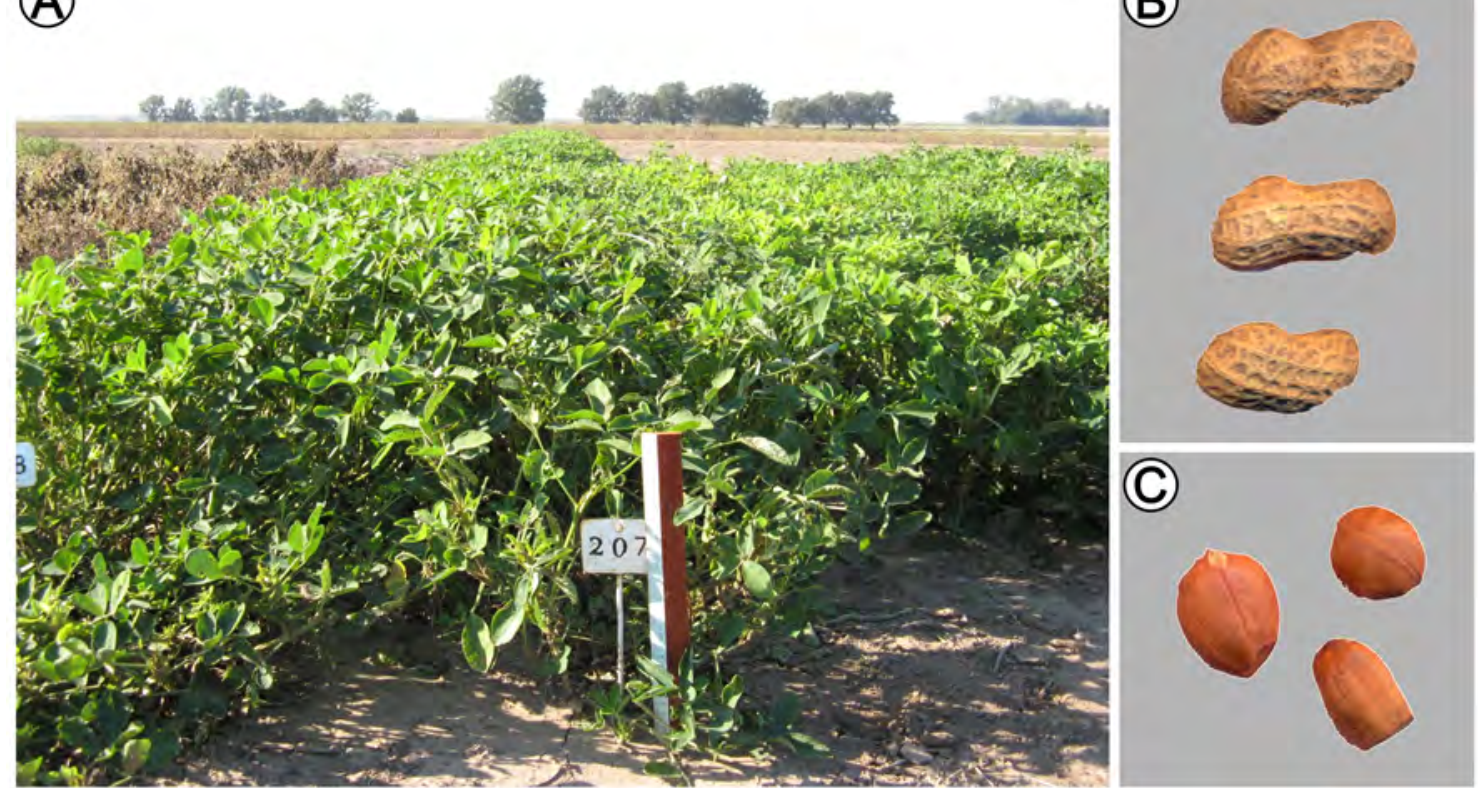

Fig. 6. Folíolos plegados, colorado, 207. A: Planta. B: Fruto. C: Semillas.

Fig. 6. Folíolos plegados, colorado, 207. A: Plant. B: Fruit. C: Seeds.

Mdi.

$86 / 2752-1$
US

$695(2)$
Leg.

BPZHa

\section{Procedencia}

Guayas, Pedro Carbo, almacén 


\section{Pepón rastrero}

Planta rastrera, compacta; eje central algo aparente. Tallo verde. Estípulas sin cerdas. Inflorescencias breves, hasta 2-3 cm long. Estandarte con aro.

Cajas redondeadas, grandes, con algo de carena y algo a bien estranguladas en la separación del tercer grano; con 2-3 granos rosado-pálidos.
2009/10 1374
US $686(1)$
BPZ Pichincha, Quito, almacén
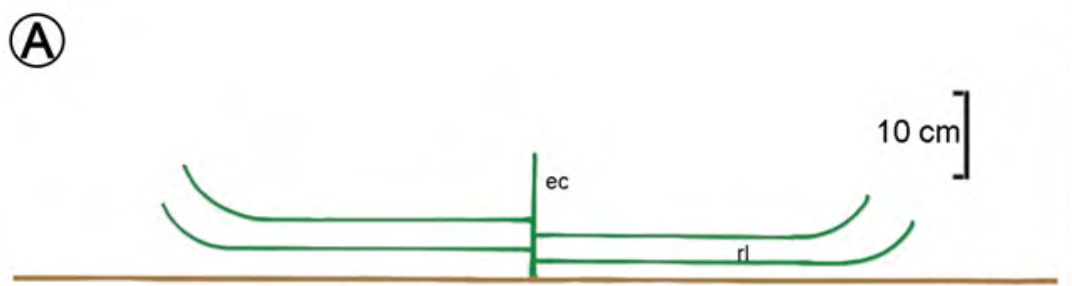

1374
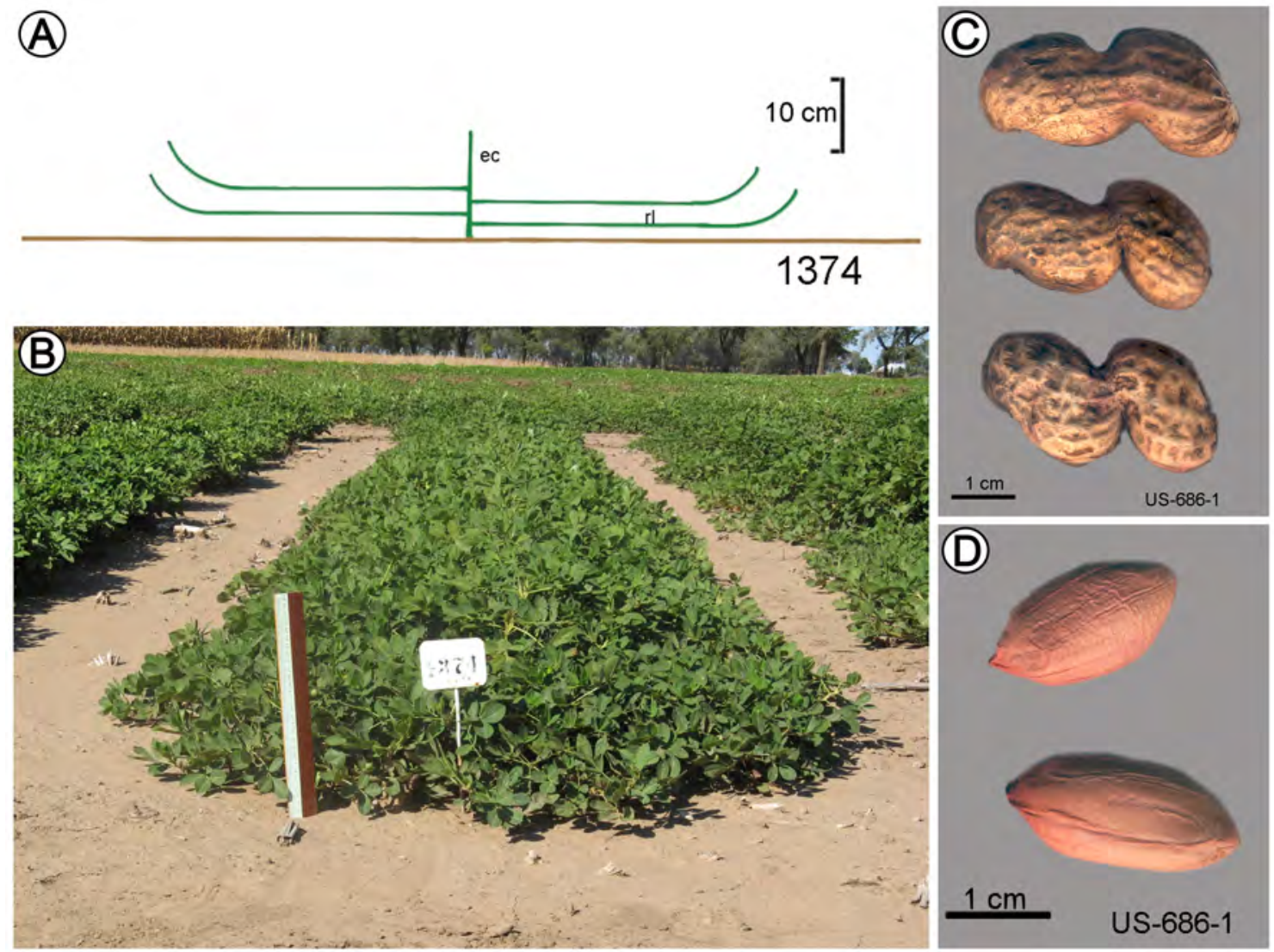

Fig. 7. Pepón rastrero, 1374. A: Esquema de la planta. B: Planta. C: Frutos. D: Semillas Fig. 7. Pepón rastrero, 1374. A: Planta outline. B. Plant. C: Fruit. C: Seeds.

\begin{tabular}{|c|c|c|c|c|}
\hline Mdi. & US & Leg. & Nombre original & Procedencia \\
\hline $86 / 2757$ & 692 & ВРZНа & Pepón & Guayas, Pedro Carbo, almacén \\
\hline $86 / 2758$ & $693(4)$ & ВРZНа & Charapotó & Guayas, Pedro Carbo, almacén \\
\hline $86 / 2759$ & $695(1)$ & ВРZНа & Pepón & Guayas, Pedro Carbo, almacén \\
\hline 98/99 2606 & WWT 1314 Grif 12507 & & & Pichincha, Quito, from Manabí \\
\hline 98/99 2607 & WTS 55 Grif 13836 & & & Manabí, Calceta, 180 m s.n.m. \\
\hline
\end{tabular}

Obs. La parcela 86/2758 presenta plantas más abiertas y con eje central más aparente. 


\section{Pepón cojín}

Planta en cojín muy compacto; eje central no aparente; ramas reproductivas breves. Sin cerdas. Tallo verde. Estandarte con aro.

Cajas similares a las de Pepón rastrero, con 2-1 granos (raros los de 3), de color rosado pálido.
2009/10 1372
US 695(1) BPZ
Guayas, Pedro Carbo

(A)

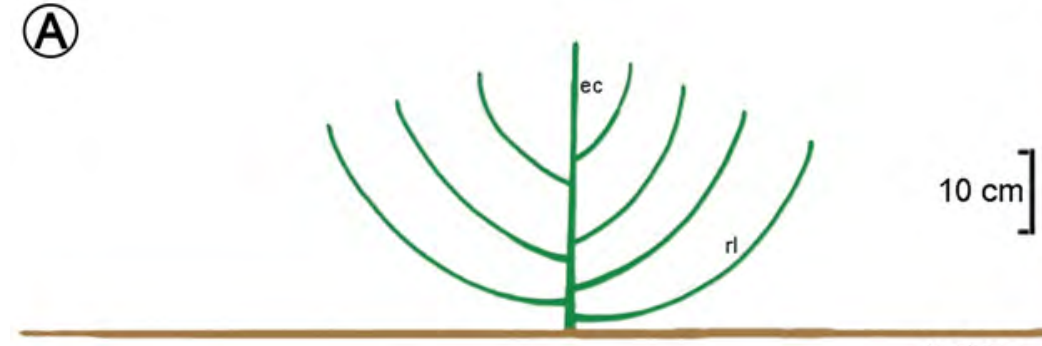

(C)
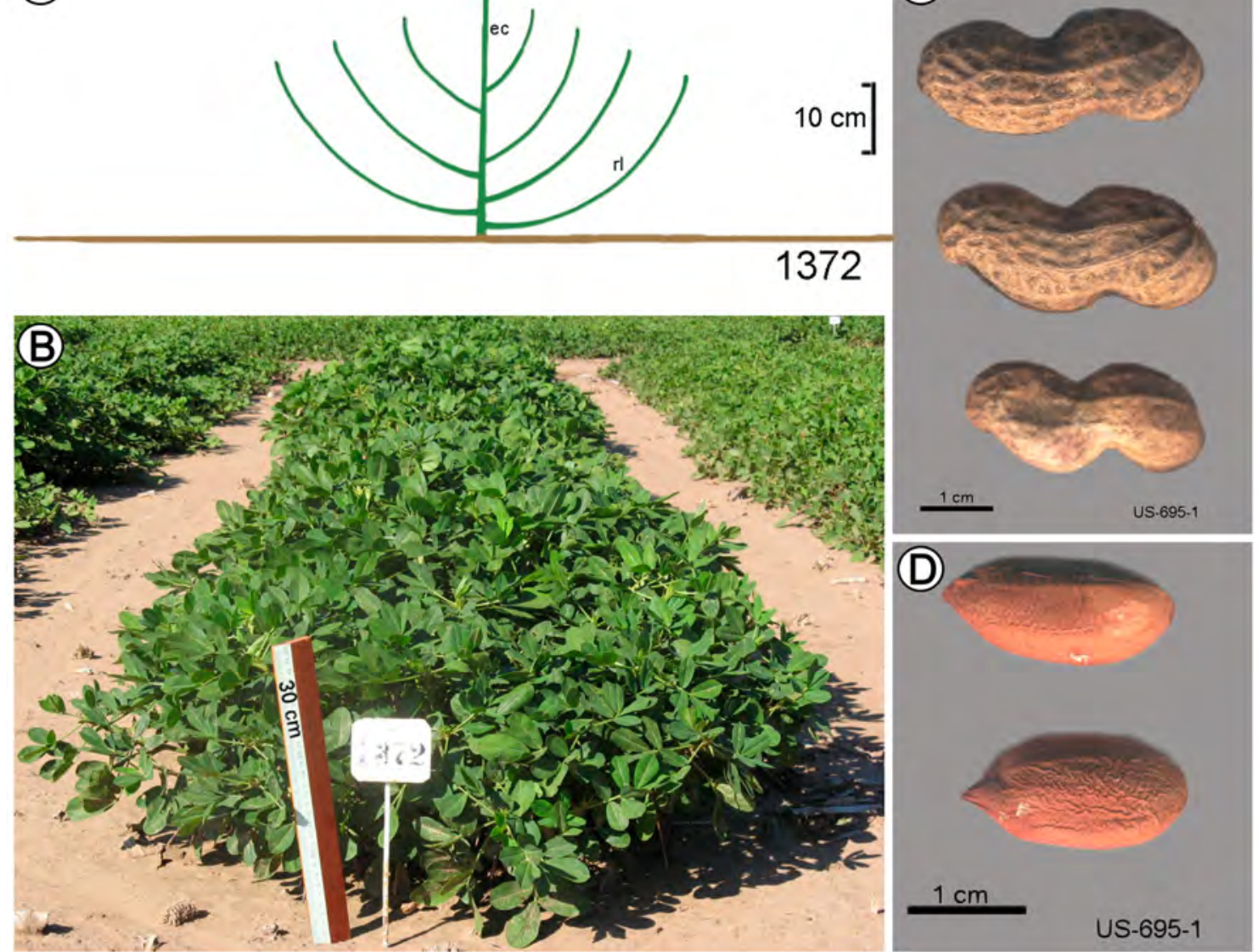

Fig. 8. Pepón cojín, 1372. A: Esquema de la planta. B: Planta. C: Fruto. D: Semillas. Fig. 8. Pepón cojín, 1372. A: Plant outline. B: Plant. C: Fruit. D: Seeds.

$\begin{array}{lllll}\text { Mdi. } & \text { US } & \text { Leg. } & \text { Nombre original } & \text { Procedencia } \\ \text { 86/2748 } & 686(1) & \text { BPZ } & \text { Pepón } & \text { Pichincha, Quito, almacén } \\ 86 / 2750 & 692 & \text { BPZ } & \text { Pepón } & \text { Guayas, Pedro Carbo, almacén } \\ \text { 86/2751 } & 693(4) & \text { BPZHa } & \text { Charapotó } & \text { Guayas, Pedro Carbo, almacén } \\ 86 / 2754 & 695(1) & \text { BPZHa } & \text { Charapotó } & \text { Guayas, Pedro Carbo, almacén }\end{array}$




\section{Colorado rastrero}

Planta rastrera, más o menos extendida; eje central algo aparente. Tallo verde. Estípulas con cerdas. Ramas reproductivas alargadas (con hojitas) hasta $4 \mathrm{~cm}$ de long. Folíolos más o menos oscuros que las demás razas rastreras. Estandarte con aro.

Cajas redondeadas, sin pico ni carena, apenas estranguladas. Con 2-1 granos color colorado fuerte.
2009/10 1379
US 694

(A)

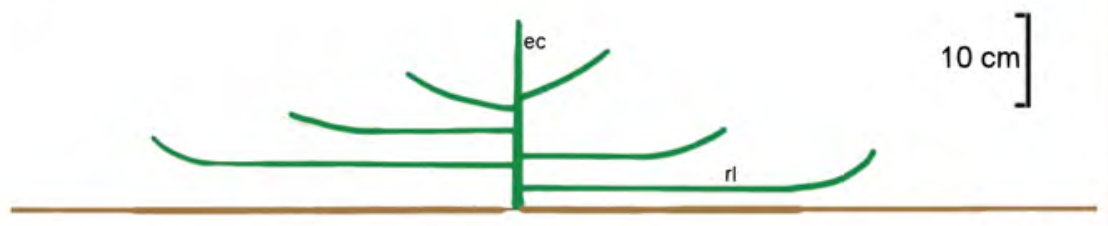

(C)

1378
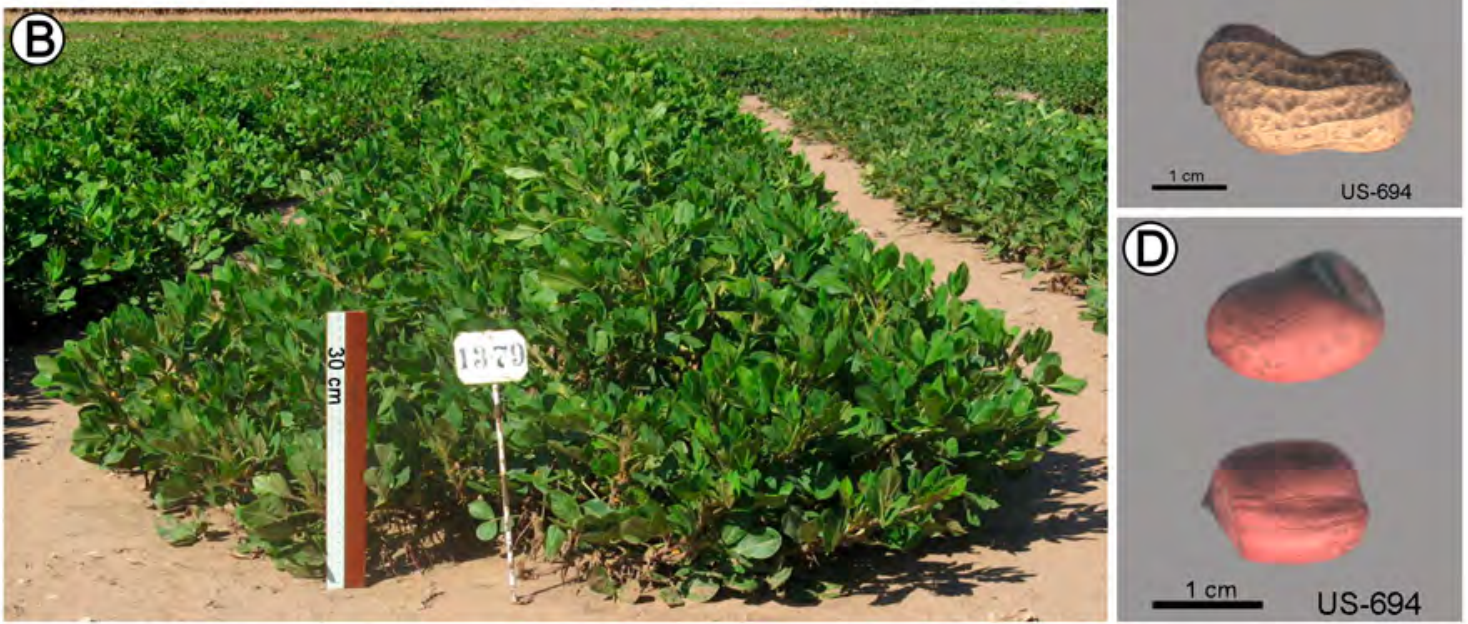

Fig. 9. Colorado rastrero, 1378. A: Esquema de la planta. B: Planta. C: Fruto. D: Semillas. Fig. 9. Colorado rastrero, 1378. A: Plant outline. B: Plant. C: Fruit. D: Seeds.

Mdi.

86/2765
US

694
Leg.

BPZHa
Nombre original

Rosita

\section{Procedencia}

Guayas, Pedro Carbo, almacén 


\section{Higuerilla}

Planta en cojín mediano, algo abierto; eje central apenas aparente. Tallo verde. Estípulas con cerdas. Por lo común con ramas reproductivas cortas. Estandarte con aro poco marcado.

Cajas medianas, redondeadas, apenas o no estranguladas, sin carena ni pico, con 2-1 granos colorado fuerte.
Mdi. 2015/208
WWT 1373 Grif 12596
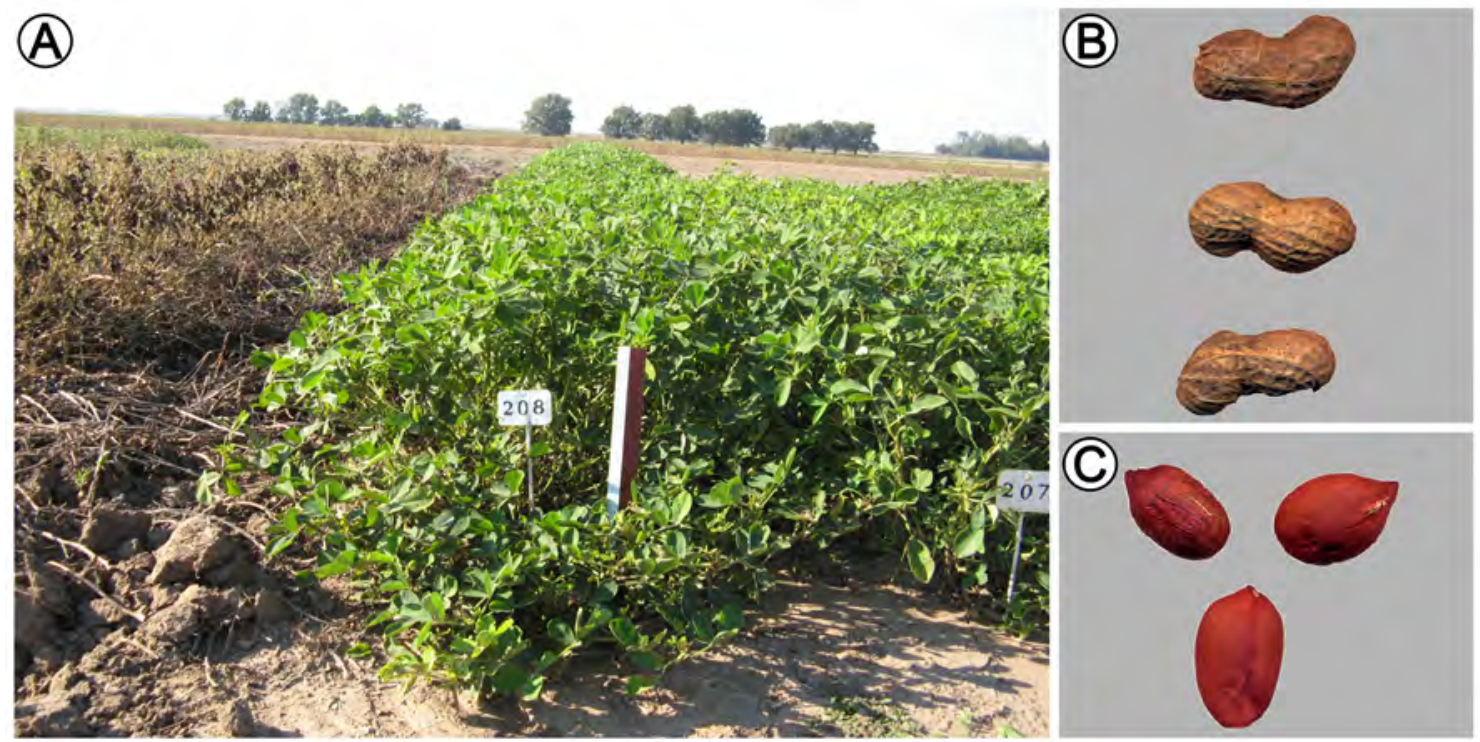

Fig. 10. Higuerilla, 208. A: Planta. B: Fruto. C: Semillas Fig. 10. Higuerilla, 208. A: Plant. B: Fruit. C: Seeds.

$\begin{array}{lllll}\text { Mdi. } & \text { US } & \text { Leg. } & \text { Nombre original } & \text { Procedencia } \\ \text { 86/2761 } & 687(2) & \text { BPZ } & \text { Higuerilla } & \text { Pichincha, Quito, almacén } \\ \text { 86/2764 } & 694 & \text { BPZHa } & \text { Rosita } & \text { Guayas, Pedro Carbo, almacén } \\ \text { 86/2766 } & 695(2) & \text { BPZHa } & \text { Pepón } & \text { Guayas, Pedro Carbo, almacén } \\ \text { 86/2767 } & 695(3) & \text { BPZHa } & \text { Pepón } & \text { Guayas, Pedro Carbo, almacén } \\ \text { 98/99 2609 } & \text { WWT 1373 Grif 12596 } & & & \text { Manabí, Corre Agua, 5 m s.n.m. }\end{array}$

Obs. Todas las parcelas presentan gran resistencia a los ataques de "viruela” (Cercospora spp.). 


\section{Cultivar Santa Rosa}

Planta en cojín grande a mediano; eje central apenas aparente. Tallo verde. Estípulas sin cerdas. Se presentan ramas reproductivas alargadas, de hasta $11 \mathrm{~cm}$ long., con hojitas en el ápice. Estandarte con aro.

Cajas algo estranguladas, con carena y algo de pico, con 2-1 granos colorado fuerte.

2009/10 1377 US690

(A)

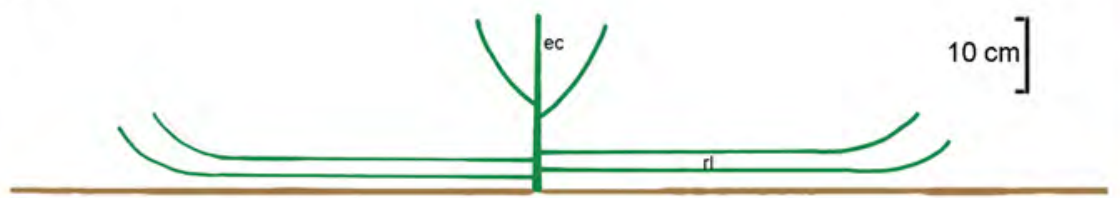

1377
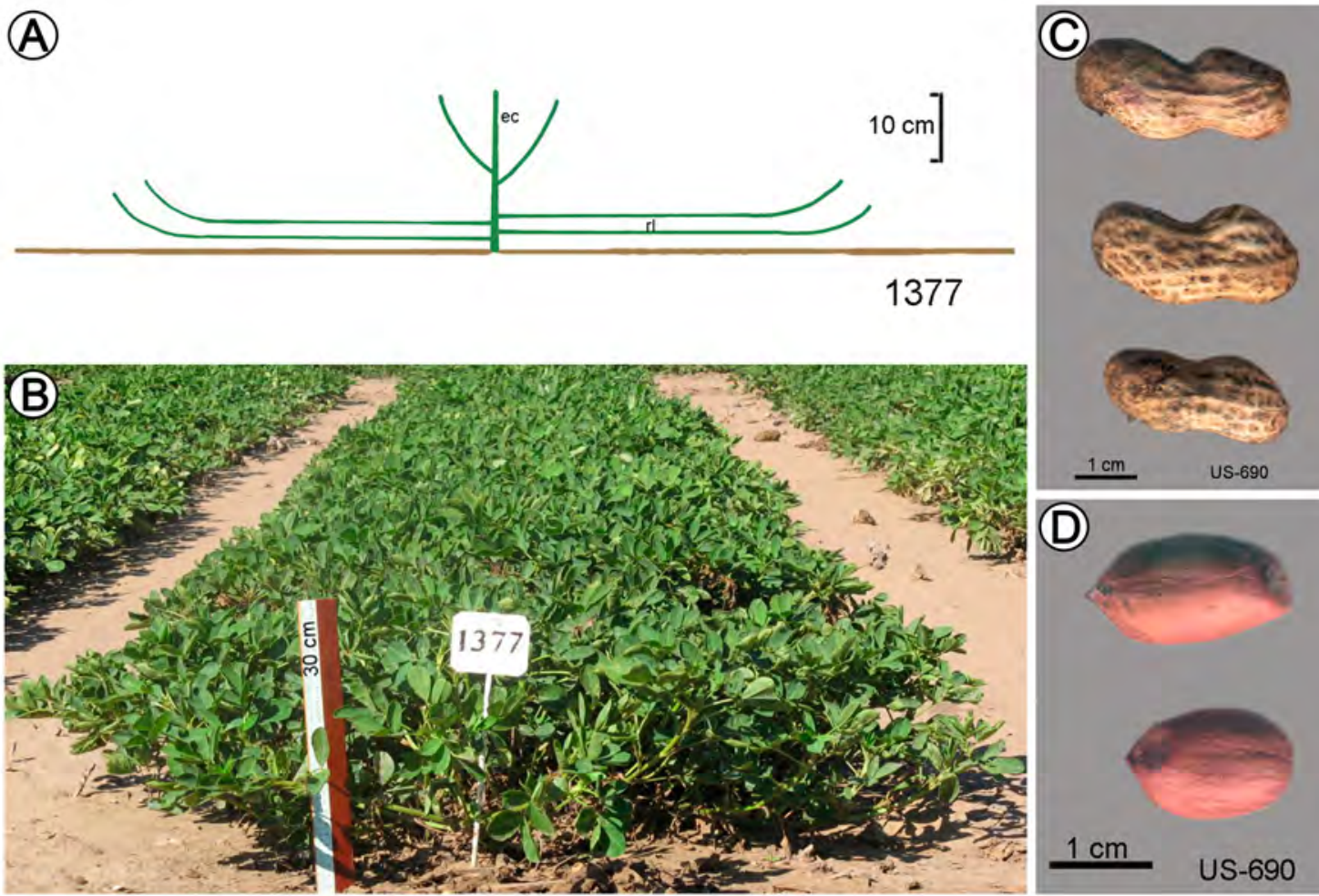

$1 \mathrm{~cm}$

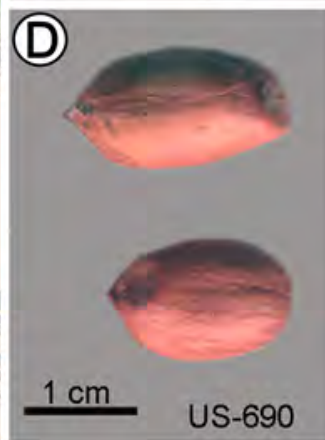

Fig. 11. Santa Rosa, 1377. A: Esquema de la planta. B: Planta. C: Fruto. D: Semillas. Fig. 11. Santa Rosa, 1377. A: Plant outline. B: Plant. C: Fruit. D: Seeds.

$\begin{array}{lllll}\text { Mdi. } & \text { US } & \text { Leg. } & \text { Nombre original } & \text { Procedencia } \\ 86 / 2763 & 690 & \text { BPZ } & \text { cv. Santa Rosa } & \text { Guayas, EEA Boliche, Guayaquil }\end{array}$

Obs. La Estación Experimental Boliche la difundió como cultivar. 


\section{Cojín pequeño colorado}

Planta en cojín pequeño, compacto, eje central no aparente. Tallo verde. Estípulas sin cerdas. Ramas reproductivas alargadas, hasta $7 \mathrm{~cm}$ long., con hojitas en el ápice. Estandarte con aro.

Cajas estranguladas, con retículo marcado, con pico y carena, con 2-1 granos colorado fuerte.
2009/10 1376
$687(2)$
BPZ Higuerilla
Pichincha, Quito (1), almacén
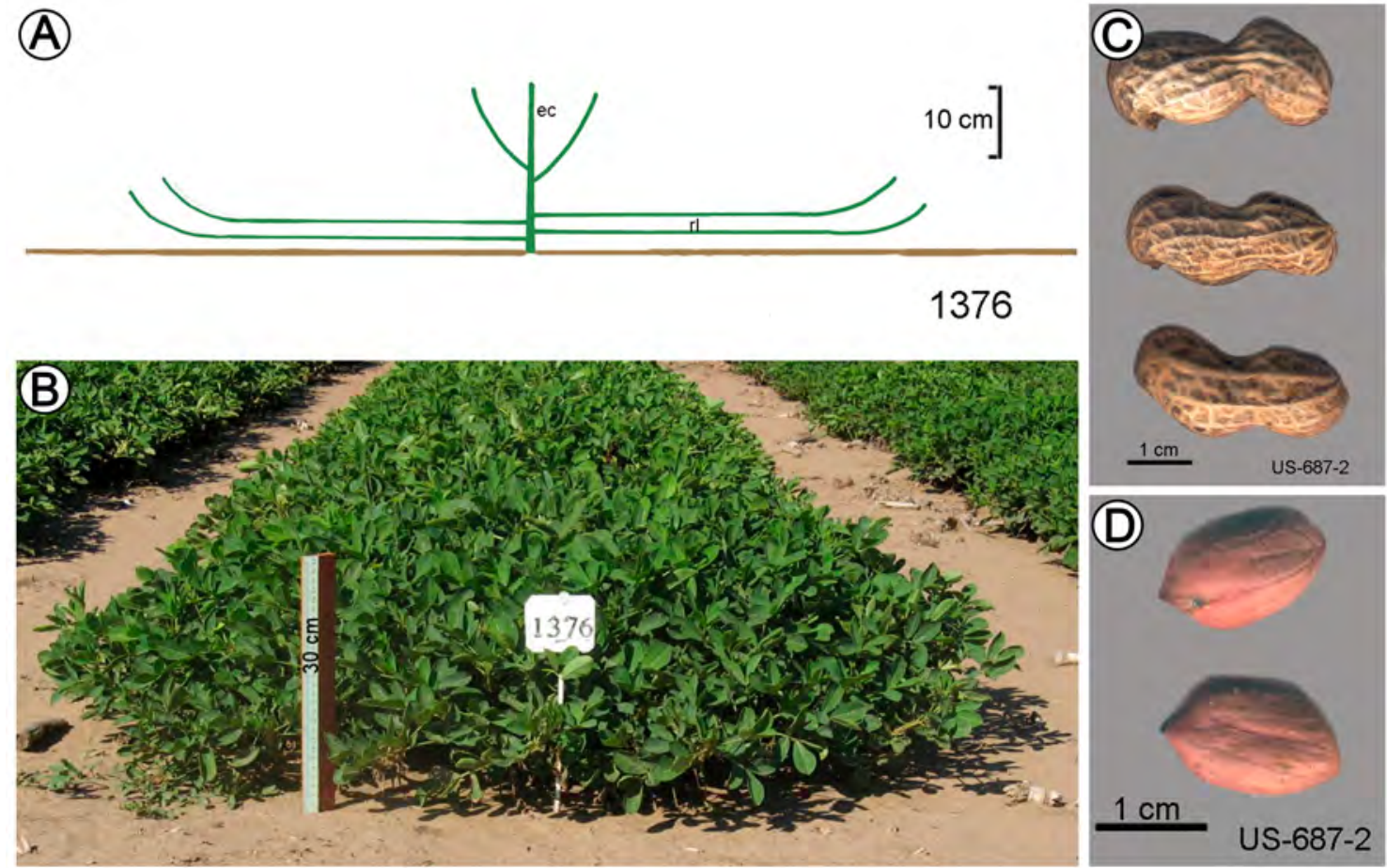

Fig. 12. Cojín pequeño colorado, 1376. A: Esquema de la planta. B: Planta. C: Fruto. D: Semillas.

Fig. 12. Cojín pequeño colorado, 1376. A: Plant outline. B: Plant. C: Fruit. D: Seeds.
Mdi.
US
Leg.
Nombre original
Procedencia
$86 / 2760$
$687(2)$
BPZ
Higuerilla
Pichincha, Quito, almacén

Obs. Presenta gran resistencia a los ataques de “viruela” (Cercospora spp.). 


\section{Rastrero salmón}

Planta rastrera bien adherida al suelo, compacta. Eje central bien aparente. Tallo verde. Estandarte con aro. Clavo violáceo.

Cajas pequeñas, estranguladas. Con algo de carena y pico incipiente. Con 2-1 granos de color salmón.

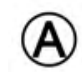

A

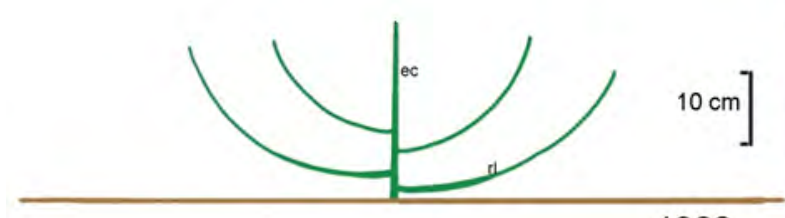

1382

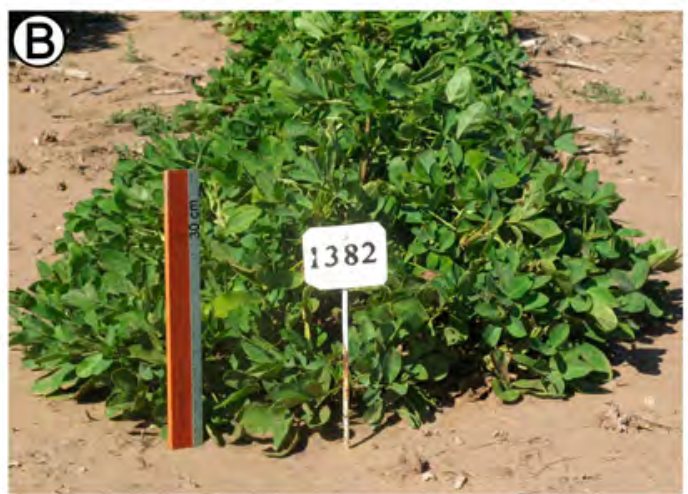

Fig. 13. Rastrero salmón, 1382. A: Esquema de la planta. B: Planta.

Fig. 13. Rastrero salmón, 1382. A: Plant outline. B: Plant.

$\begin{array}{lllll}\text { Mdi. } & \text { US } & \text { Leg. } & \text { Nombre original } & \text { Procedencia } \\ 86 / 2713(1) & 698(3) & \text { BPZHa } & \text { Rosita } & \text { Lomas de Sargentillo, almacén }\end{array}$




\section{Semirastrero salmón, 2-4 granos}

2009/10 1390
PI 390429
(A)
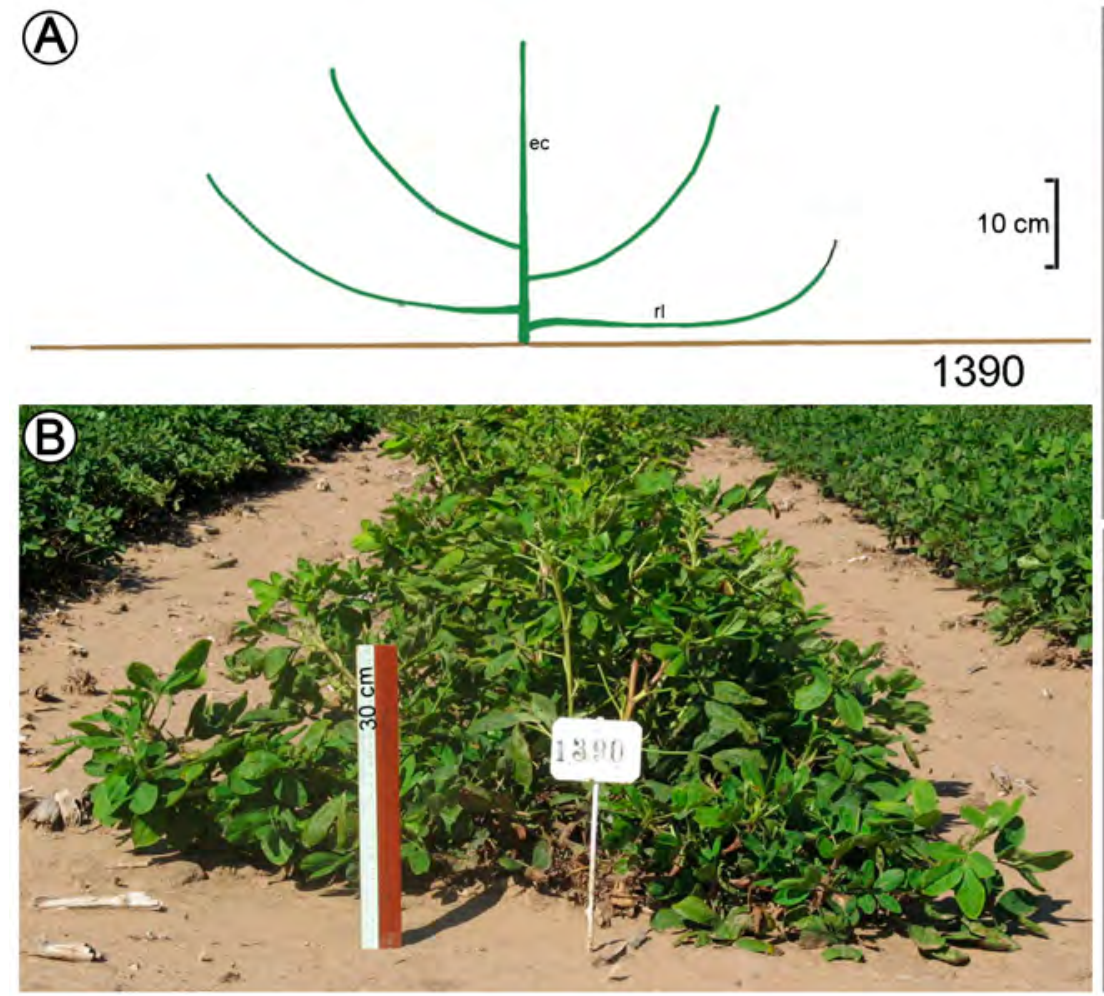

(C)
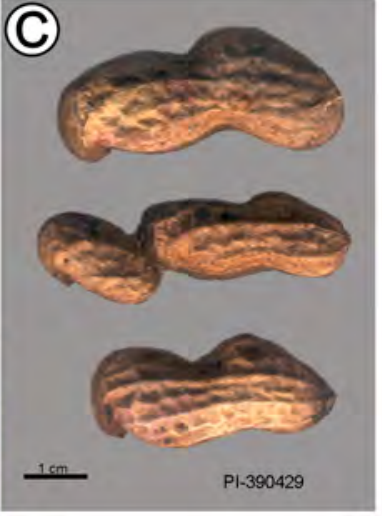

(D)

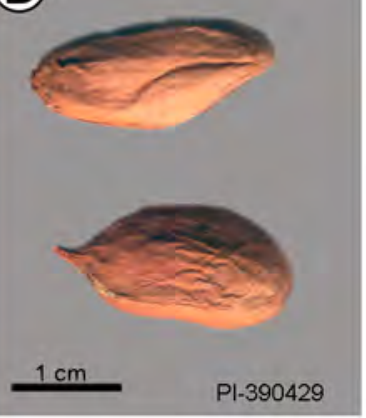

Fig. 14. Semirastrero salmón, $2-4$ granos, 1390. A: Esquema de la planta. B: Planta. C: Fruto. D: Semillas. Fig. 14. Semirastrero salmón, 2-4 granos, 1390. A: Plant outline. B: Plant. C: Fruit. D: Seeds. 


\section{Caja fastigiata, pálido, 3-4 granos}

Hojas verde claro.
2009/10 1405
$\mathrm{N}^{\mathrm{o}} 1379$
PI 241632

(A)
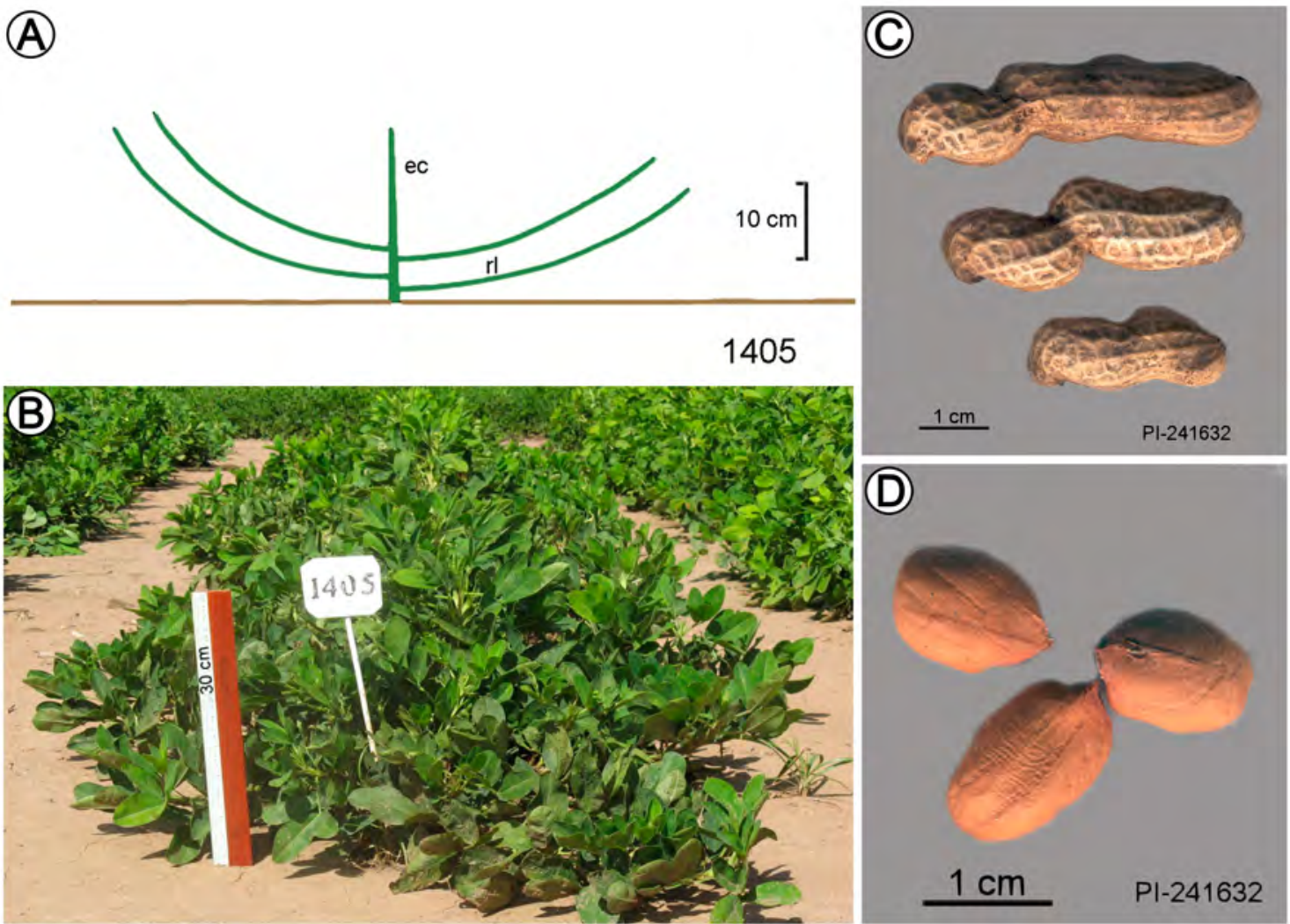

Fig. 15. Caja fastigiata pálido, 3-4 granos, 1405. A: Esquema de la planta. B: Planta. C: Fruto. D: Semillas. Fig. 15. Caja fastigiata pálido, 3-4 granos, 1405. A: Plant outline. B: Plant. C: Fruit. D: Seeds.

PI 241632 


\section{Caja peruviana, salmón, 4 granos}

2009/10 1393

WTS 12 Grif 13799 Imbabura, Sta. Rosa, 1980 m s.n.m.
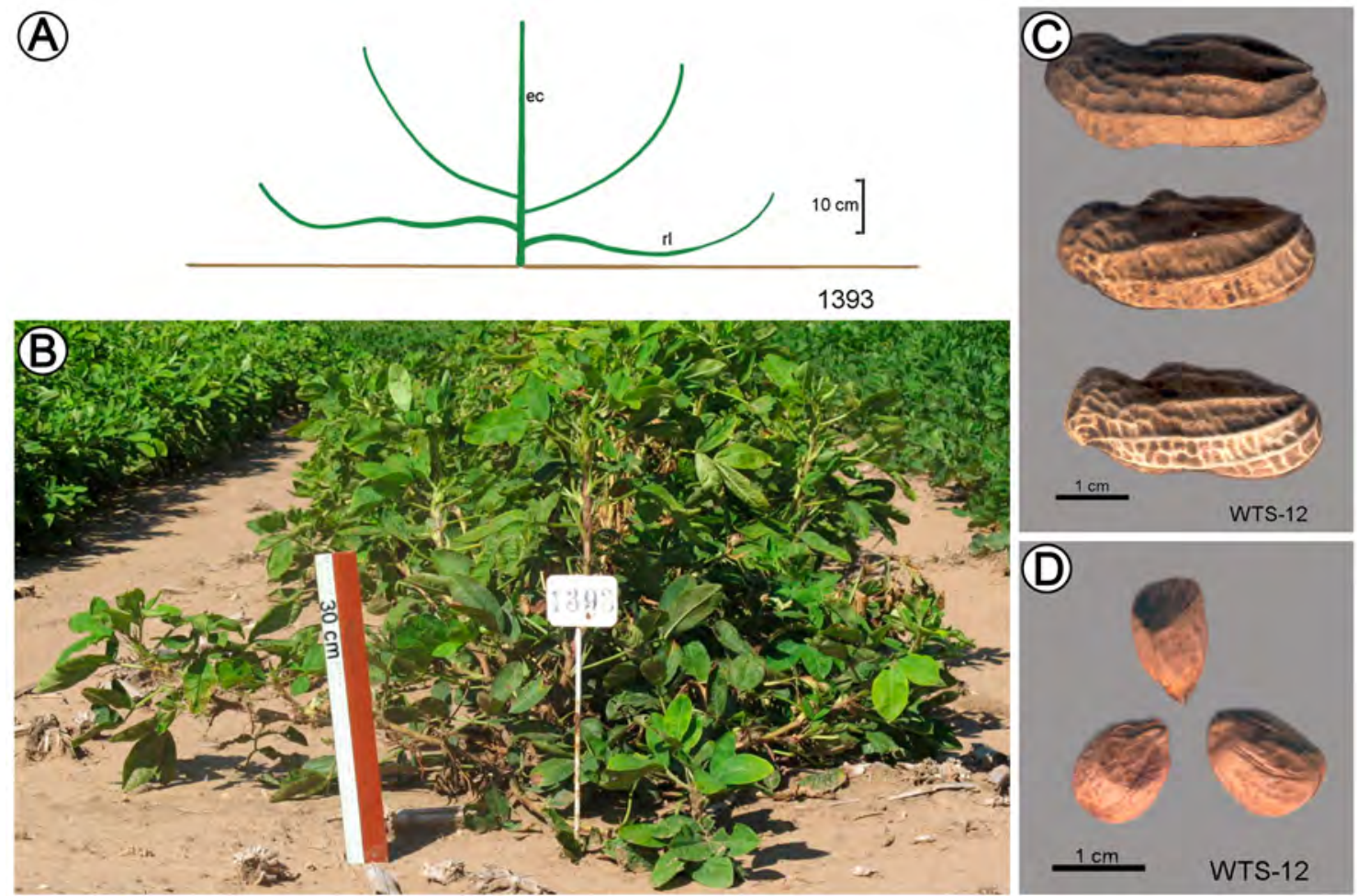

Fig. 16. Caja peruviana salmón, 4 granos, 1393. A: Esquema de la planta. B: Planta. C: Fruto. D: Semillas. Fig. 16. Caja peruviana salmón, 4 granos, 1393. A: Plant outline. B: Plant. C: Fruit. D: Seeds.

Mdi.

98/99 2617

98/99 2650

98/99 2713
US

WTS 12 Grif 13799

WTS 74 Grif 13855

WTS 57 Grif 13838

\section{Procedencia}

Imbabura, Santa Rosa, 1980 m s.n.m.

Los Ríos, Vinces, 110 m s.n.m.

Manabí, Calceta, 180 m s.n.m. 


\section{Caja reticulada, pálido 3-4 granos}

Hojas verde claro.

2009/10 1420
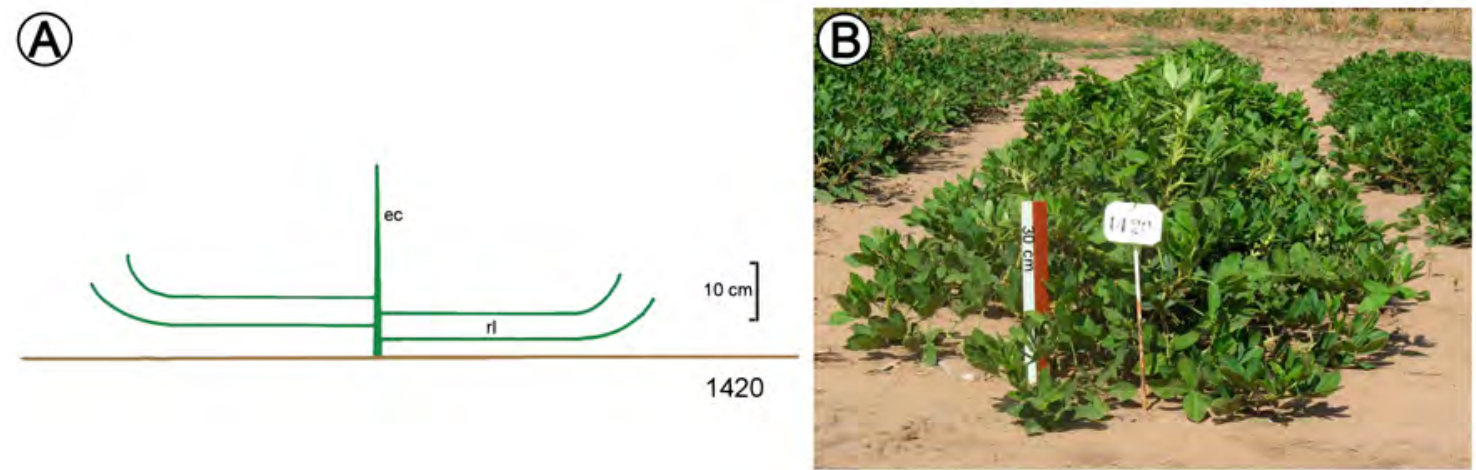

Fig. 17. Caja reticulada, pálido, 3-4 granos, 1420. A: Esquema de planta. B: Planta. Fig. 17. Caja reticulada, pálido, 3-4 granos, 1420. A: Plant outline. B: Plant. 


\section{Negro cojín}

Planta en cojín semirastrero; eje central no aparente. Tallo algo morado. Folíolos grandes de color verde claro; estípulas sin cerdas. Brotes verdes. Flor muy morada; estandarte con aro. Clavo morado vinoso. Ramas reproductivas muy cortas. El eje central presenta algunas ramitas (vegetativas).

Cajas largas y angostas, con retículo muy marcado, con nervios longitudinales y transversales más o menos iguales, con jorobas y pico. Contienen 3-2-1 granos de color violáceo, con algunas manchas blanquecinas.

2009/10 $1411 \quad$ WTS 75 Grif $13856 \quad$ Los Ríos, Vinces, 110 m s.n.m.
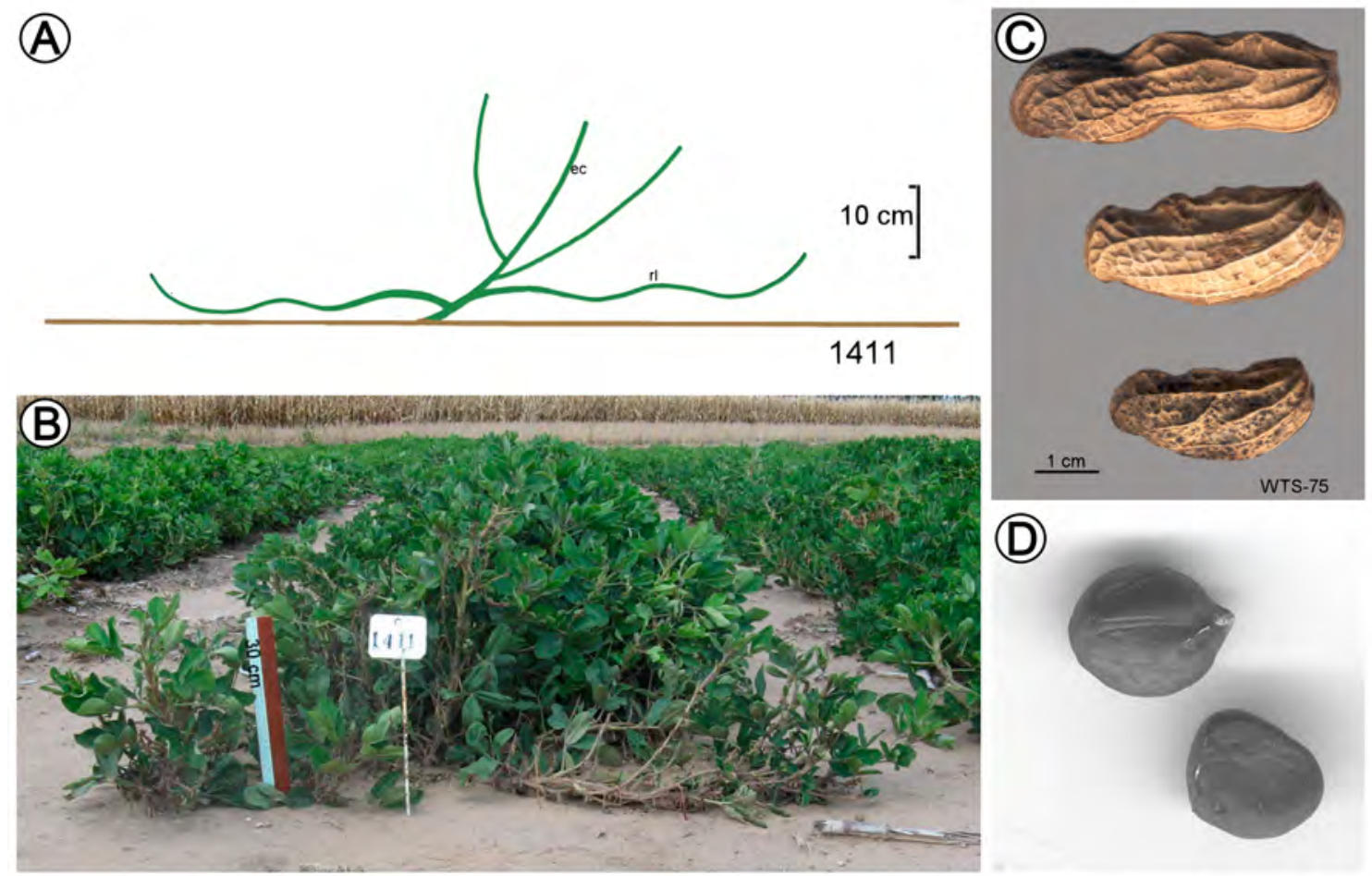

Fig. 18. Negro cojín, 1411. A: Esquema de la planta. B: Planta. C: Fruto. D: Semillas.

Fig. 18. Negro cojín, 1411. A: Plant outline. B: Plant. C: Fruit. D: Seeds.

\begin{tabular}{|c|c|c|c|}
\hline Mdi. & US & Leg. & Procedencia \\
\hline $86 / 2768$ & 696 & ВРZНа & Guayas, Bachiller, agricultor \\
\hline 98/99 2658 & WTS 75 Grif 13856 & & Los Ríos, Vinces, 110 m s.n.m \\
\hline 98/99 2717 & WTS 50 Grif 13831 & & Los Ríos, Vinces, 110 m s.n.m. \\
\hline
\end{tabular}




\section{Cojín negro, caja peruviana}

2009/10 1386

(A)
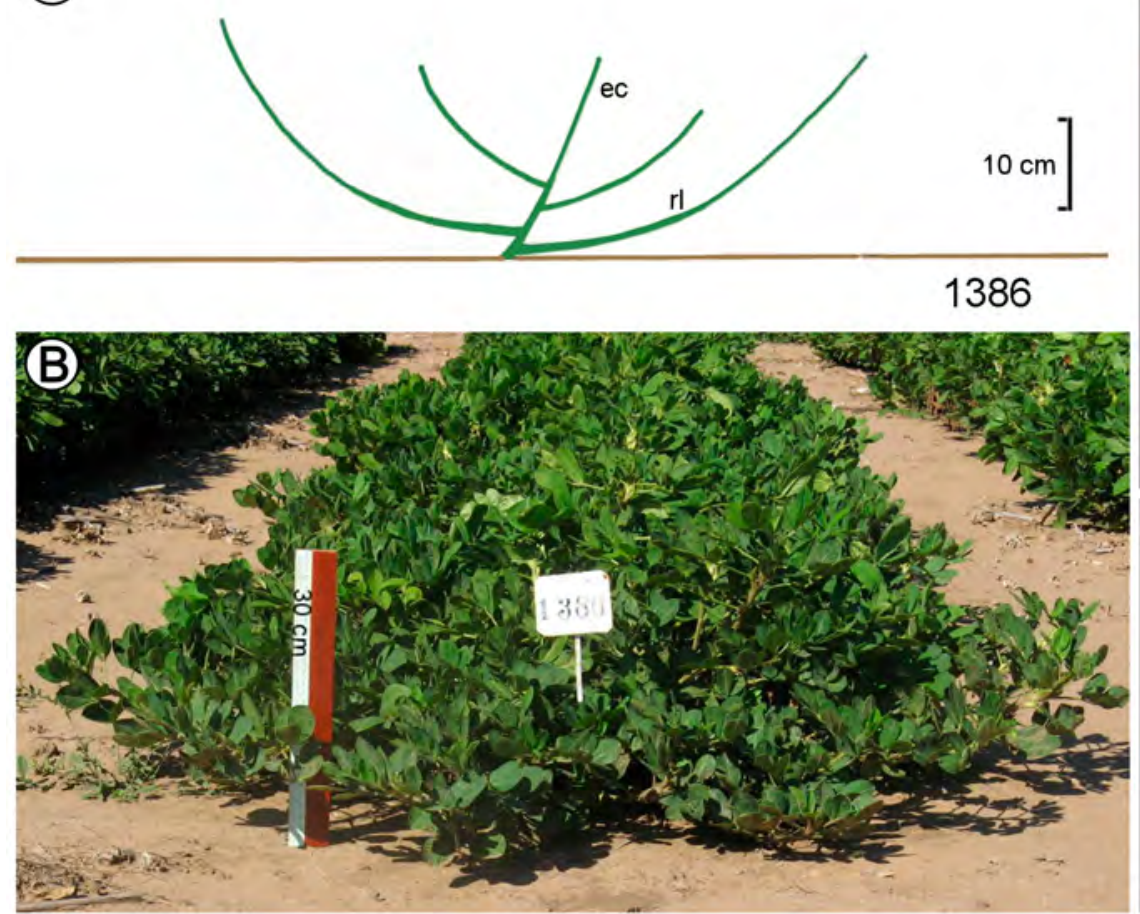

Manabí, Charapotó
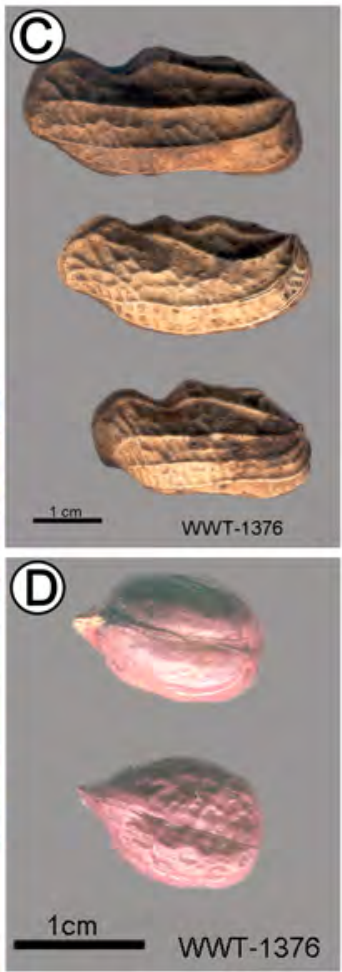

Fig. 19. Cojín negro, caja peruviana, 1386. A: Esquema de la planta. B: Planta. C: Fruto. D: Semillas. Fig. 19. Cojín negro, caja peruviana, 1386. A: Plant outline. B: Plant. C: Fruit. D: Seeds. 


\section{8'. PI 390431 reticulado, violáceo}

Plantas verde oscuro, cajas tipo hirsuta, retículo uniforme, granos negros.

2009/10 1425
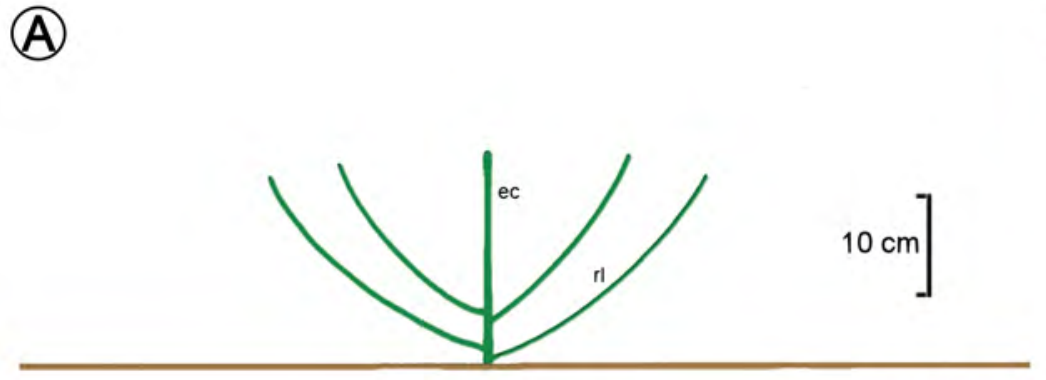

1425

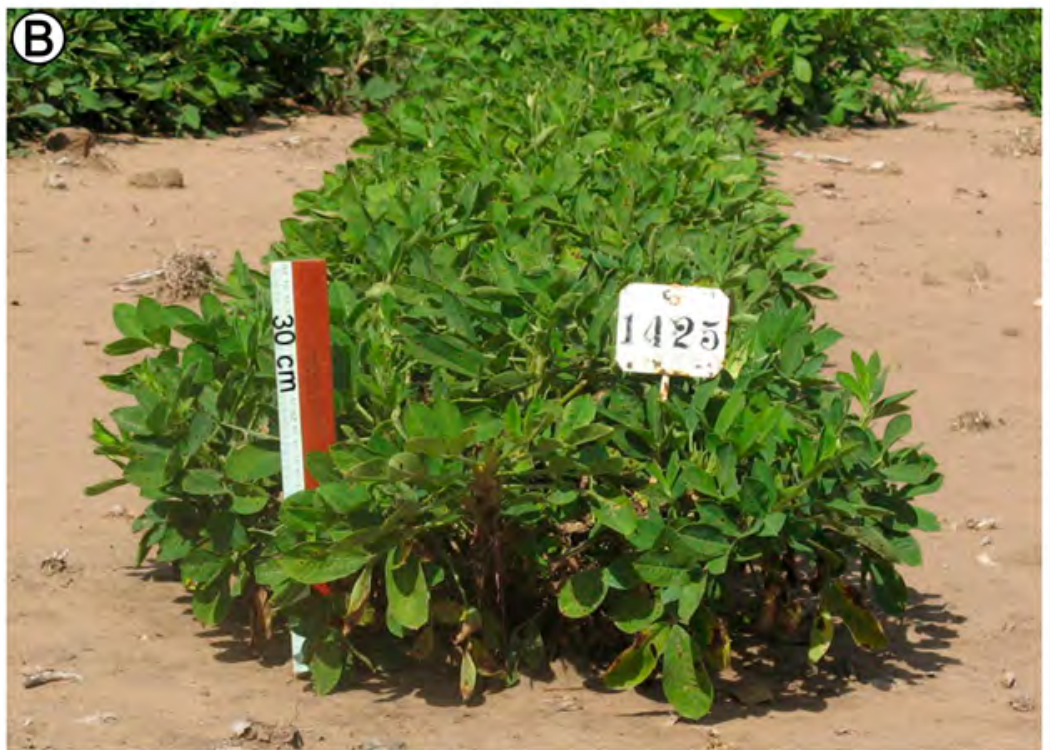

(C)
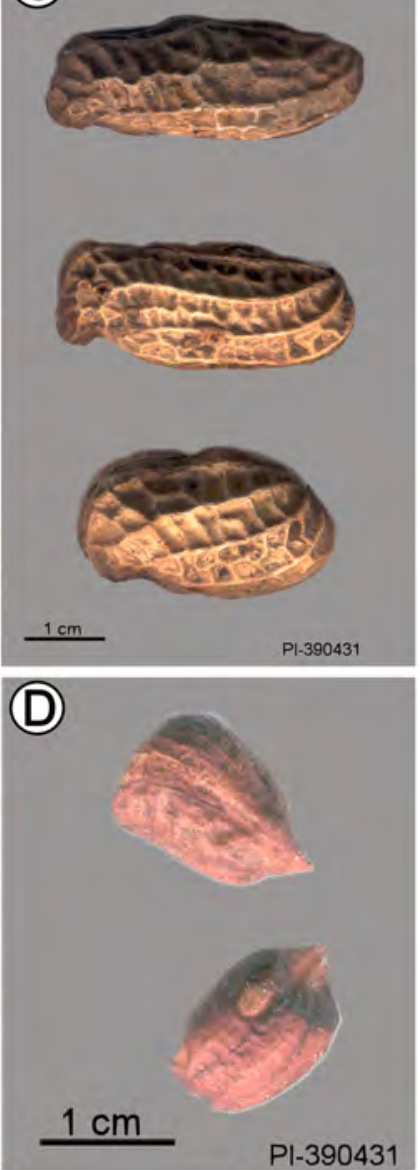

Fig. 20. Reticulado violáceo, 1425. A: Esquema de la planta. B: Planta. C: Fruto. D: Semillas. Fig. 20. Reticulado violáceo, 1425. A: Plant out line. B: Plant. C: Fruit. D: Seeds. 


\section{8". Cajas retículo fino}

Planta verde oscuro, cajas con retículo fino, granos negros.

2009/10 1387

WTS 8 Grif 13798-1

(A)

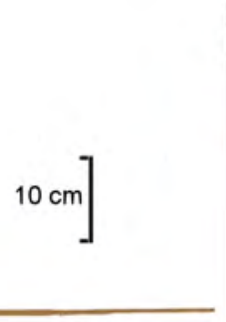

(C)
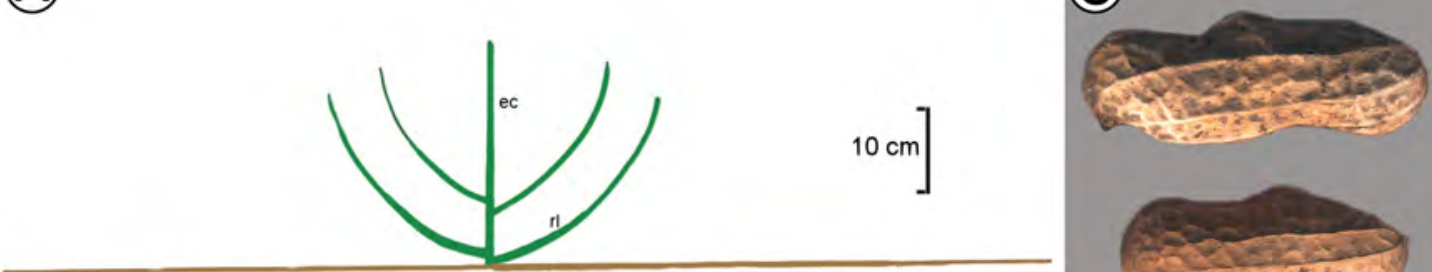

1387
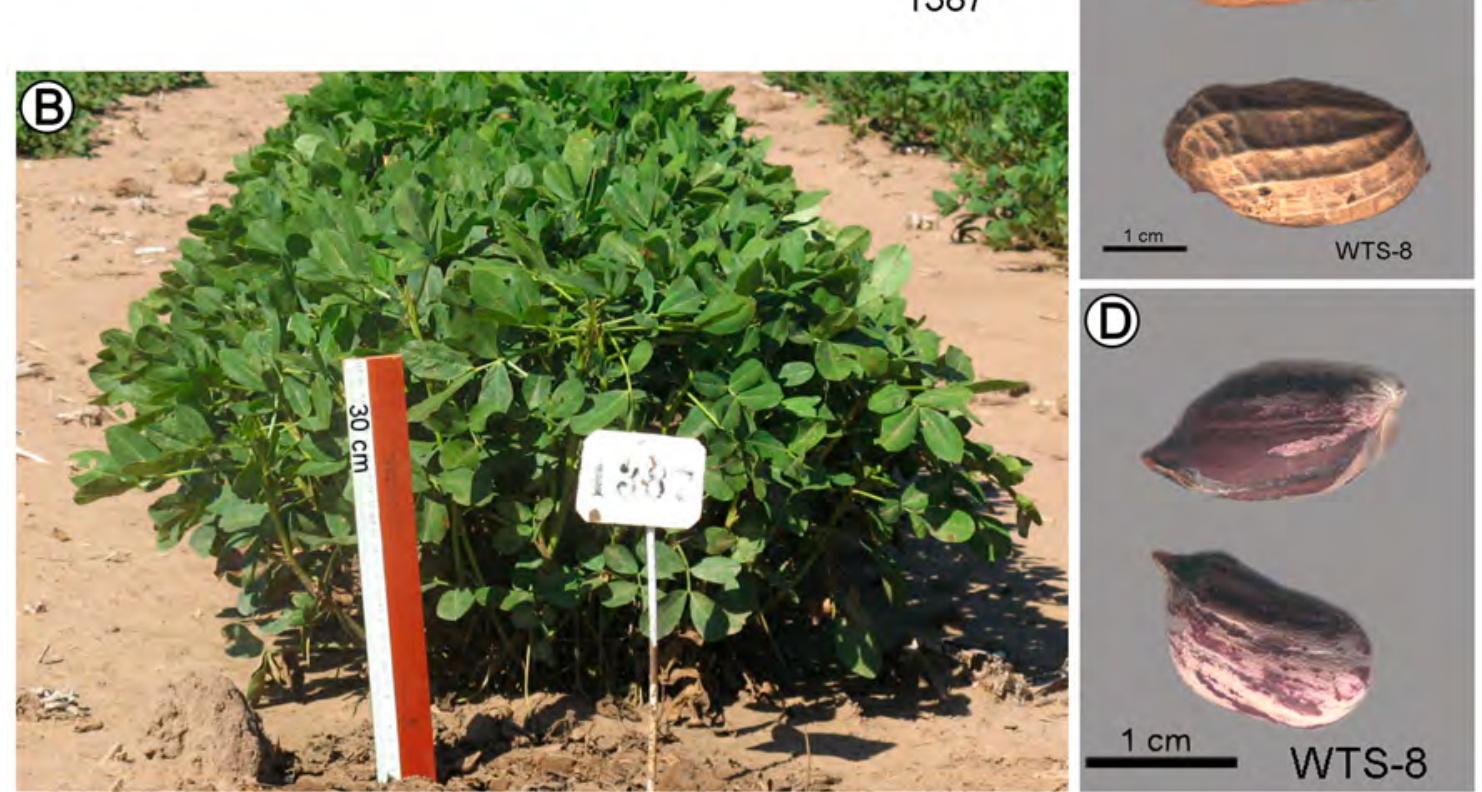

(D)
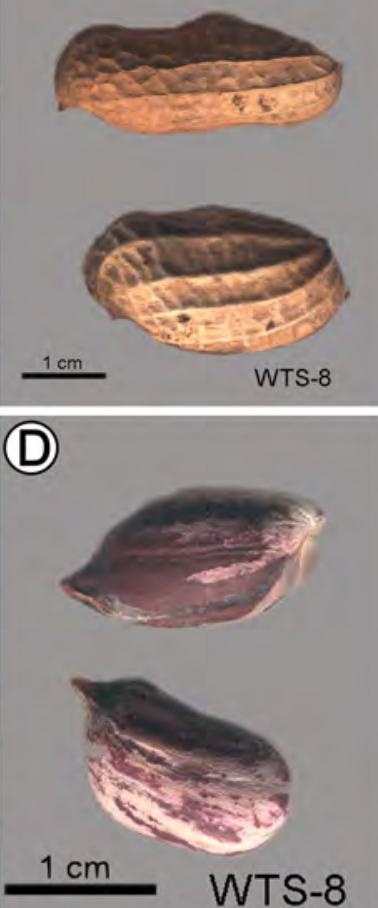

Fig. 21. Cajas retículo fino, 1387. A: Esquema de la planta. B: Planta. C: Fruto. D: Semillas. Fig. 21. Cajas retículo fino, 1387. A: Plant outline. B: Plant. C: Fruit. D: Seeds. 


\section{8'". Semirastrero salmón}

Plantas verde oscuro, semirastreras, cajas con retículo uniforme, granos salmón.

2009/10 1388

(A)

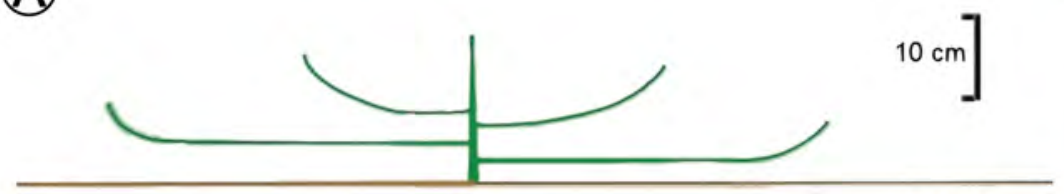

1388

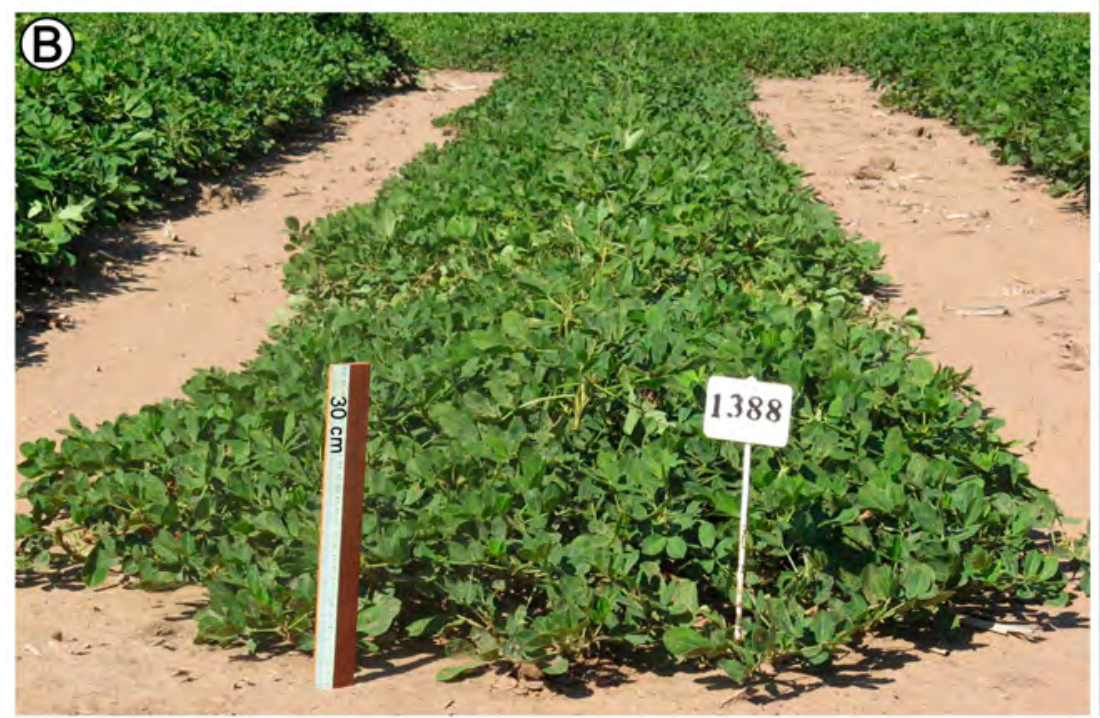

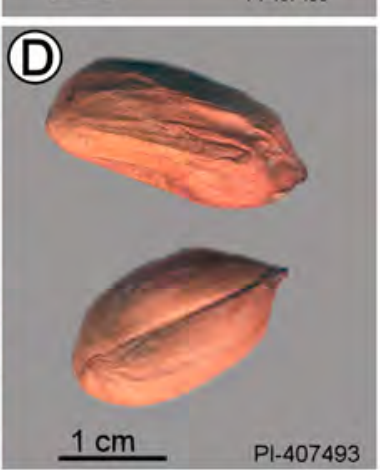

Fig. 22. Semirastrero salmón, 1388. A: Esquema de la planta. B: Planta. C: Fruto. D: Semillas. Fig. 22. Semirastrero salmon, 1388. A. Plant outline. B: Plant. C: Fruit. D: Seeds.

97/98 1526 
Arachis hypogaea subsp. hypogaea var. hirsuta (Fig. 1B)

\section{Maní de la mitad del mundo}

Planta rastrera muy abierta, algo cojín, muy ramificada, ramas sinuosas con puntas levantadas. Eje central bien aparente. Tallo, brote y pecíolo violáceos. Folíolos plegados. Estípulas con cerdas. Flor morada. Estandarte con aro. Clavos morados.

Cajas cortas, con 2-3-1 granos violáceos.
2009/10 1380
US $732(2)$
PI 497669
Pichincha, San Antonio
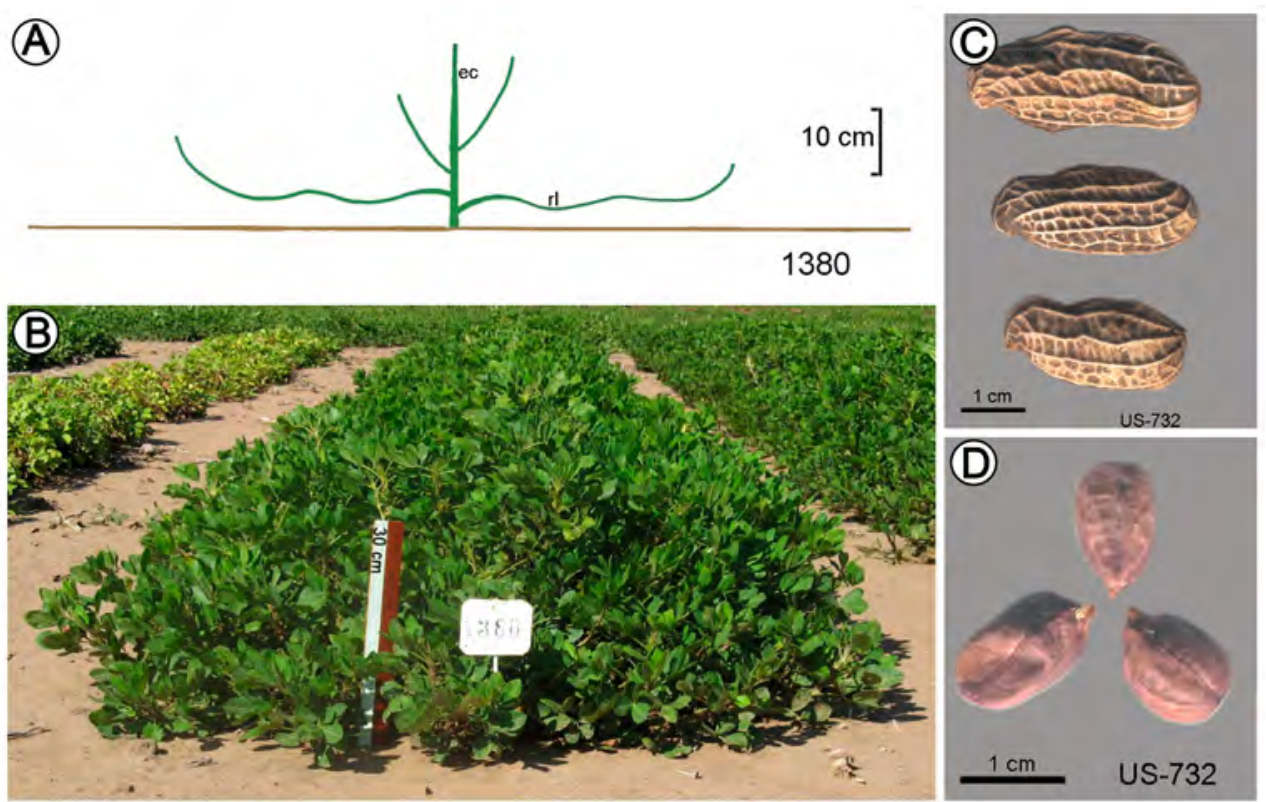

Fig. 23. Var. hirsuta. Maní de la mitad del mundo, 1380. A: Esquema de la planta. B: Planta. C: Fruto. D: Semillas. Fig. 23. Var. hirsuta. Maní de la mitad del mundo, 1380. A: Plant outline. B: Plant. C: Fruit. D: Seeds.

\begin{tabular}{|c|c|c|c|c|}
\hline Mdi. & US & PI & Leg. & Procedencia \\
\hline $86 / 2769$ & 732 & & $\mathrm{BPVz}$ & Pichincha, San Antonio, agricultor \\
\hline $86 / 2770$ & 733 & & $\mathrm{BPVz}$ & Pichincha, Rumicucho, agricultor \\
\hline 97/98 1533 & $732(2)$ & PI 497669 & & \\
\hline 97/98 1534 & 733 & PI 498670 & & \\
\hline $98 / 992611$ & WT 1313 Grif 12508 & & & Pichincha, Mitad del Mundo, 2685 m s.n.m. \\
\hline 98/99 2612 & WWT 1317 Grif 12510 & & & Pichincha, Caspigasi \\
\hline 98/99 2612 & WWT 1317 Grif 12511 & & & \\
\hline 98/99 2613 & WWT 1317 Grif 12511 & & & \\
\hline 98/99 2614 & WWT 1318 Grif 12513 & & & \\
\hline 98/99 2615 & WWT 1318 Grif 12514 & & & Pichincha. Tanlahuila, 2560 m s.n.m. \\
\hline 98/99 2743 & WWT 1317 Grif 12511 & & & Pichincha, Caspigasi \\
\hline 98/99 2744 & WWT 1318 Grif 12514 & & & Pichincha, Tanlahuilla \\
\hline
\end{tabular}




\section{Arachis hypogaea subsp. fastigiata var. fastigiata (Fig. 1C)}

\section{Colorado caja grande}

Planta más o menos pequeña, erecta. Eje central no aparente. Con cerdas.

Cajas reticuladas, con jorobas dorsales, con carena y con pico pequeño, con 2-3-1 granos de color colorado.
2009/10 1394
WWT 1355 Grif 12572
WWT 1351
Loja, Sacapianga, 1140 m s.n.m.
1391
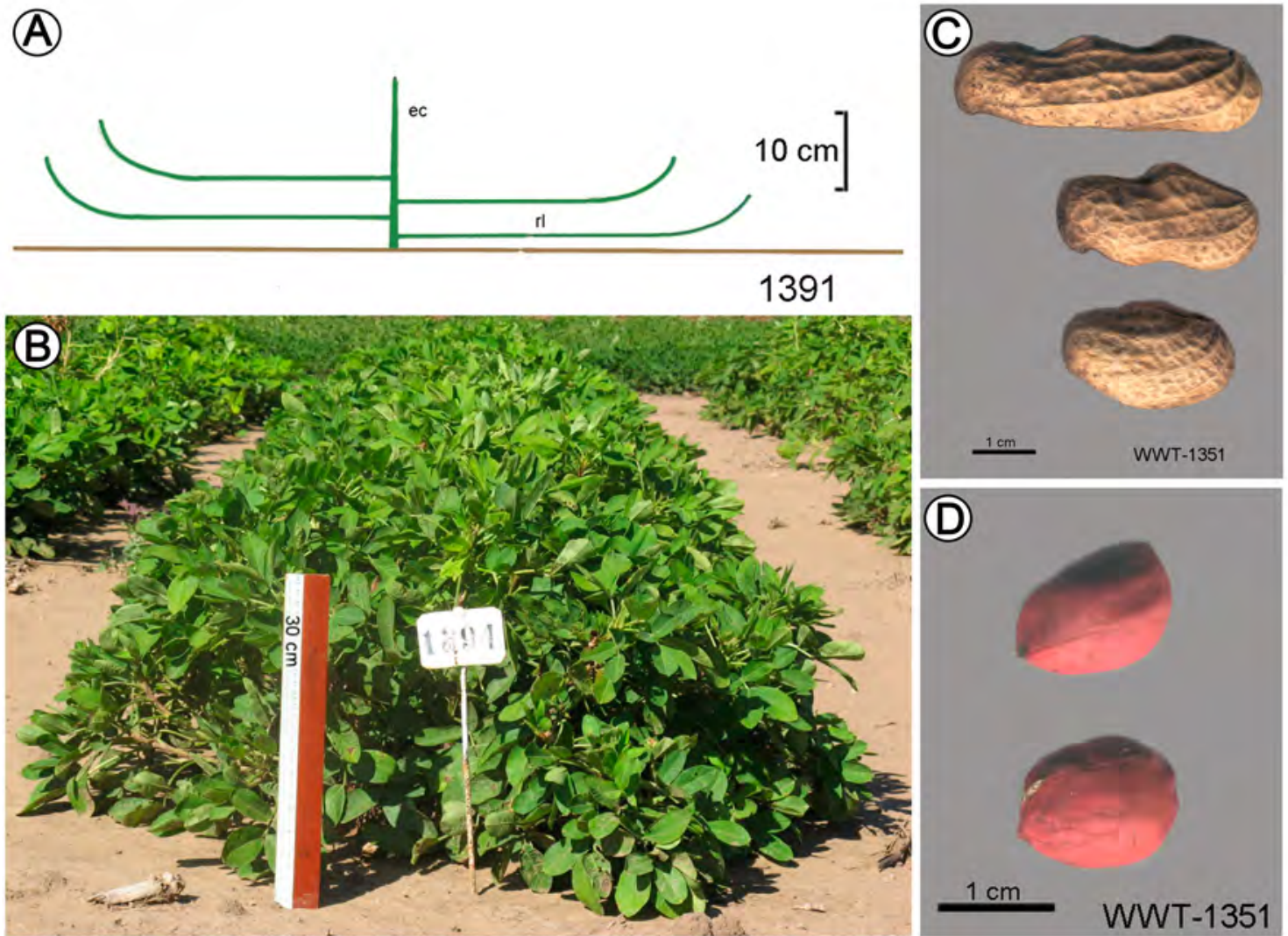

Fig. 24. Subsp. fastigiata var. fastigiata, Colorado caja grande, 1391. A: Esquema de la planta. B: Planta. C: Fruto. D: Semillas.

Fig. 24. Subsp. fastigiata. var. fastigiata, Colorado caja grande, 1391. A: Plant outline. B: Plant. C: Fruit. D: Seeds.

$\begin{array}{lllll}\text { Mdi. } & \text { US } & \text { Leg. } & \text { Nombre original } & \text { Procedencia } \\ \text { 86/2742 (2) } & \text { 698 (3) } & \text { BPZHa } & \text { Rosita } & \text { Lomas de Sargentillo, almacén. } \\ \text { 98/99 2608 } & \text { WWT 1351 Grif 12562 } & & \text { Morona } & \text { Santiago, Bomboisa, 850 m s.n.m. } \\ \text { 98/99 2618 } & \text { WWT 1355 Grif 12572 } & & & \text { Loja, Sacapianga, 1140 m s.n.m. }\end{array}$




\section{Colorado precoz}

Planta muy chica, chata, compacta. Eje central no aparente; entrenudos muy breves. Estípulas sin cerdas. Ramas reproductivas muy cortas.

Cajas angostas, chicas, con 2-3-1 granos colorados, muy pequeños.

2009/10 $1354 \quad$ US 698(3) BPZHa
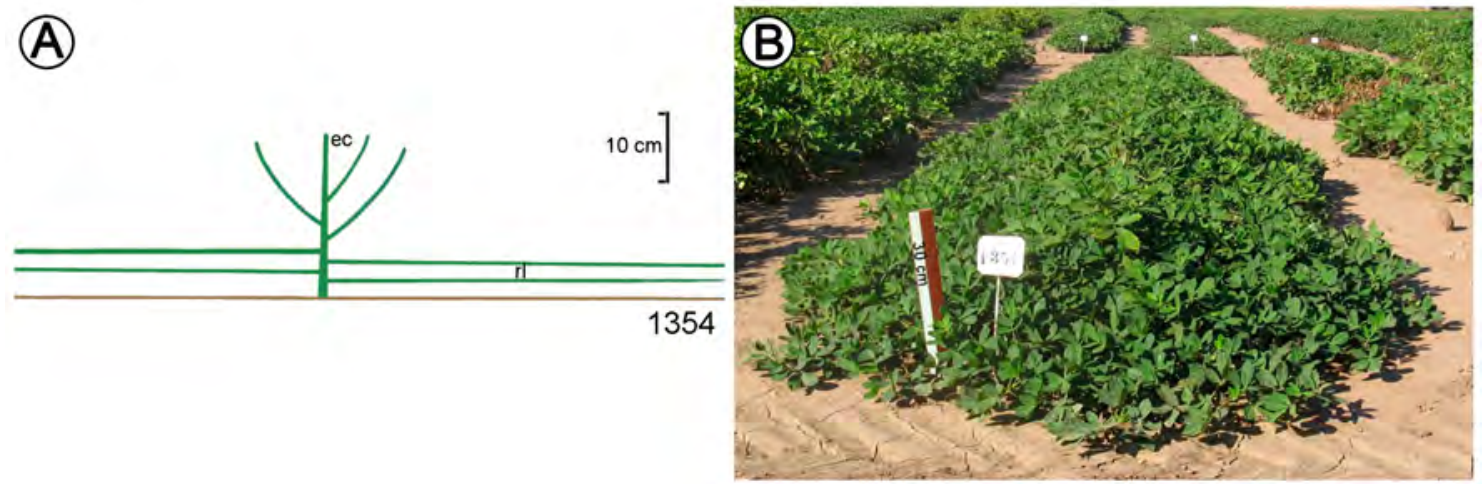

Fig. 25. Colorado precoz, 1354. A: Esquema de la planta. B: Planta.

Fig. 25. Colorado precoz, 1354. A: Plant outline. B: Plant.

$\begin{array}{lllll}\text { Mdi. } & \text { US } & \text { Leg. } & \text { Nombre original } & \text { Procedencia } \\ \text { 86/2866 (2) } & 698(3) & \text { BPZHa } & \text { Rosita } & \text { Lomas de Sargentillo, almacén }\end{array}$




\section{Colorado pequeño}

Planta pequeña, erecta poco ramificada. Eje central no aparente. Tallo verde con tono violáceo. Estandarte con aro.

Cajas con retículo más o menos marcado, con carena, con 2-3-1 granos colorados.
Mdi. 2015/204
US 698 (3)
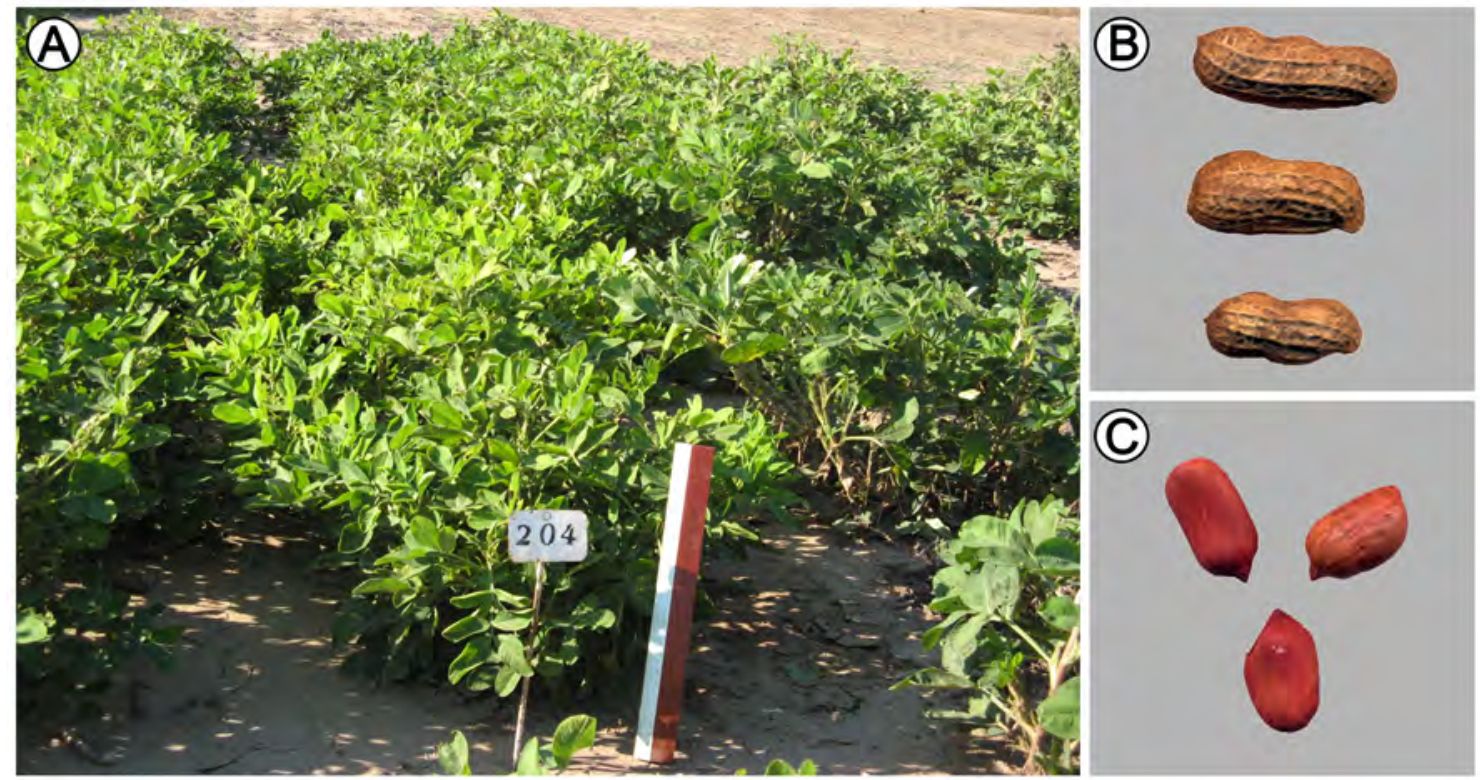

Fig. 26. Colorado pequeño, 204. A: Planta. B: Fruto. C: Semillas.

Fig. 26. Colorado pequeño, 204. A: Plant. B: Fruit. C: Seed. 


\section{Colorado Portoviejo}

2009/10 1396

WWT 1367 Grif 12592 El Oro, Zaruma, 1265 m s.n.m.

(A)

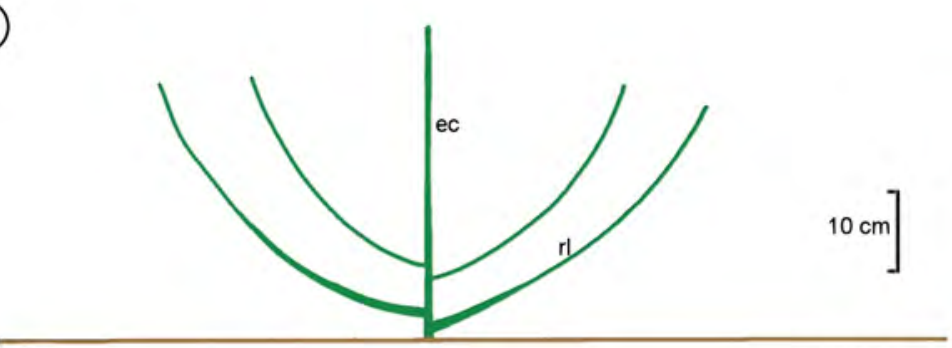

1396

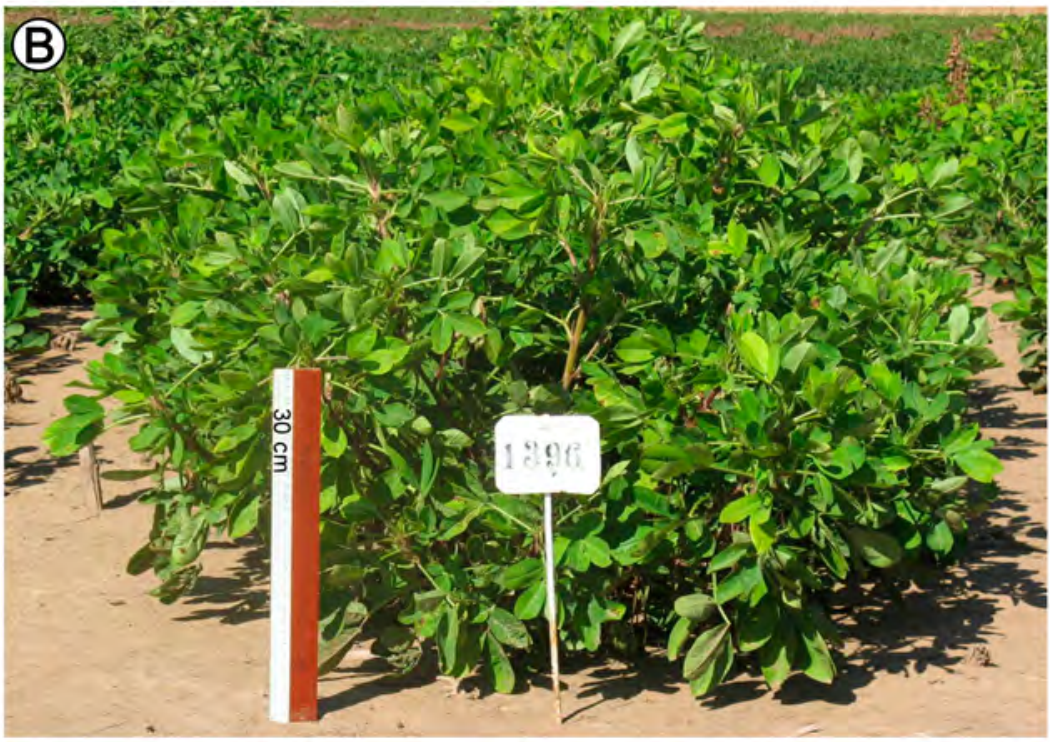

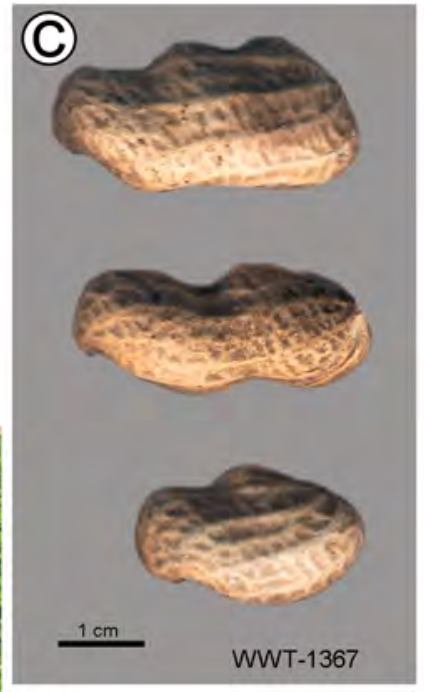

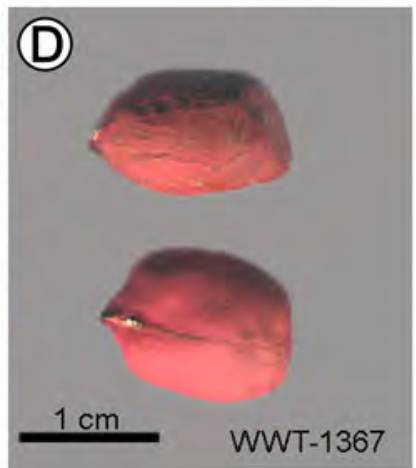

Fig. 27. Colorado Portoviejo, 1396. A: Esquema de la planta. B: Planta. C: Fruto. D: Semillas. Fig. 27. Colorado Portoviejo, 1396. A: Plant outline. B: Plant. C: Fruit. D: Seeds.

Mdi.

98/99 2621

98/99 2739
US

WWT 1382 Grif 12608

$\mathrm{N}^{\circ} 1379$
PI

PI 241362-1

\section{Procedencia}

Manabí, Portoviejo, 15 m s.n.m. 


\section{Colorado Sargentillo}

Parecido al Rosita, pero tiene además cajas de 3 granos, con una constricción apical y cajas de 4 granos. Colorado.
2009/10 1358
US 698 (1)
BPZHa Guayas, Lomas de Sargentillo
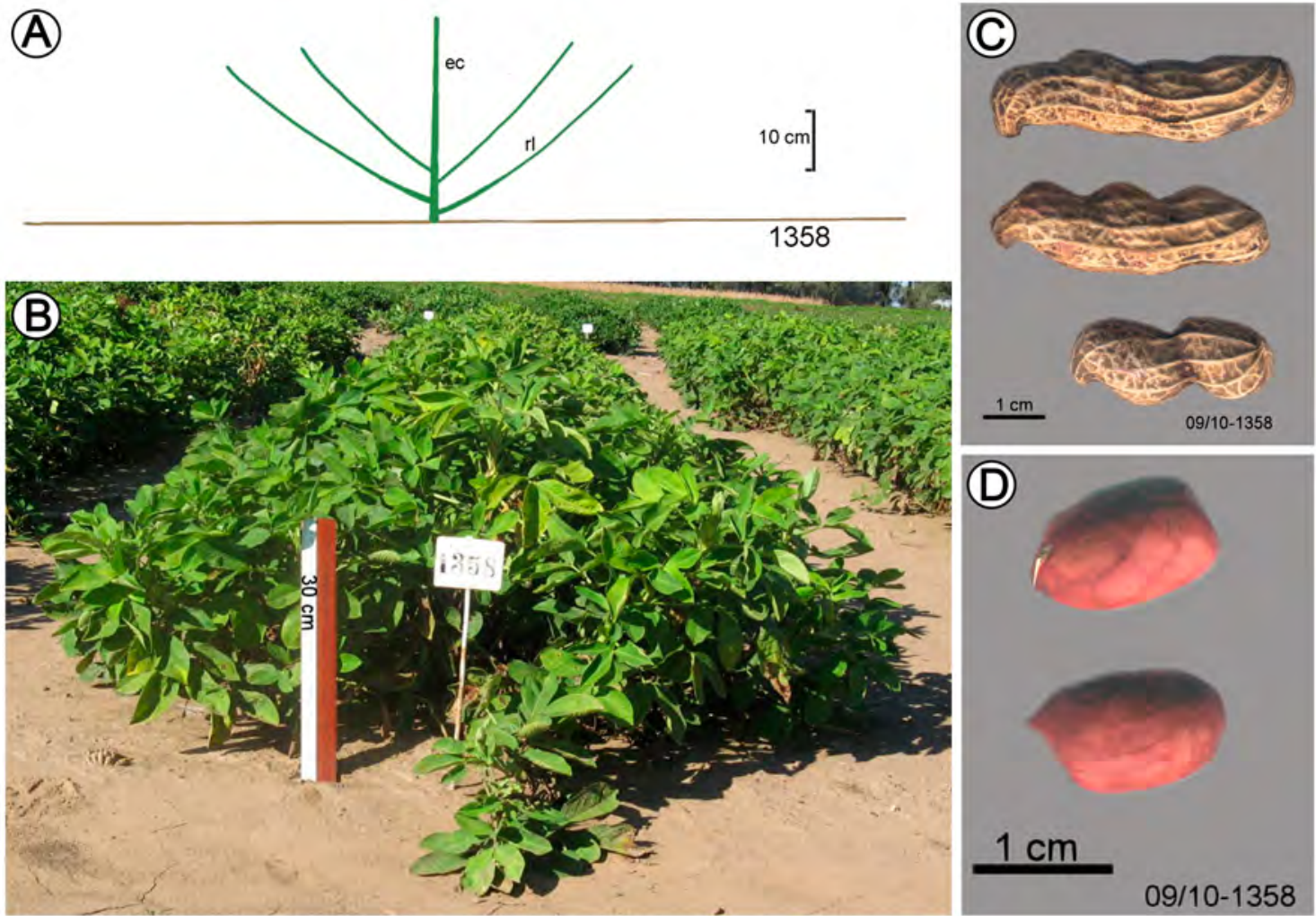

Fig. 28. Colorado Sargentillo, 1358. A: Esquema de la planta. B: Planta. C: Fruto. D: Semillas.

Fig. 28. Colorado Sargentillo, 1358. A: Plant outline. B: Plant. C: Fruit. D: Seeds.

Mdi. US PI

97/98 $1518 \quad 698(1) \quad$ PI 497611 


\section{Colorado chico}

Planta bien desarrollada, cubre los surcos, cajas reticuladas con costillas longitudinales algo más marcadas, con pico y carena, granos colorados. Frutos menores.

Mdi. 2009/10 1426 WWT 1344 Grif 12545
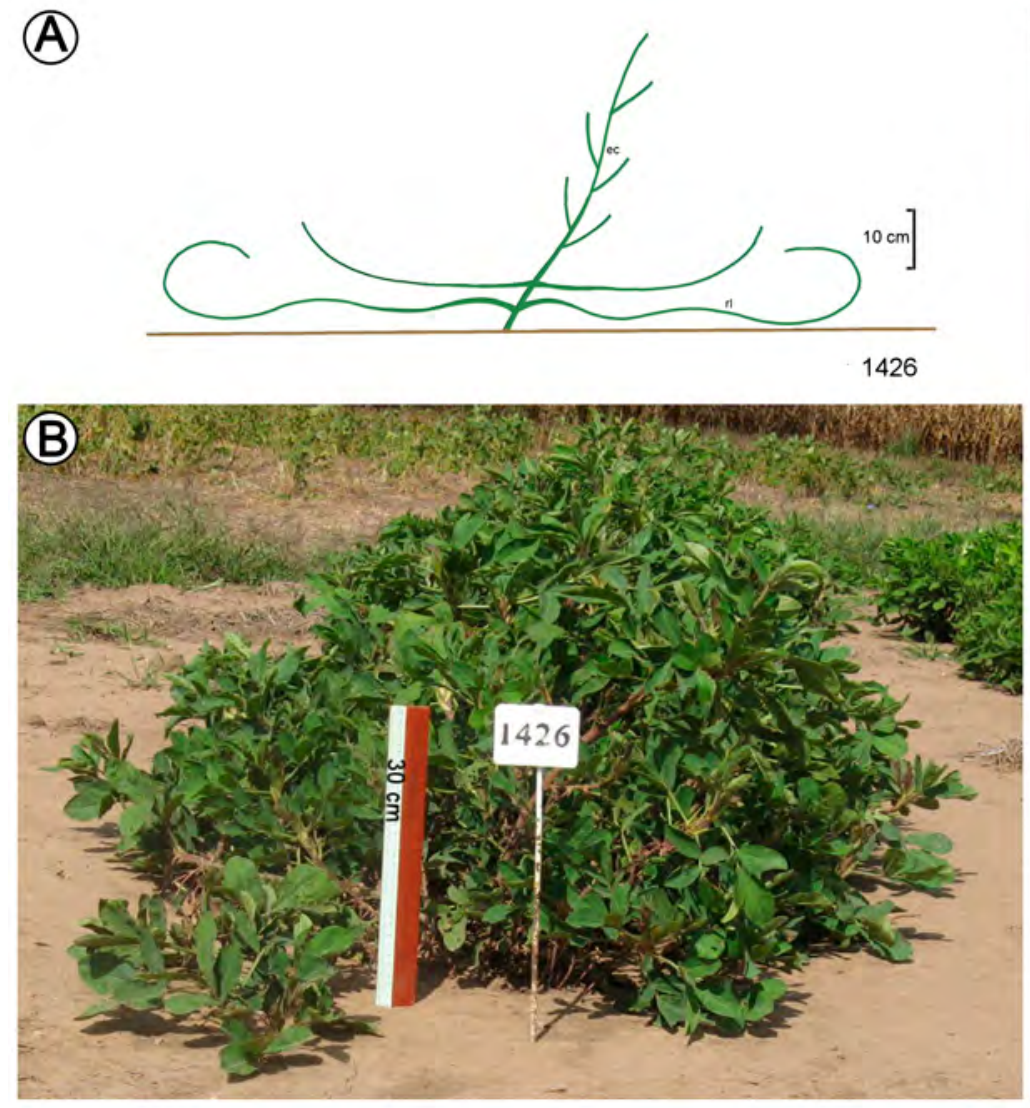

Pastaza, Puyo, 987 m s.n.m.

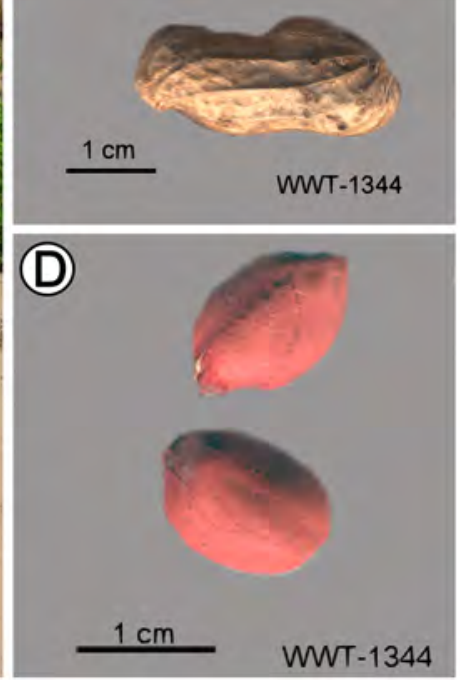

Fig. 29. Colorado chico, 1426. A: Esquema de la planta. B: Planta. C: Fruto. D: Semillas. Fig. 29. Colorado chico, 1426. A: Plant outline. B: Plant. C: Fruit. D: Seeds. 


\section{Rosita}

Planta erecta, ramificada, compacta. Eje central no aparente. Ramas reproductivas cortas, que se alternan con algunas reproductivas alargadas de hasta $10 \mathrm{~cm}$ long. y con algunas hojitas en el ápice. Tallo verde. Estípulas con 0-1 cerdas. Folíolos verde claro, algo arrugados. Estandarte con aro.

Cajas medianas, reticuladas, con costillas longitudinales algo marcadas, con pico y carena y algo de joroba. Con 2-3-4-1 granos colorados.

$\begin{array}{llrl}\text { 2009/10 } 1395 & \text { WWT } 1355 \text { Grif } 12574 & \text { Loja, Sacapianga, } 1140 \text { m s.n.m. } \\ \text { 2009/10 } 1357 & \text { US } 684 & \text { PI } 497588 & \end{array}$

(A)
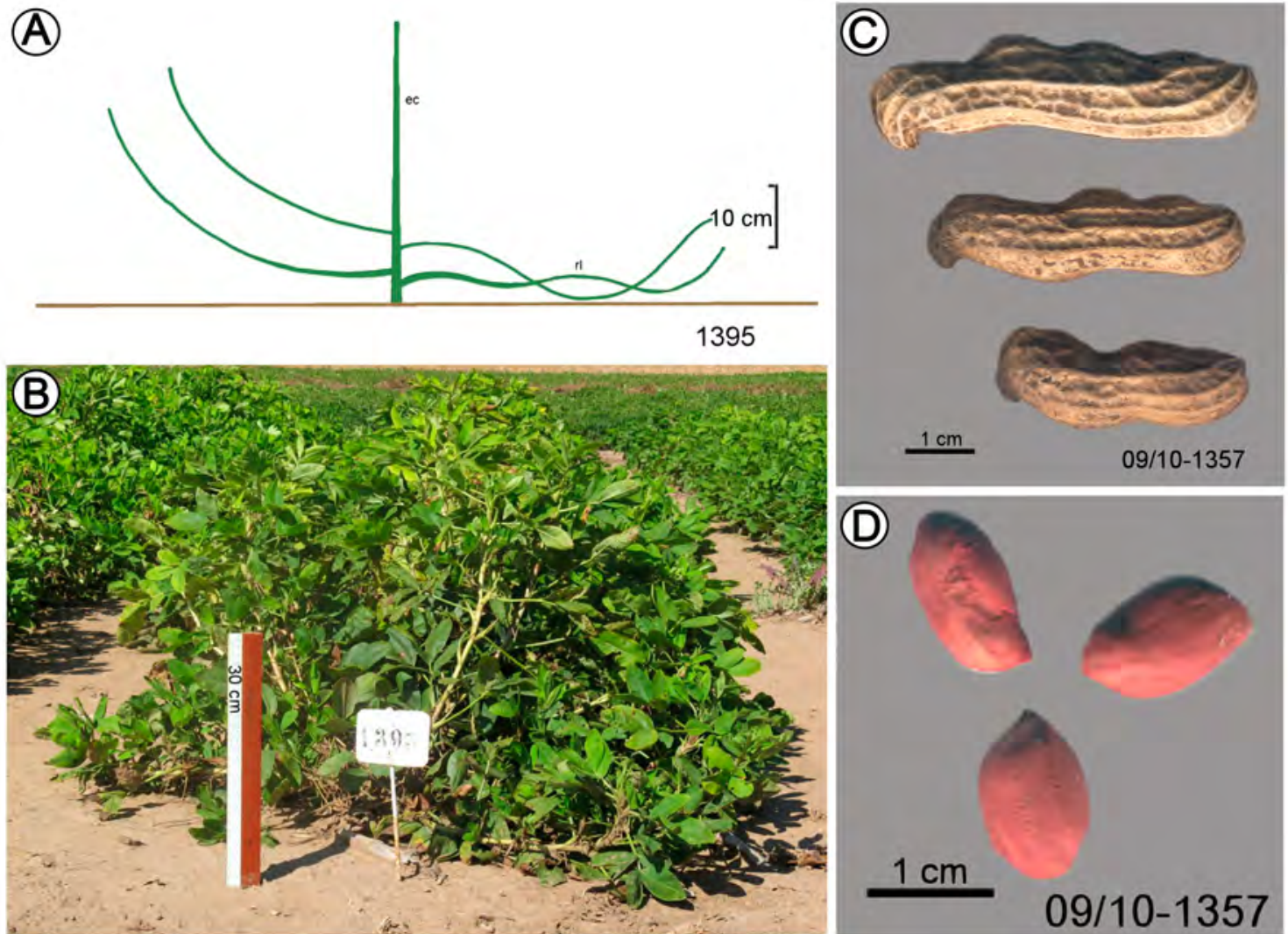

Fig. 30. Rosita, 1395. A: Esquema de la planta. B: Planta. 1357. C: Fruto. D: Semillas.

Fig. 30. Rosita, 1395. A: Plant outline. B: Plant. 1357. C: Fruit. D: Seeds.

$\begin{array}{llll}\text { Mdi. } & \text { US } & \text { PI } & \text { Procedencia } \\ \text { 86/2732 } & 684 & & \text { Pichincha, Quito } \\ 97 / 981542 & 684 & \text { PI } 497588 & \\ 86 / 2733 & 685 & & \text { Pichincha, Quito } \\ 97 / 981543 & 685 & \text { PI } 497589 & \\ 86 / 2734 & 693(2) & & \text { Guayas, Pedro Carbo }\end{array}$


A. Krapovickas et al., Las razas de maní de Ecuador

Mdi.

86/2736

$86 / 2736$

$86 / 2738$

97/98 1545

97/98 1546

98/99 2619

98/99 2622
US

$695(2)$

$697(1)$

698 (1)

697 (1)

$731(2)$

$731(1)$

WWT 1355 Grif 12574

WTS 73 Grif 13854
PI

Procedencia

Guayas, Pedro Carbo

Guayas, Bachiller

Guayas, Lomas de Sargentillo

PI 497609

PI 497666

PI 407494

Loja, Sacapianga, 1140 m s.n.m.

Los Ríos, Vinces, 110 m s.n.m. 


\section{Rosita pálido}

Planta erecta compacta, eje central no aparente; tallo verde. Similar al "Rosita", pero las hojas son verde más oscuras. Estípulas con cero a pocas cerdas. Ramas reproductivas hasta $4 \mathrm{~cm}$ long. Estandarte con aro.

Cajas chicas a medianas, reticuladas, con carena y algo de pico, con costillas longitudinales muy poco sobresalientes y con 2-1 granos pálidos.
2009/10 1359
US 697(2)
PI 497610
BPZ
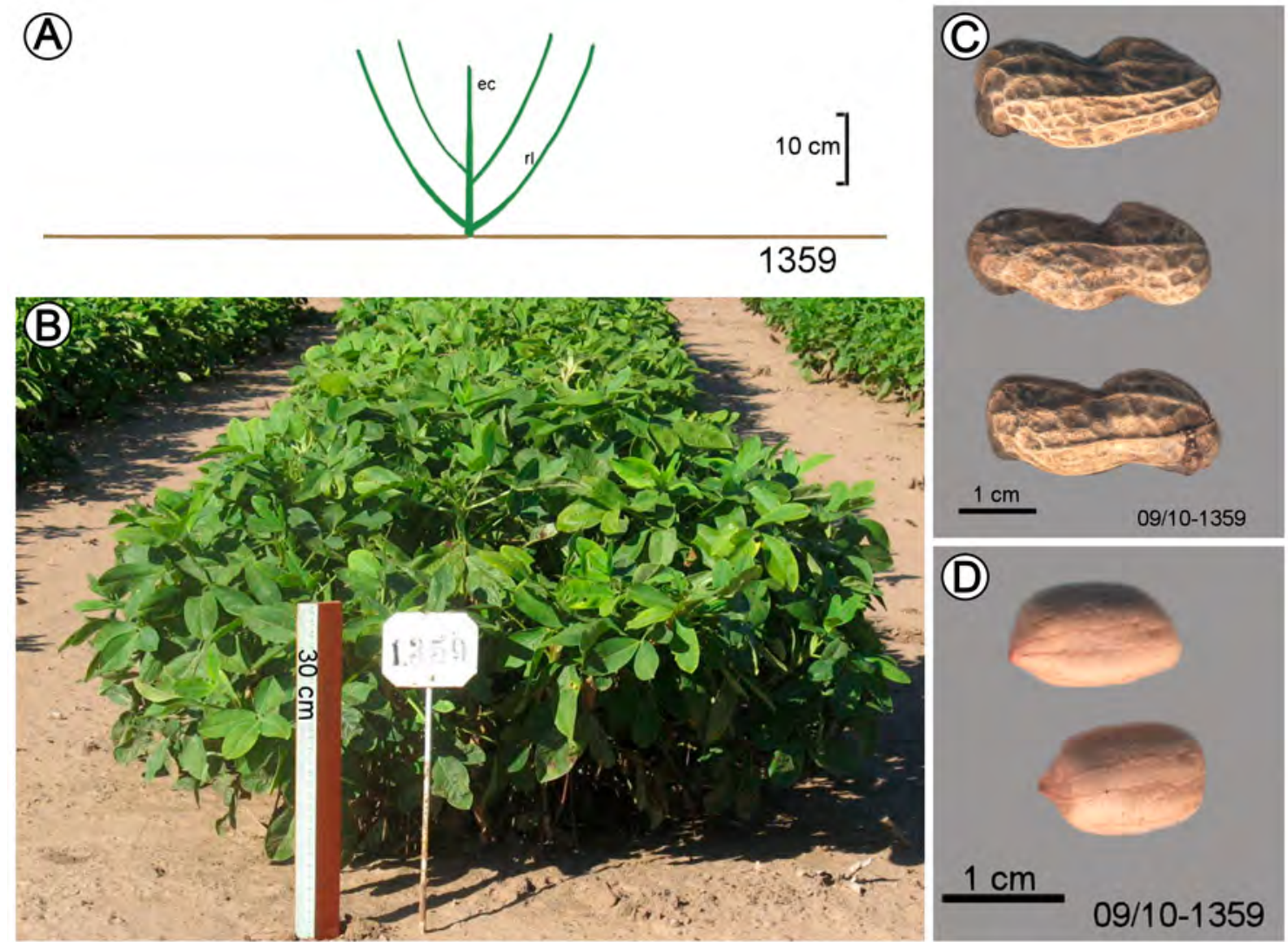

Fig. 31. Rosita pálido, 1359. A: Esquema de la planta. B: Planta. C: Fruto. D: Semillas. Fig. 31. Rosita pálido, 1359. A: Plant outline. B: Plant. C: Fruit. D: Seeds.

$\begin{array}{llll}\text { Mdi.. } & \text { US } & \text { PI } & \begin{array}{l}\text { Procedencia } \\ \text { Guayas, Bachiller }\end{array} \\ \text { 86/2739 } & 697(2) & & \\ 97 / 981553 & 697(2) & \text { PI 497610 } & \text { Guayas, Lomas de Sargentillo } \\ 86 / 2740 & 698(2) & & \\ 97 / 981519 & 698(2) & \text { PI 497612 } & \end{array}$




\section{Rosita sin pico}

Planta pequeña, erecta. Cajas gruesas de 3,34 cm long. × 1,57 cm lat., sin pico, granos pálidos. 2009/10 1362 US 698 (3) BPZHa Guayas, Lomas de Sargentillo

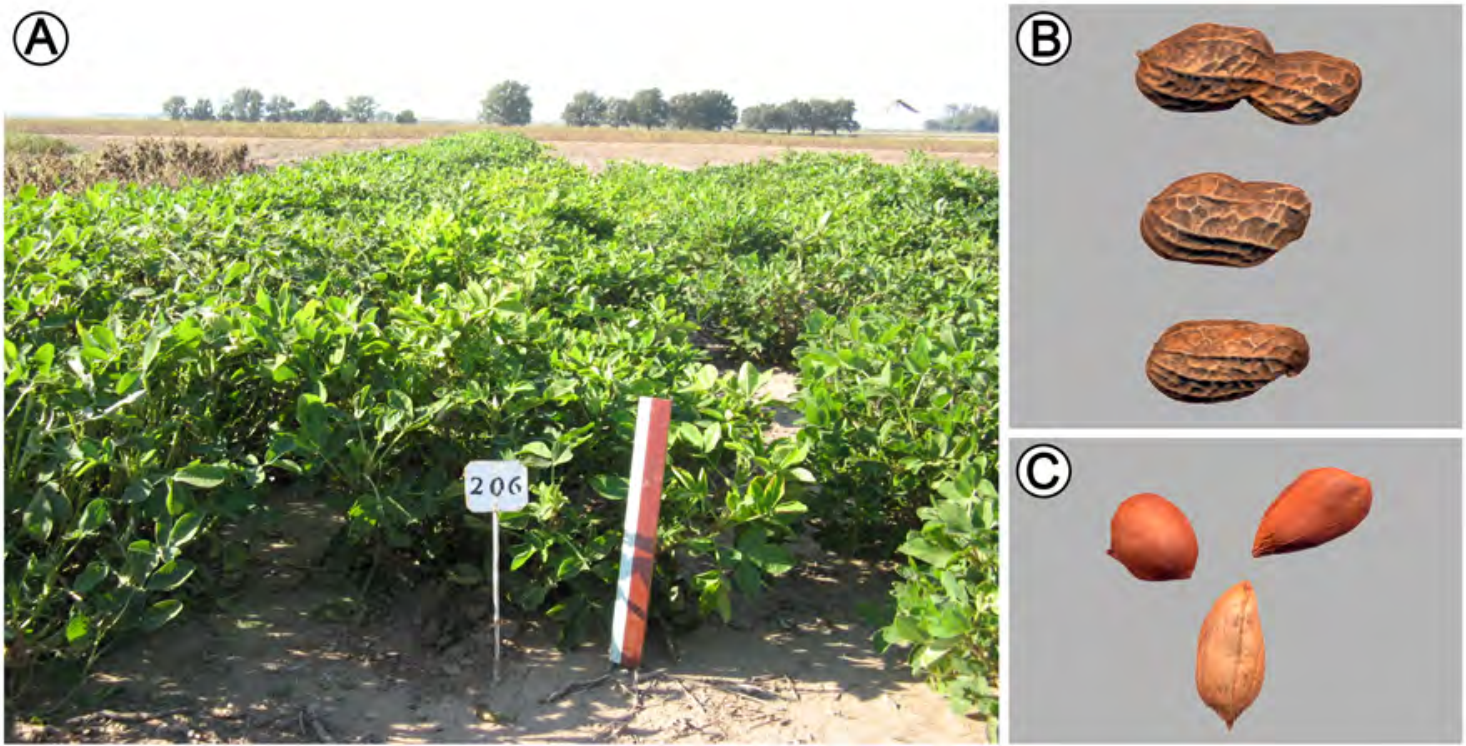

Fig. 32. Rosita sin pico, 1362. A: Planta. Mdi. 2015/ 206. B: Fruto. C: Semillas. Fig. 32. Rosita sin pico, 1362. A: Plant. Mdi. 2015/ 206. B: Fruit. C: Seeds. 


\section{Negro planta compacta}

Planta mediana, ramificada, compacta, chata; eje central no a muy poco aparente. Estípulas sin cerdas. Ramas reproductivas cortas. Tallo y pecíolos algo morados. Flor morada.

Cajas arqueadas, irregulares, reticuladas, con jorobas y carena y con poco pico. Con 3-2-1 granos negros.
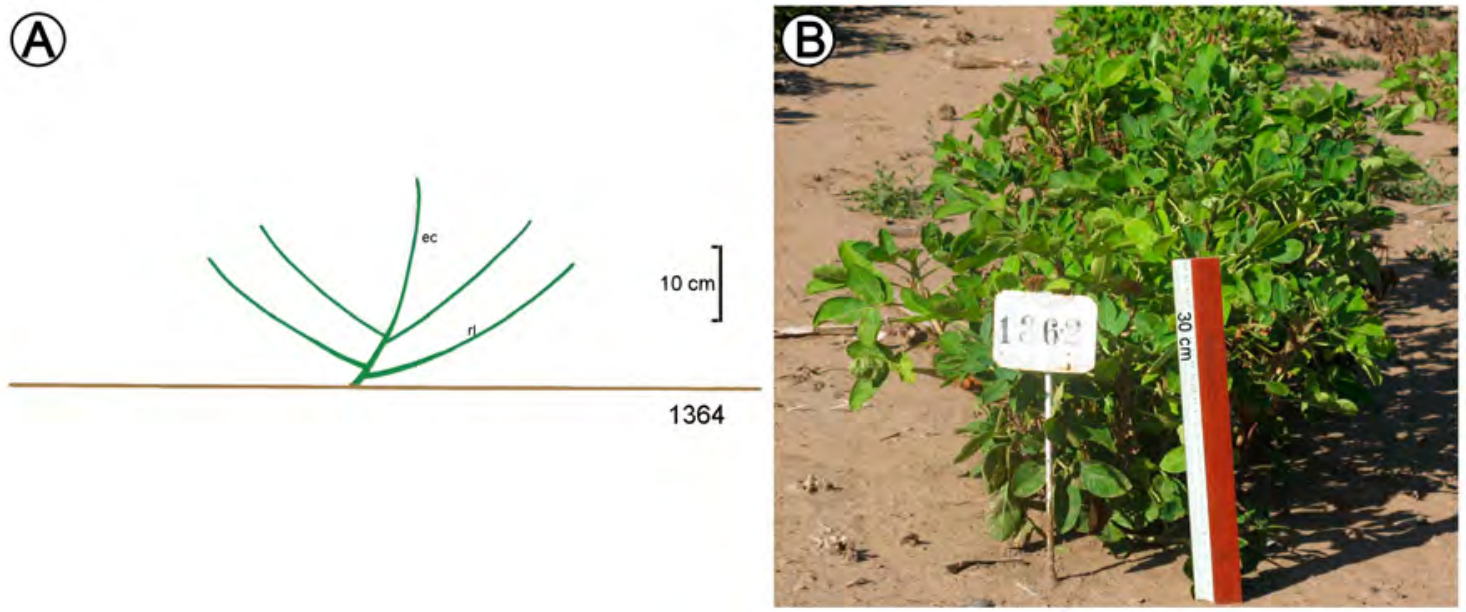

Fig. 33. Negro planta compacta, 1364. A: Esquema de la planta. B: Planta.

Fig. 33. Negro planta compacta, 1364. A: Plant outline. B: Plant. 


\section{Colorado de Piñas}

Planta abierta, con ramificación tipo Valencia; ramas dísticas, decumbentes, altas, que cubren al eje central. Tallo verde. Hojas con cerdas desde las estípulas hasta el raquis. Folíolos grandes, con ondulaciones transversales. Alternan ramas reproductivas breves con ramas reproductivas alargadas (con hojitas hacia el ápice), de hasta $5 \mathrm{~cm}$ long. Estandarte con aro.

Cajas cortas, redondeadas, gordas, sin estrangulamiento, con carena, sin pico y con 2-3-1 granos colorados.
2009/10 1361
US 701 (2) BPZHa PI 497618
El Oro, Piñas
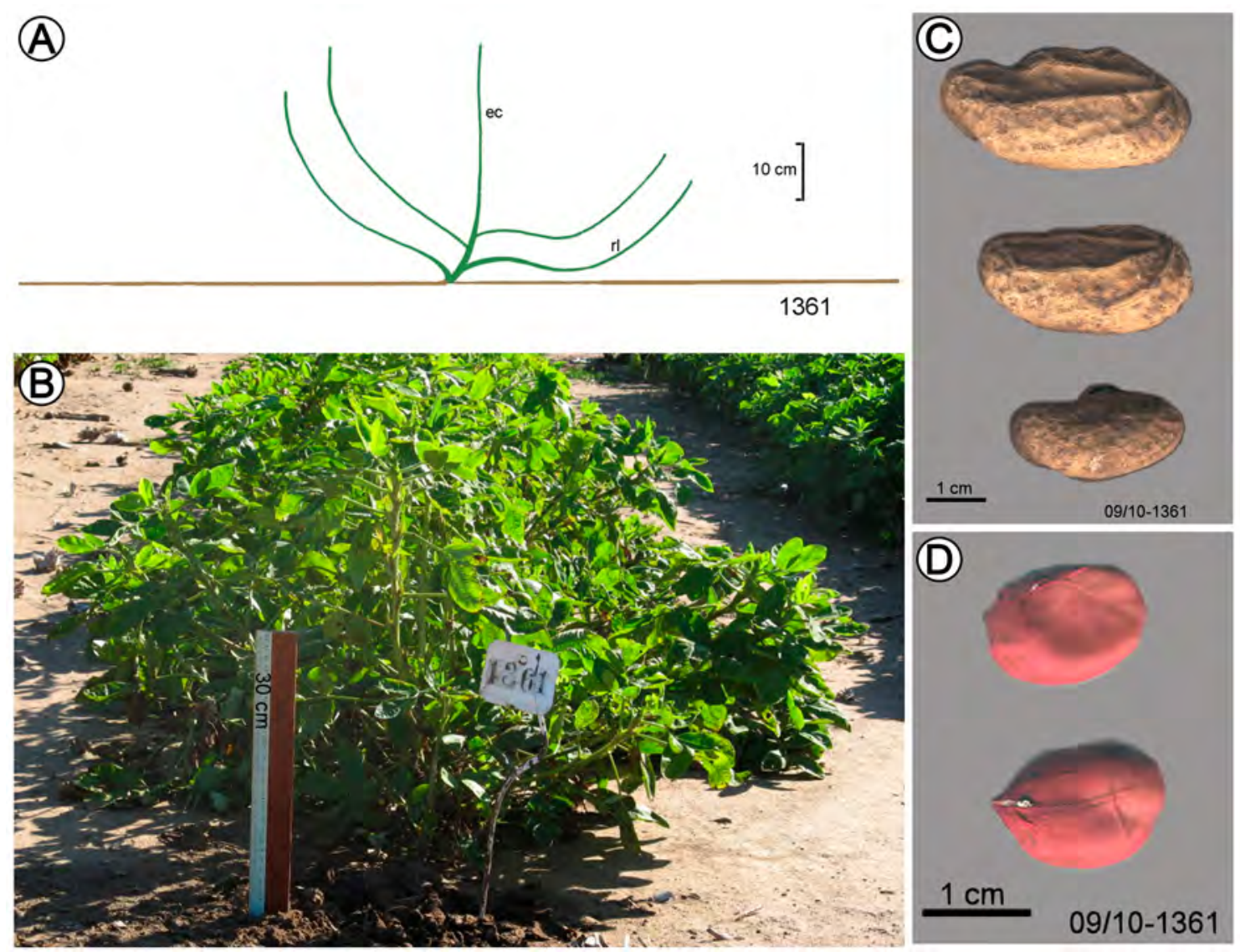

Fig. 34. Colorado de Piñas, 1361. A: Esquema de la planta. B: Planta. C: Fruto. D: Semillas.

Fig. 34. Colorado de Piñas, 1361. A: Plant outline. B: Plant. C: Fruit. D: Seeds. 


\section{Pálido de Sargentillo}

Planta erecta, pequeña a mediana; eje central aparente. Tallo verde con tono violáceo. Folíolos más o menos amarillentos, que tienden a plegarse.

Cajas con retículo grueso, con constricción que casi llega a ser como un itsmo, con carena y pico y con 2-3-1 granos color salmón.

Mdi. 2015/206 US 698 (3)
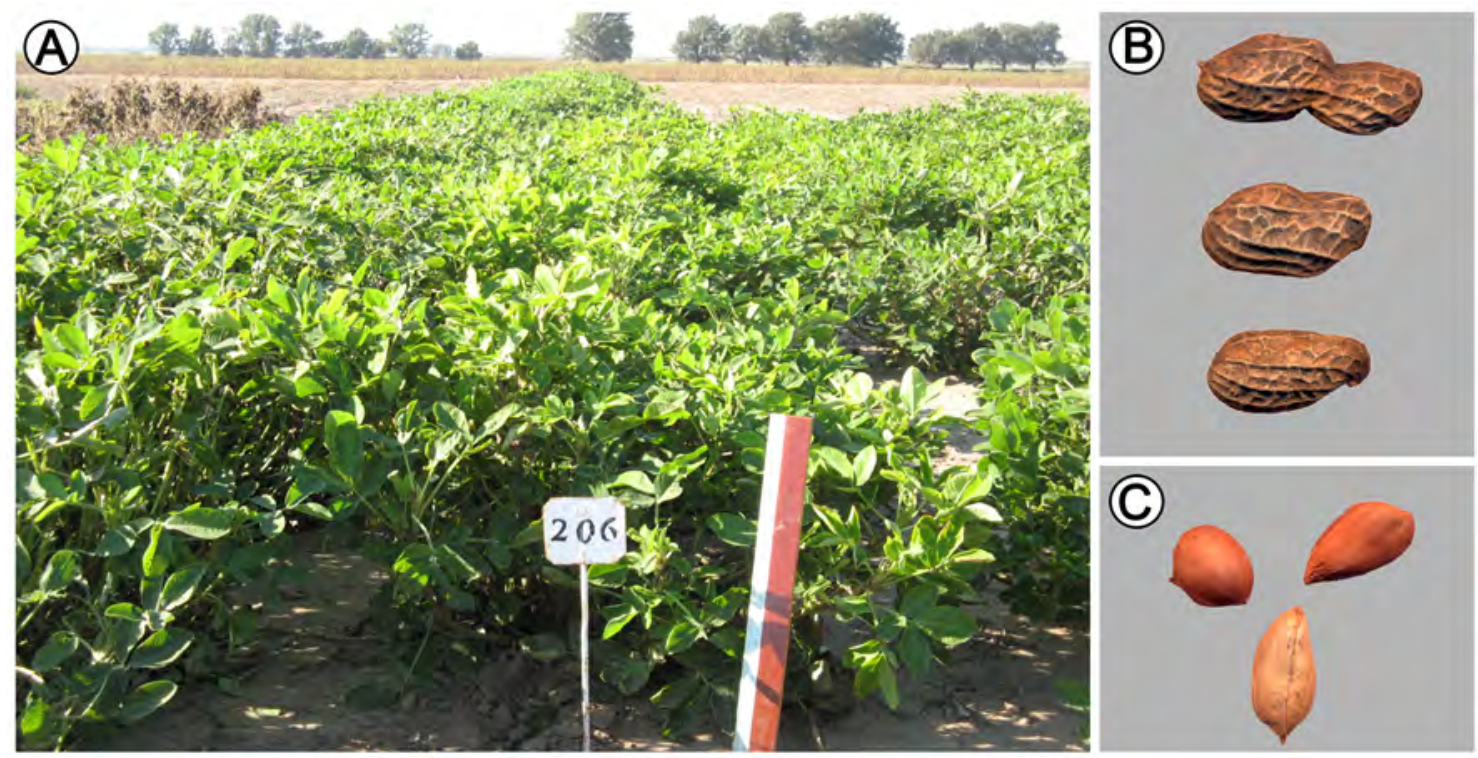

Fig. 35. Pálido de Sargentillo, 206. A: Planta. B: Fruto. C: Semillas.

Fig. 35. Pálido de Sargentillo, 206. A: Plant. B: Fruit. C: Seeds. 


\section{Zapotepamba}

Planta erecta, compacta. Eje central algo aparente. Estípulas con cerdas. Ramas reproductivas breves. Tallos y clavos verdes con tinte violáceo. Folíolos y brotes verde claro. Estandarte anaranjado, con aro marcado; alas amarillas con tinte morado, en la porción en contacto con el estandarte.

Cajas con retículo diluído, con algo de joroba y pico; con 3-2-4-1-granos morados (los no maduros son negros).
2009/10 1352
BPZ US $711(1)$
Loja, Loja
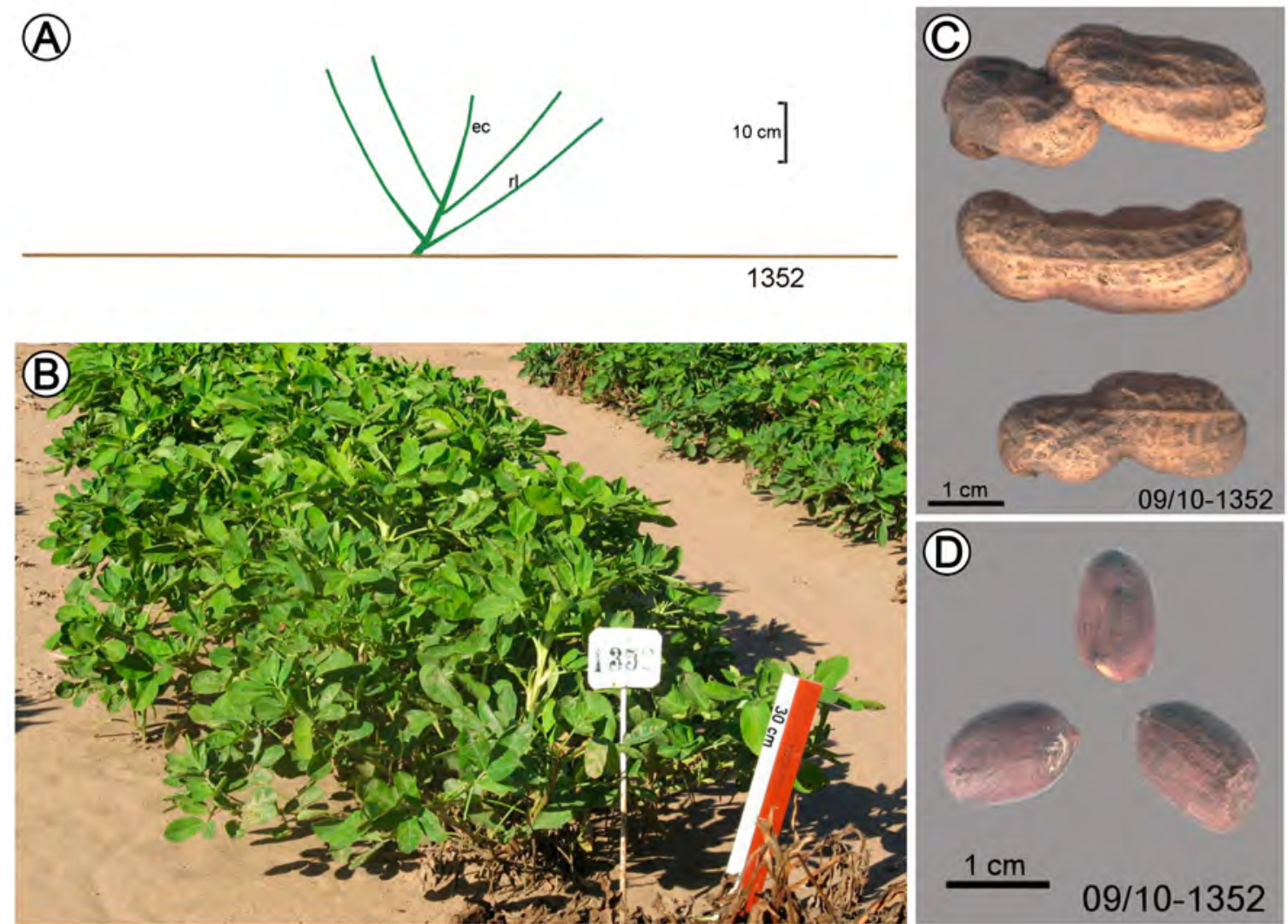

Fig. 36. Zapotepamba, 1352. A: Esquema de la planta. B: Planta. C: Fruto. D: Semillas.

Fig. 36. Zapotepamba, 1352. A: Plant outline. B: Plant. C: Fruit. D: Seeds.

Mdi.

97/98 1554

86/2707

97/98 1555

$86 / 2710$

97/98 1556

$86 / 2711$

86/2713 (2)
US

711

712

712

716

716

723

698 (3)
PI

PI 497637

PI 497638

PI 497642

PI 497650

\section{Procedencia}

Loja, Catacocha

Loja, Catacocha

Guayas, Lomas de Sargentillo 


\section{Arachis hypogaea subsp. fastigiata var. peruviana (Fig. 1C)}

\section{Tingo María}

Planta erecta, poco ramificada; eje central muy aparente, ramas arqueadas. Tallo y clavo verde. Estípulas con cerdas; folíolos grandes, verde claro. Estandarte sin aro.

Cajas con joroba y carena, sin pico, con 3-4-2-1 granos pálidos, con líneas breves de color morado.

\section{9/10 1399}

(A)
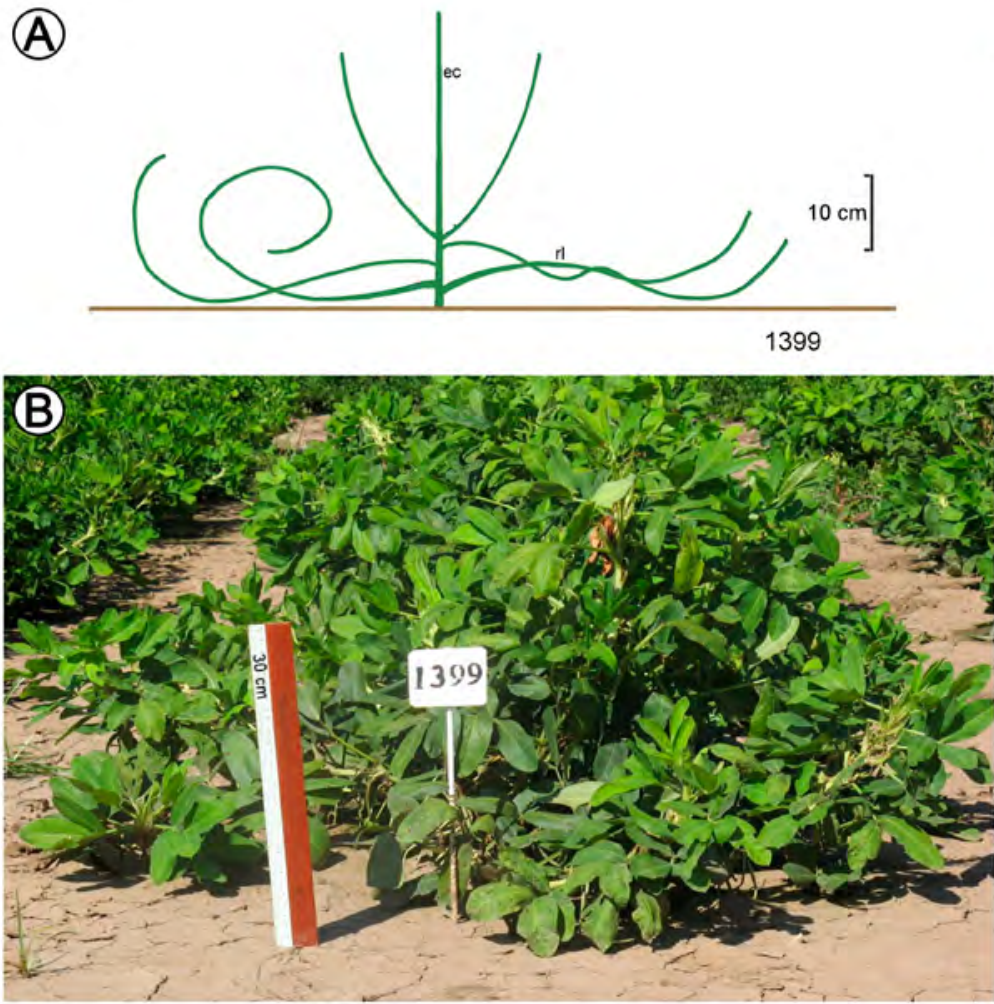
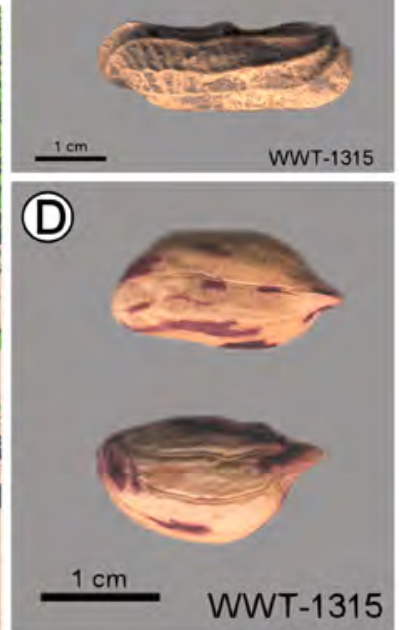

Fig. 37. Subsp. fastigiata var. peruviana. Tingo María, 1399. A: Esquema de la planta. B: Planta. C: Fruto. D: Semillas. Fig. 37. Subsp. fastigiata var. peruviana. Tingo María, 1399. A: Plant outline. B: Plant. C: Fruit. D: Seeds.

Mdi.

$86 / 2704$

98/99 2625

98/99 2626

98/99 2627

98/99 2628

98/99 2629

98/99 2630

98/99 2631

98/99 2632

98/99 2745

98/99 2746
US

693 (1)

WWT 1327 Grif 12518

WWT 1342 Grif 12537

WWT 1350 Grif 12561

WTS 22 Grif 13806

WTS 53 Grif 13834

WTS 58 Grif 13839

WTS 68 Grif 13849

WTS 76 Grif 13857

WTS 39 Grif 13821

WTS 82 Grif 13863

\section{Procedencia}

Guayas, Pedro Carbo

Sucumbios, Yamanunga, 4 granos

Pastaza, Puyo, 987 m s.n.m.

Morona-Santiago, Sucúa, 890m s.n.m.

Esmeraldas, La Unión, 340 m s.n.m.

Manabí, Calceta, 180 m s.n.m.

Manabí, Calceta, 180 m s.n.m.

Guayas, Jujan, 140 m s.n.m.

Los Ríos, Maté de Cacao, 200 m s.n.m.

Manabí, El Carmen, 400 m s.n.m.

Los Ríos, Jauneche, 210 m s.n.m. 


\section{Jaspeado con setas}

Planta con eje central poco aparente, estípulas con setas, ramas casi erectas. Cajas hasta $5 \mathrm{~cm}$ long., con pico y joroba. Granos bicolores violáceos a pálidos con manchas apicales más oscuras 2009/10 1402 WWT 1350 Grif 12560 Morona, Santiago, Sucúa, 890 m s.n.m.
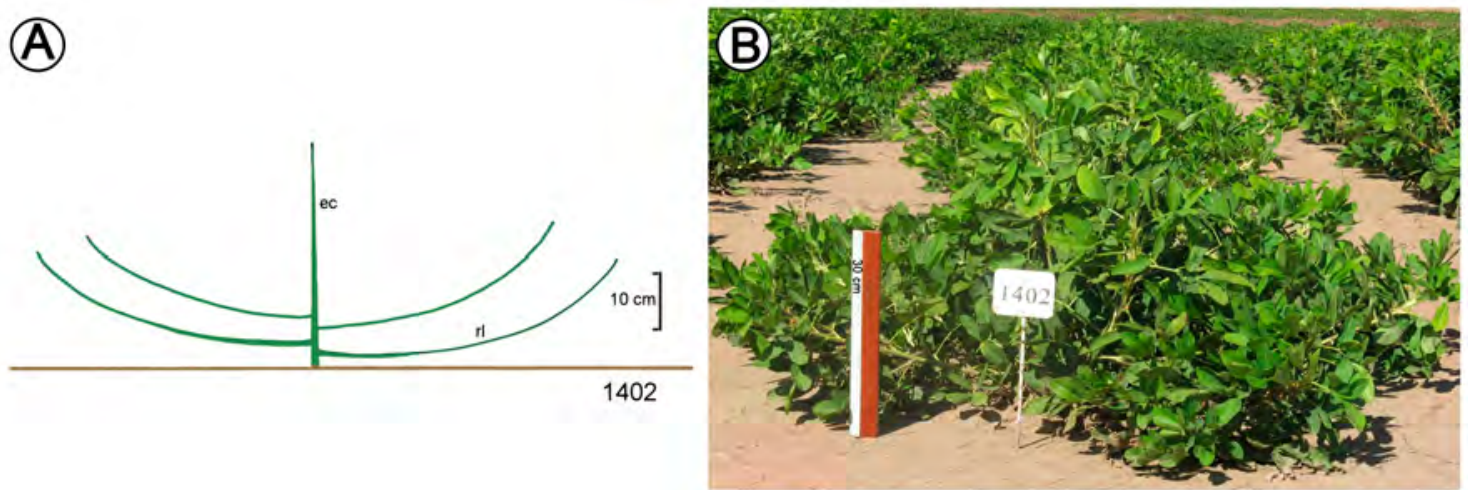

Fig. 38. Jaspeado con cerdas, 1402. A: Esquema de la planta. B: Planta. Fig. 38. Jaspeado con cerdas, 1402. A: Plant outline. B: Plant.

Mdi.

98/99 2670

98/99 2798
US

WWT 1343 Grif 12540

WWT 1343 Grif 12542

\section{Procedencia}

Pastaza, Puyo, 987 m s.n.m.

Pastaza, Puyo, 987 m s.n.m. 


\section{Jaspeado sin setas}

Planta con eje central aparente, estípulas sin setas, ramas decumbentes. Cajas hasta 4 cm long., sin pico y sin joroba. Granos bicolores, pálidos, con manchas apicales más oscuras.
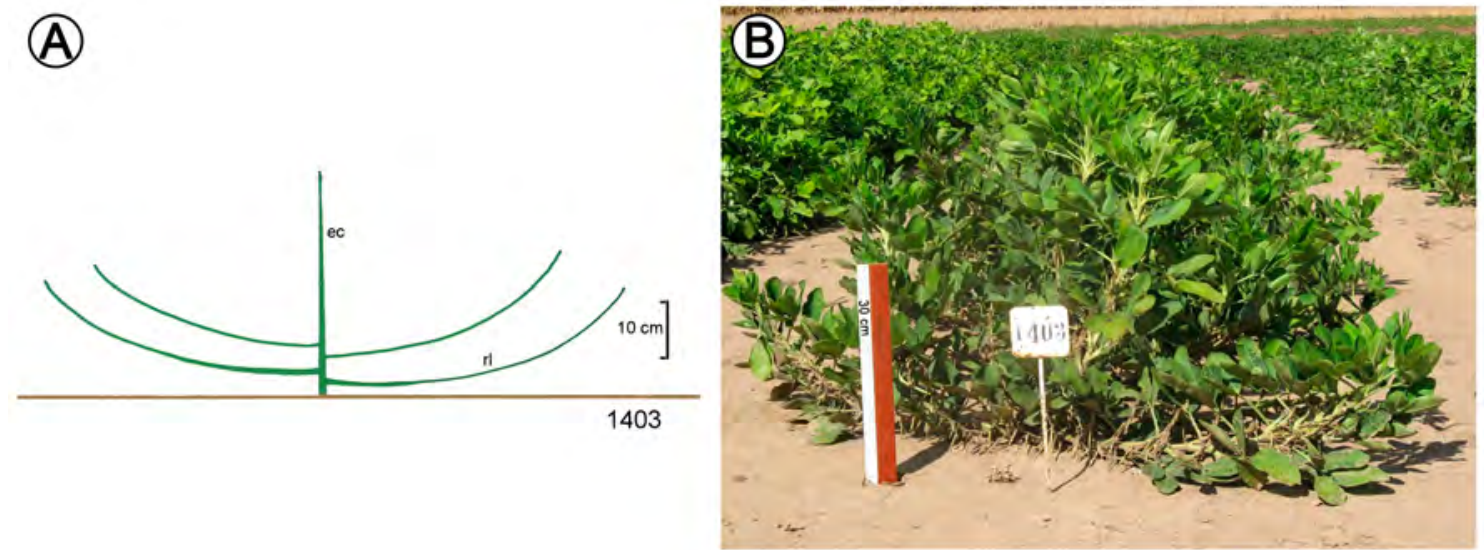

Fig. 39. Jaspeado sin cerdas, 1403. A: Esquema de la planta. B: Planta.

Fig. 39. Jaspeado sin cerdas, 1403. A: Plant outline. B: Plant.

Mdi.

98/99 2633

98/99 2634

98/99 2637

98/99 2638

98/99 2639

98/99 2640

98/99 2641

98/99 2642

98/99 2666

98/99 2730

98/99 2747
US

WWT 1342 Grif 12538

WWT 1344 Grif 12544-1

WTS 25 Grif 13809

WTS 34 Grif 13817

WTS 38 Grif 13820

WTS 43 Grif 13824

WTS 59 Grif 13840

WTS 63 Grif 13844

WWT 1332 Grif 12525

WWT 1344 Grif 12544-2

WWT 1332 Grif 12528

\section{Procedencia}

Pastaza, Puyo, 987 m s.n.m.

Pastaza, Puyo, 987 m s.n.m.

Esmeraldas, Pambula, 260 m s.n.m.

Pichincha, Macache, 360 m s.n.m.

Pichincha, El Carmen, 400 m s.n.m.

Manabí, La Cresta, 590 m s.n.m.

Manabí, Calceta, 180 m s.n.m.

Manabí, Calceta, 180 m s.n.m.

Napo, Francisco de Orellana, 340 m s.n.m.

Pastaza, Puyo, 987 m s.n.m.

Napo, Francisco de Orellana, 340 m s.n.m. 


\section{Morado de Cotacocha}

Planta erecta, mediana, poco ramificada; eje central aparente; ramas dísticas, semierectas. Tallo morado. Estípulas con cerdas; folíolos verde oscuro. Brote y pecíolo algo violáceo Ramas reproductivas relativamente gruesas. Estandarte anaranjado, con aro; alas amarillas, con manchita morada.

Cajas con joroba y carena, sin pico. Nervaduras longitudinales sobresalientes; con 3-2-4-1 granos violáceos (negros cuando inmaduros).

$$
\text { 2009/10 } 1351 \quad \text { US 717(2) BPZHa Loja, Catacocha }
$$

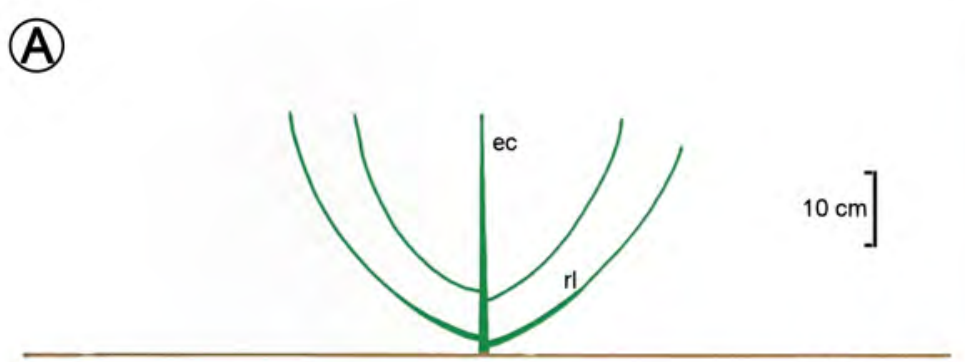

1351
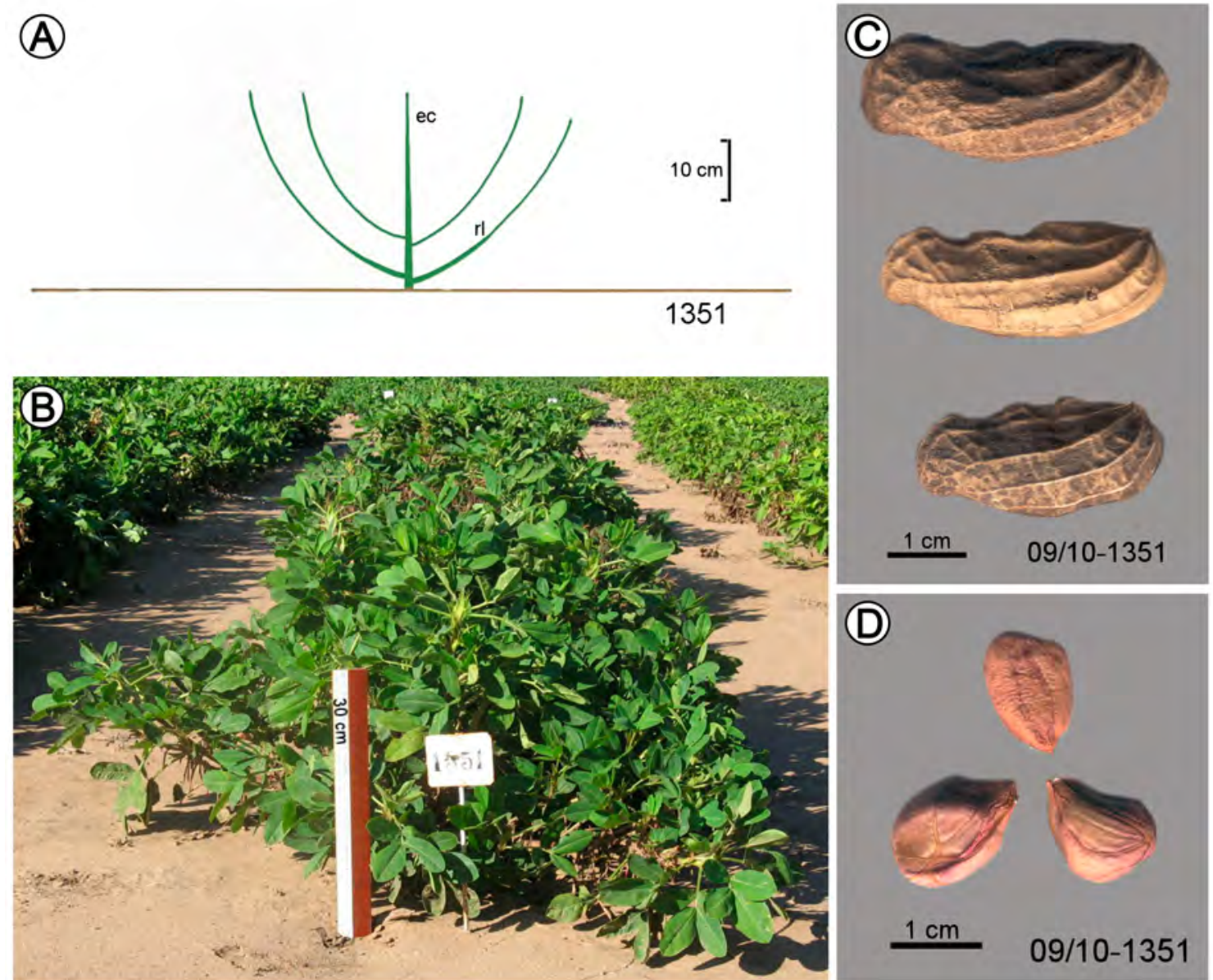

Fig. 40. Morado de Catacocha, 1351. A: Esquema de la planta. B: Planta. C: Fruto. D: Semillas. Fig. 40. Morado de Catacocha, 1351. A: Plant outline. B: Plant. C: Fruit. D: Seeds. 


\section{Verde de Cotacocha}

Planta más o menos grande, abierta, más o menos ramificada; eje central aparente. Tallo verde con tono violáceo. Brote y pecíolo verdes. Folíolos grandes, verde oscuro. Estandarte anaranjado, con aro; alas amarillas.

Cajas con jorobas y carena, sin pico, con 3-2-4-1 granos violáceos con punta clara.
2009/10 1356
US714 (2)
PI 497640
BPZHa Loja, Catacocha
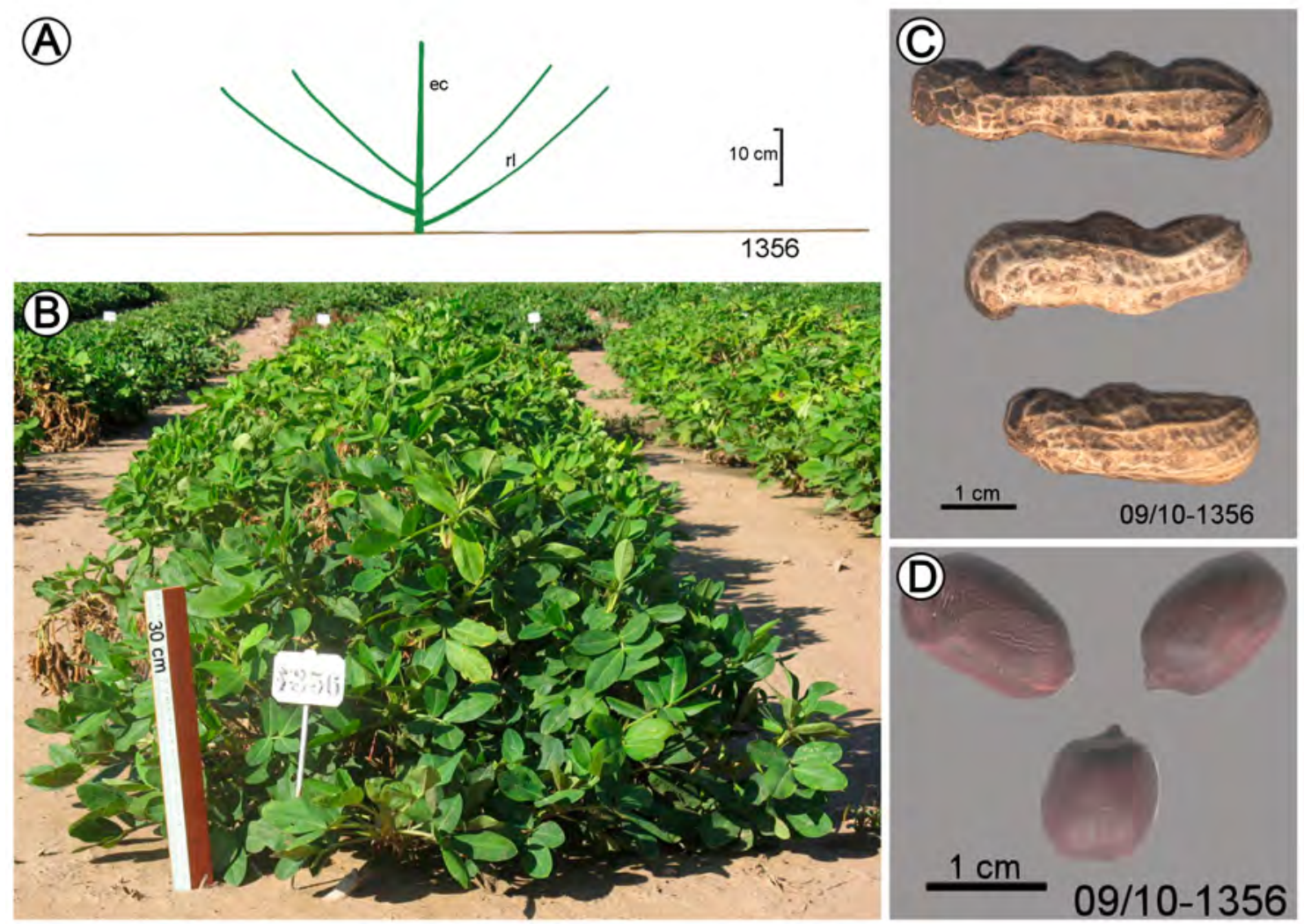

Fig. 41. Verde de Cotacocha, 1356. A: Esquema de la planta. B: Planta. C: Fruto. D: Semillas. Fig. 41. Verde de Cotacocha, 1356. A: Plant outline. B: Plant. C: Fruit. D: Seeds. 


\section{Negro criollo}

Planta erecta, compacta, ramificada; eje central apenas aparente. Ramas dísticas. Tallos verdes a violáceo claro. Brote apenas violáceo. Estípulas con cerdas. Estandarte y alas moradas. Clavo violáceo

Cajas cortas y redondeadas, con 2-3 granos, con diferentes intensidades de morado a violáceo.
2009/10 1348
US 681
Pichincha, Sangolquí

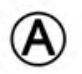

(A)
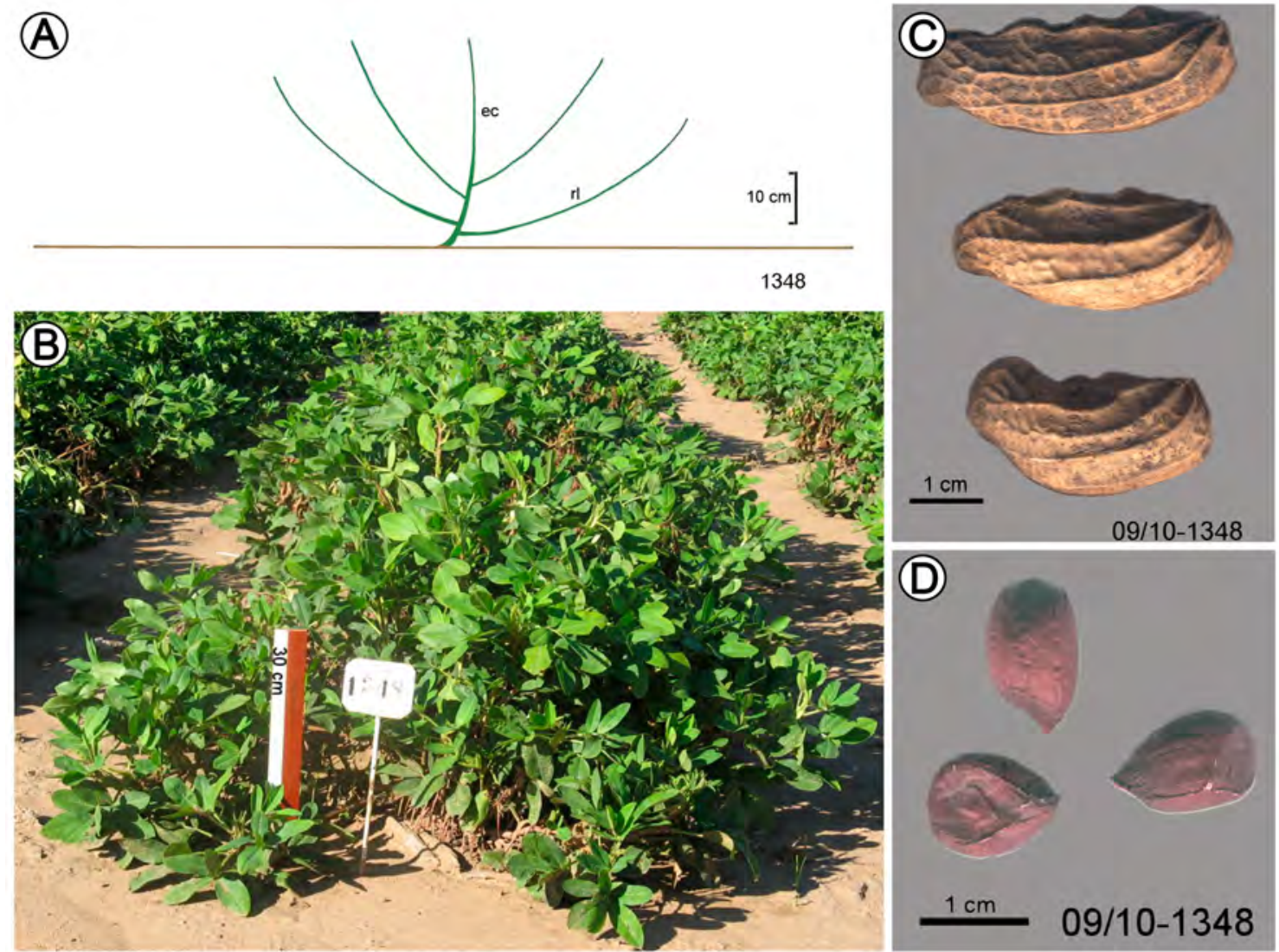

Fig. 42. Negro criollo, 1348. A: Esquema de la planta. B: Planta. C: Fruto. D: Semillas.

Fig. 42. Negro criollo, 1348. A: Plant out line. B: Plant. C: Fruit. D: Seeds.

$\begin{array}{llll}\text { Mdi. } & \text { US } & \text { PI } & \text { Procedencia } \\ 97 / 981586 & 681 & \text { PI } 497582 & \\ 86 / 2666 & 682 & & \text { Pichincha, Sangolquí } \\ 86 / 2667 & 688 & & \text { Pichincha, Quito } \\ 97 / 981587 & 688 & \text { PI } 49759 & \\ 86 / 2669 & 689 & & \text { Guayas, Boliche } \\ 97 / 981588 & 689 & \text { PI } 497595 & \\ 86 / 2670 & 691 & & \text { Guayas, Boliche }\end{array}$




\begin{tabular}{|c|c|c|c|}
\hline Mdi. & US & PI & Procedencia \\
\hline 97/98 1589 & 691 & PI 497597 & \\
\hline $86 / 2671$ & $693(1)$ & & Guayas, Pedro Carbo \\
\hline $86 / 2672$ & $693(3)$ & & \\
\hline 97/98 1517 & $693(1)$ & PI 497600 & \\
\hline $86 / 2676$ & $695(5)$ & & Guayas, Pedro Carbo \\
\hline 97/98 1516 & $695(3)$ & PI 497607 & \\
\hline $86 / 2677$ & $698(3)$ & & Guayas, Lomas de Sargentillo \\
\hline $86 / 2678$ & $698(3)$ & & Guayas, Lomas de Sargentillo \\
\hline $86 / 2680$ & $699(1)$ & & \\
\hline 86/2682 & $700(1)$ & & El Oro, Piñas \\
\hline 97/98 1695 & $700(1)$ & PI 497614 & \\
\hline 97/98 $1696(2)$ & $700(2)$ & PI 497615 & \\
\hline $86 / 2683$ & $702(1)$ & & El Oro, Piñas \\
\hline $86 / 2684$ & $706(2)$ & & El Oro, Portovelo \\
\hline 97/98 1697 & 709 & PI 497635 & \\
\hline $86 / 2688$ & 710 & & El Oro, Ambocos \\
\hline 86/2689 & $711(1)$ & & Loja, Loja \\
\hline 86/2692 & $717(1)$ & & Loja, Catacocha \\
\hline 86/2695 & 719 & & Loja, Catacocha \\
\hline 97/98 1590 & 719 & PI 497636 & \\
\hline $86 / 2699$ & 724 & & Loja, Maracá \\
\hline $86 / 2701$ & 727 & & Loja, Maracá \\
\hline 97/98 1591 & 727 & PI 497655 & \\
\hline $86 / 2708$ & 709 & & El Oro, Pindo-Bado-Ancho \\
\hline 98/99 2652 & WWT 1334 Grif 12351 & & Napo, Tena, 458 m s.n.m. \\
\hline 98/99 2655 & WTS 28 Grif 13812 & & Esmeraldas, Cucaracha, 260 m s.n.m \\
\hline 98/99 2657 & WTS 51 Grif 13832 & & Manabí, Tosagua, 350 m s.n.m. \\
\hline 98/99 2659 & WTS 86 Grif 13867 & & Los Rios, Quevedo, 330 m s.n.m. \\
\hline 97/98 $1619(2)$ & 719 & PI 497646 & \\
\hline 97/98 $1622(2)$ & 724 & PI 497651 & \\
\hline 97/98 $1630(2)$ & $739(4)$ & PI 497665 & \\
\hline 98/99 2664 & WWT 1319 Grif 12516 & & Sucumbios, Lumbaqui, 578 m s.n.m. \\
\hline 98/99 2665 & WWT 1330 Grif 12523 & & Sucumbios, Playa Yacu, 382 m s.n.m. \\
\hline 98/99 2667 & WWT 1334 Grif 12530 & & Napo, Pusuno, 453 m s.n.m. \\
\hline 98/99 2669 & WWT 1343 Grif 12540 & & Pastaza, Puyo, 987 m s.n.m. \\
\hline 98/99 2672 & WWT 1351 Grif 12563 & & Morona Santiago, Pumpuis, 850 m s.n.m. \\
\hline 98/99 2677 & WWT 1362 Grif 12582 & & Loja, Cochapamba, 860 m s.n.m. \\
\hline 98/99 2686 & WWT 1376 Grif 12602 & & Manabí, Charapotó, 10 m s.n.m. \\
\hline 98/99 2687 & WWT 1380 Grif 12603 & & Manabí, Portoviejo \\
\hline 98/99 2688 & WTS 15 Grif 13800 & & Pichincha, Quito, 1110 m s.n.m. \\
\hline 98/99 2690 & WTS 18 Grif 13802 & & Pichincha, Quito, 1110 m s.n.m. \\
\hline 98/99 2691 & WTS 19 Grif 13803 & & Pichincha, San Miguel, 120 m s.n.m. \\
\hline
\end{tabular}


A. Krapovickas et al., Las razas de maní de Ecuador

Mdi.

98/99 2694

98/99 2695

98/99 2696

98/99 2697

98/99 2698

98/99 2703

98/99 2720

97/98 1703

97/98 1704

98/99 2721

98/99 2729

98/98 2734

98/99 2735

98/99 2759

98/99 2760

98/99 2761

98/99 2616

98/99 2755
US

WTS 56 Grif 13837

WTS 62 Grif13843

WTS 65 Grif 13846

WTS 85 Grif 13866

WTS 89 Grif 13870

WTS106 Grif 13884

$\mathrm{N}^{\circ} 2$

Romulo

WWT 1316 Grif 12509

WWT 1344 Grif 12544

WWT 1376 Grif 12599

WWT 1376 Grif 12599

WWT 1332 Grif 12527

WWT 1343 Grif 12543

WWT 1352 Grif 1256

WTS 8 Grif 13798

WWT 1344 Grif 12550
PI

\section{Procedencia}

Manabí, Calceta, 180 m s.n.m.

Manabí, Calceta, 180 m s.n.m.

Guayas, Jujan, 140 m s.n.m.

Los Ríos, Valencia, 230 m s.n.m.

Cotopaxi, Moraspungo, 510 m s.n.m.

Morona Santiago, Sinai, 1290 m s.n.m.

PI 407452 Napo, cerca de Limoncocha

PI 405132

PI 414901

Tarapoto

Quito

Pastaza, Puyo, 987 m s.n.m.

Manabí, Charapotó, 10 m s.n.m.

Manabí, Charapotó, 10 m s.n.m.

Napo, Francisco de Orellana, 340 m s.n.m.

Pastaza, Puyo, 987 m s.n.m.

Zamora-Chinchipe

El Pangui, 885 m s.n.m.

Carchi, El Laurel, store 2490 m s.n.m.

Pastaza, Puyo, 987 m s.n.m. 


\section{Criolla}

Planta ramificada, algo abierta, algo más alta que el "Negro criollo", eje central apenas aparente. Tallo verde con algo de violáceo. Estandarte anaranjado, con aro; alas amarillas con mancha morada.

Cajas similares a las del "Negro criollo”.
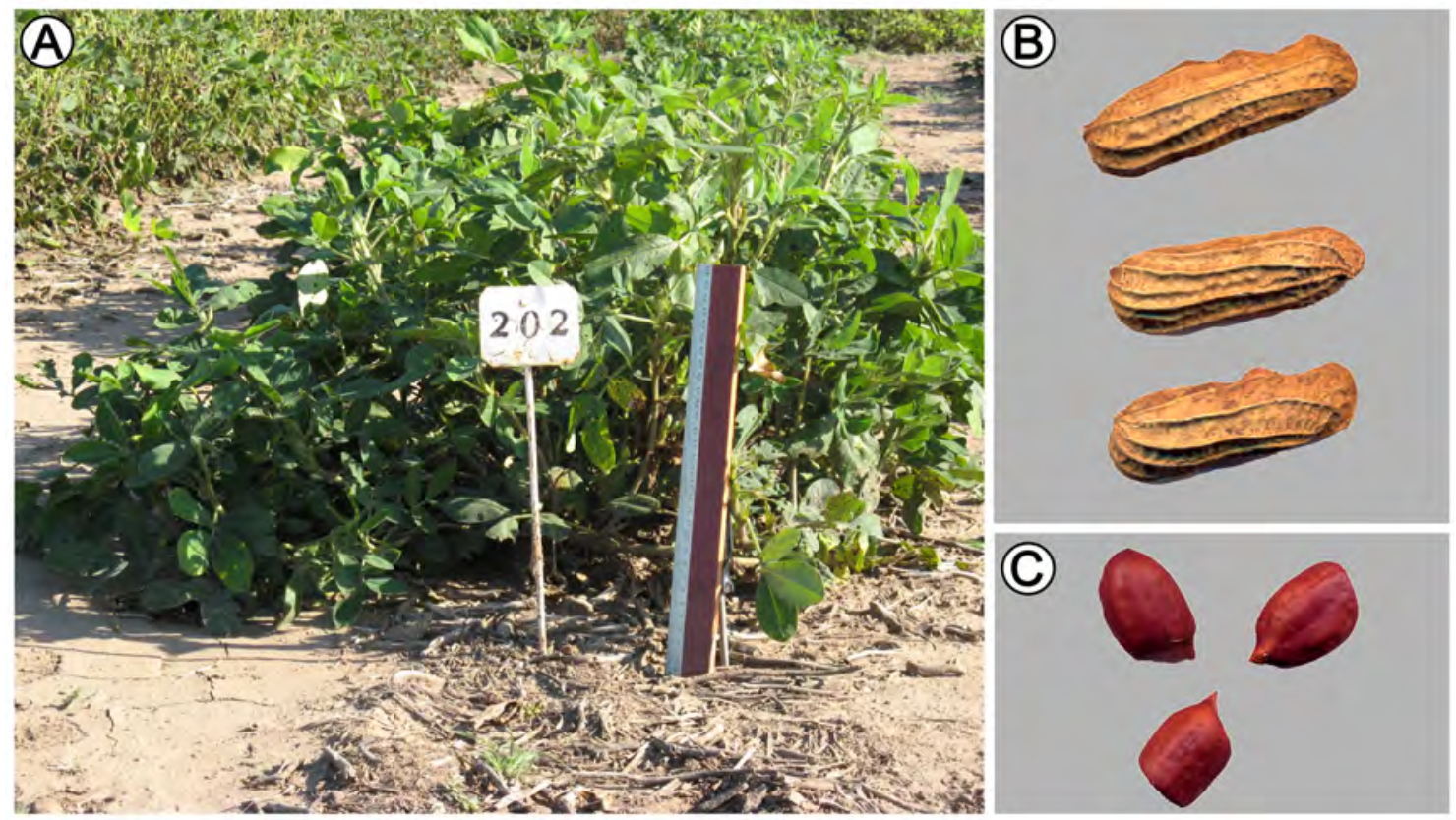

Fig. 43. Criolla, 202. A: Planta. B: Fruto. C: Semillas.

Fig. 43. Criolla, 202. A: Plant. B: Fruit. C: Seeds. 


\section{Morado rojizo}

Planta abierta. Frutos hasta 4 granos, cajas con joroba y carena, sin pico. Granos morados con tintes rojizos
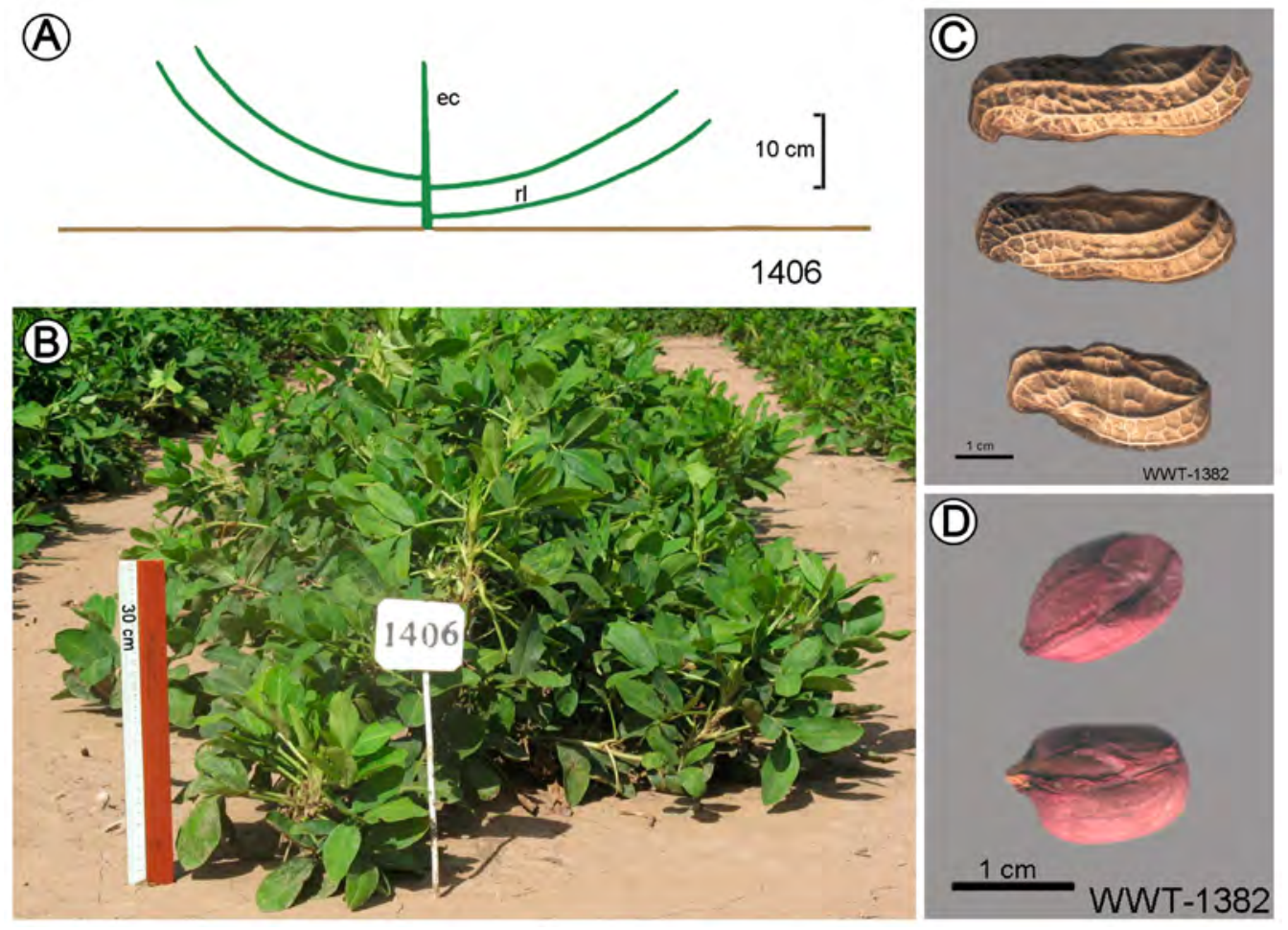

Fig. 44. Morado rojizo, 1406. A: Esquema de la planta. B: Planta. C: Fruto. D: Semillas.

Fig. 44. Morado rojizo, 1406. A: Plant out line. B: Plant. C: Fruit. D: Seeds.

Mdi.

98/99 2647

98/99 2656

98/99 2718

98/99 2722

98/99 2726

98/99 2727

98/99 2731

98/99 2732

98/99 2736

98/99 2737

98/99 2740

98/99 2741
US

WWT 1382 Grif 12609-1

WTS 37 Grif 13819

WTS 72 Grif 13853

WWT 1327 Grif 12517

WWT 1342 Grif 12535

WWT 1342 Grif 12539

WWT 1345 Grif 12551-1

WWT 1345 Grif 12553

WWT 1382 Grif 12604

WWT 1382 Grif 12607

WWT 1379 Grif 12609

WTS 3 Grif 13795

\section{Procedencia}

Manabí, Portoviejo

Manabí, El Carmen, 400 m s.n.m.

Los Ríos, Vinces, 110 m s.n.m.

Sucumbios, Shushufindi, 375 m s.n.m.

Pastaza, Puyo, 987 m s.n.m.

Pastaza, Puyo, 987 m s.n.m.

Pastaza, Conguqui, 975 m s.n.m.

Manabí, Portoviejo, 15 m s.n.m.

Imbabura, Cuambo, 1490 m s.n.m. 


\section{Peruano pálido}

Planta abierta, frutos hasta 4 granos, por lo común de $4 \mathrm{~cm}$ long., raro hasta $5 \mathrm{~cm}$. Granos pálidos.
$2009 / 101404 \quad N^{\circ} 1$
PI 407451
Orellana, cerca de Limoncocha
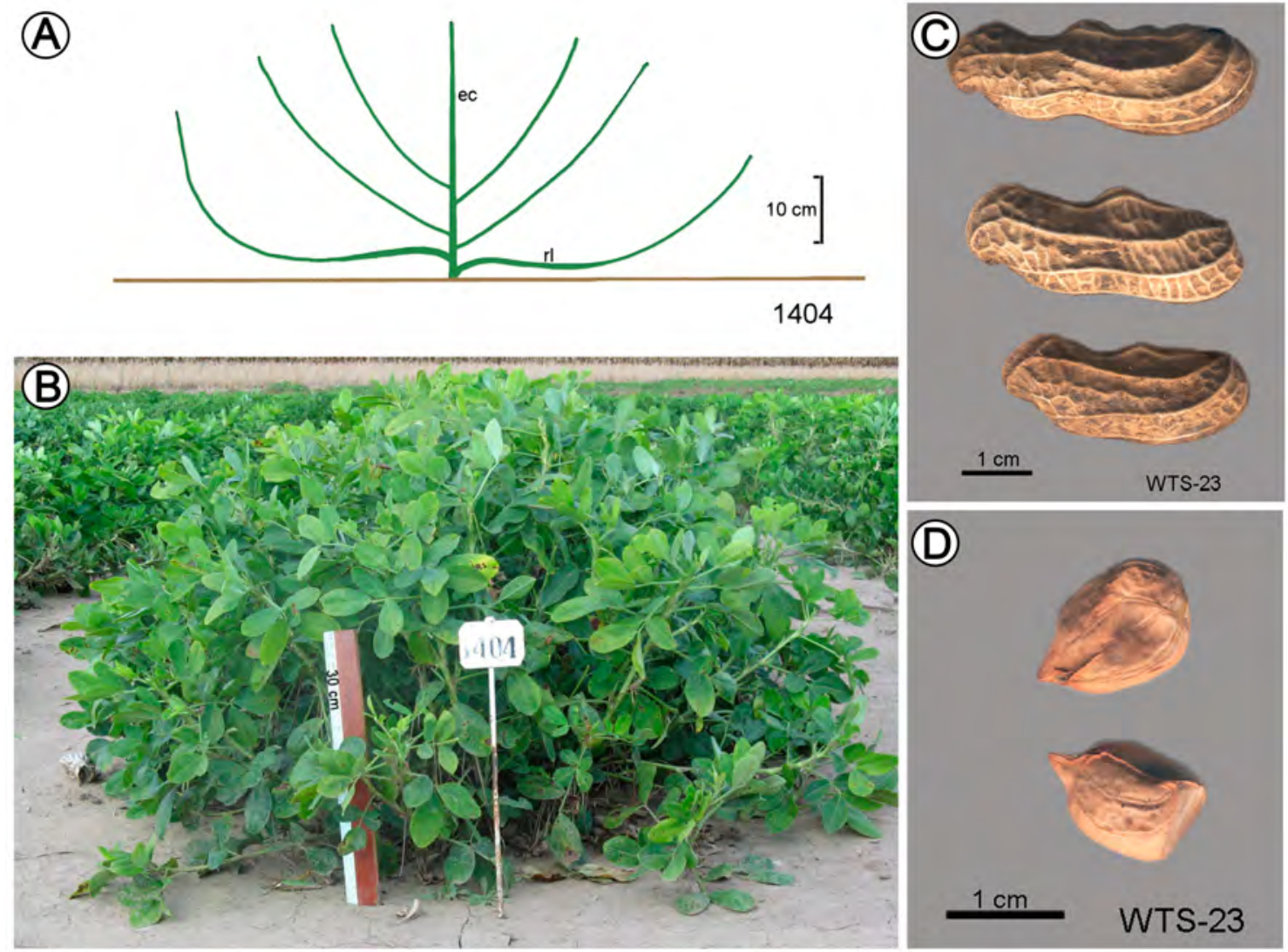

Fig. 45. Peruano pálido, 1404. A: Esquema de la planta. B: Planta. C: Fruto. D: Semillas. Fig. 45. Peruano pálido, 1404. A: Plant out line. B: Plant. C: Fruit. D: Seeds.

Mdi.

98/99 2644

98/99 2645

98/99 2648

98/99 2649

98/99 2749

98/99 2751

98/99 2654
US

$\mathrm{N}^{\circ} 3$

$\mathrm{N}^{\circ} 4$

WTS 23 Grif 13807

WTS 54 Grif 13835

WWT 1343 Grif 12541

WTS 44 Grif 13825

WWT 1357 Grif 12577
PI

PI 407453

PI 407454

\section{Procedencia}

Orellana, cerca de Limoncocha Orellana, cerca de Limoncocha Esmeraldas, La Unión, 340 m s.n.m. Manabí, Calceta, 180 m s.n.m. Pastaza, Puyo, 987 m s.n.m. Manabí, La Cresta, 590 m s.n.m. Loja, Sacapianga, 1140 m s.n.m. 


\section{Catalán}

Planta erecta, grande, abierta con ramas decumbentes, postradas o suberectas. Eje central aparente. Tallo verde a ligeramente morado. Ramas generalmente dísticas, pero a veces hay ramas basales torcidas. Estípulas con cerdas. Pecíolo verde. Ramas reproductivas largas, gruesas, a veces con hojitas en el ápice.

Cajas grandes, alargadas, con jorobas y pico, con hasta 4 granos morados.

$$
\text { 2009/10 } 1410 \text { WWT } 1357 \text { Grif } 12577 \text { Loja, Sacapianga, } 1140 \text { m s.n.m. }
$$
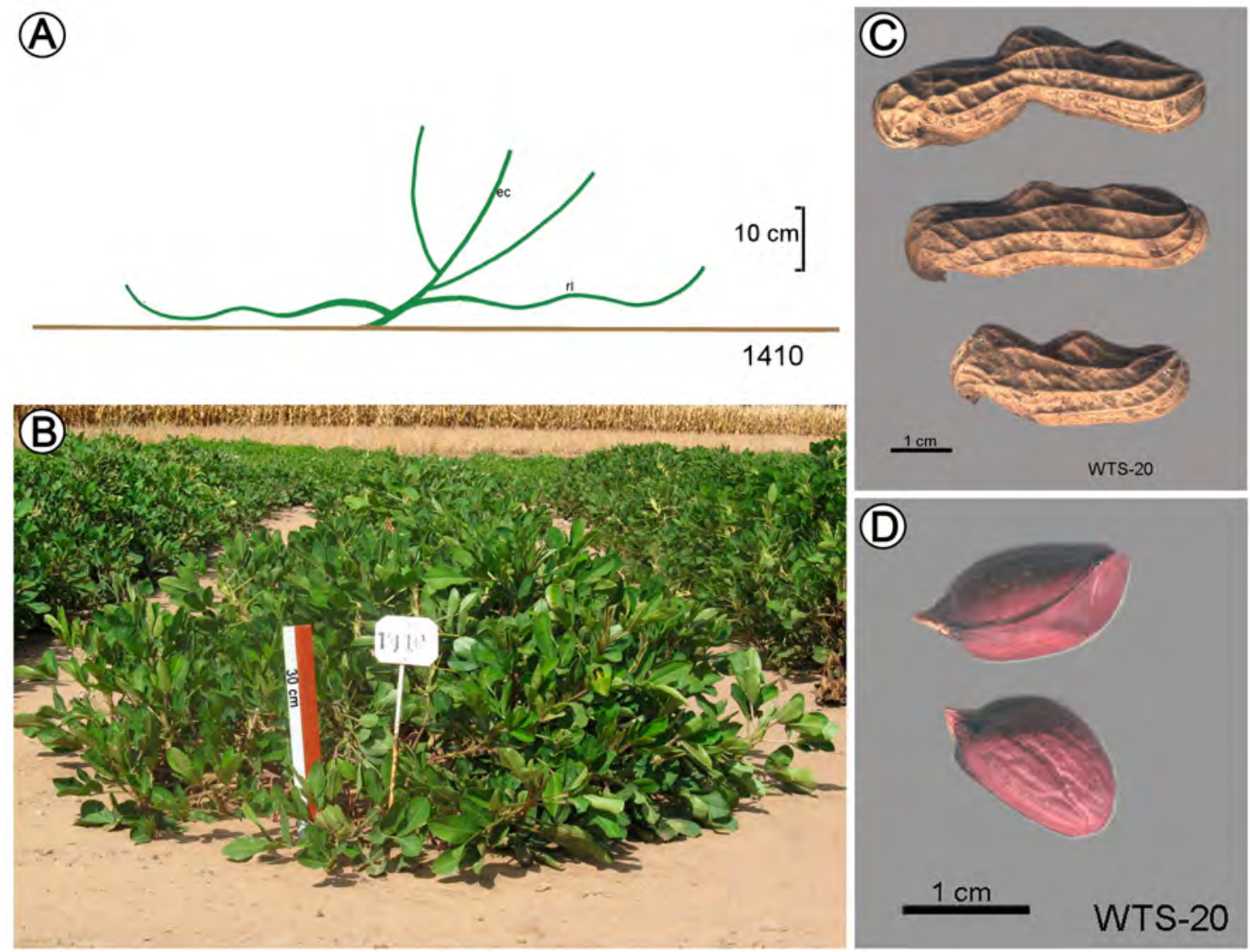

Fig. 46. Catalán, 1410. A: Esquema de la planta. B: Planta. C: Fruto. D: Semillas.

Fig. 46. Catalán, 1410. A: Plant out line. B: Plant. C: Fruit. D: Seeds.

Mdi.

$\begin{array}{ll}\text { US } & \\ \text { US } 682 & 86 / 2716 \\ \text { US 713 } & 86 / 2717 \\ \text { US 713 } & 86 / 2718 \\ \text { US 714 (1) } & 86 / 2719 \\ \text { US 714 (2) } & 86 / 2722 \\ \text { US 715 (1) } & 86 / 2723\end{array}$

PI

Procedencia

Pichincha, Sangolquí

Loja, Catacocha

Loja, Catacocha

Loja, Catacocha

Loja, Catacocha

Loja, Casanga 
Mdi.

\section{US}

98/99 2692

98/99 2693

98/99 2714

98/99 2610

98/99 2653
US 715 (1)

$86 / 2725$

US 718

US 718

US 721

US 721

US 722

US 722

US 722

US 726

US 726

WTS 20 Grif 13804

WTS 42 Grif 13823

US 713

WWT 1361 Grif 12581

US 682

US 714

US 715

WWT 1347 Grif 12554

PI

$86 / 2727$

$86 / 2728$

$86 / 2729$

$86 / 2663$

$86 / 2730$

WWT 1357 Grif 12577

\section{Procedencia}

Loja, Opoluca

PI 497645

Loja, Casanga

PI 497648

Loja, Casanga

Loja, Casanga

PI 497649

Loja, Macará

PI 497654

Pichincha, Puerto Quito, 300 m s.n.m.

Manabí, La Cresta, 480 m s.n.m.

PI 497639

Loja, Yamana, 1200 m s.n.m.

PI 497583

PI 497640

PI 497641

Morona-Santiago, Macas, 1078 m s.n.m.

Loja, Sacapianga, 1140 m s.n.m. 
Arachis hypogaea subsp. fastigiata var. aequatoriana (Fig. 1D)

\section{Zaruma}

Planta erecta, abierta; eje central muy aparente, sinuoso; ramas largas, gruesas, tendidas; las ramas $n+2$ son casi erectas. Tallo morado. Brotes y pecíolo bien morados. Estípulas con cerdas. Estandarte morado, con aro; alas moradas.

Cajas más o menos cortas, con nervaduras longitudinales prominentes, con carena pequeña y sin pico. Con 2-3 (raro 4) granos violáceos con punta clara, variables en la extensión e intensidad del violáceo, aún en una misma planta.

$$
\text { 2009/10 } 1416 \text { WWT } 1363 \text { Grif } 12584
$$

(A)
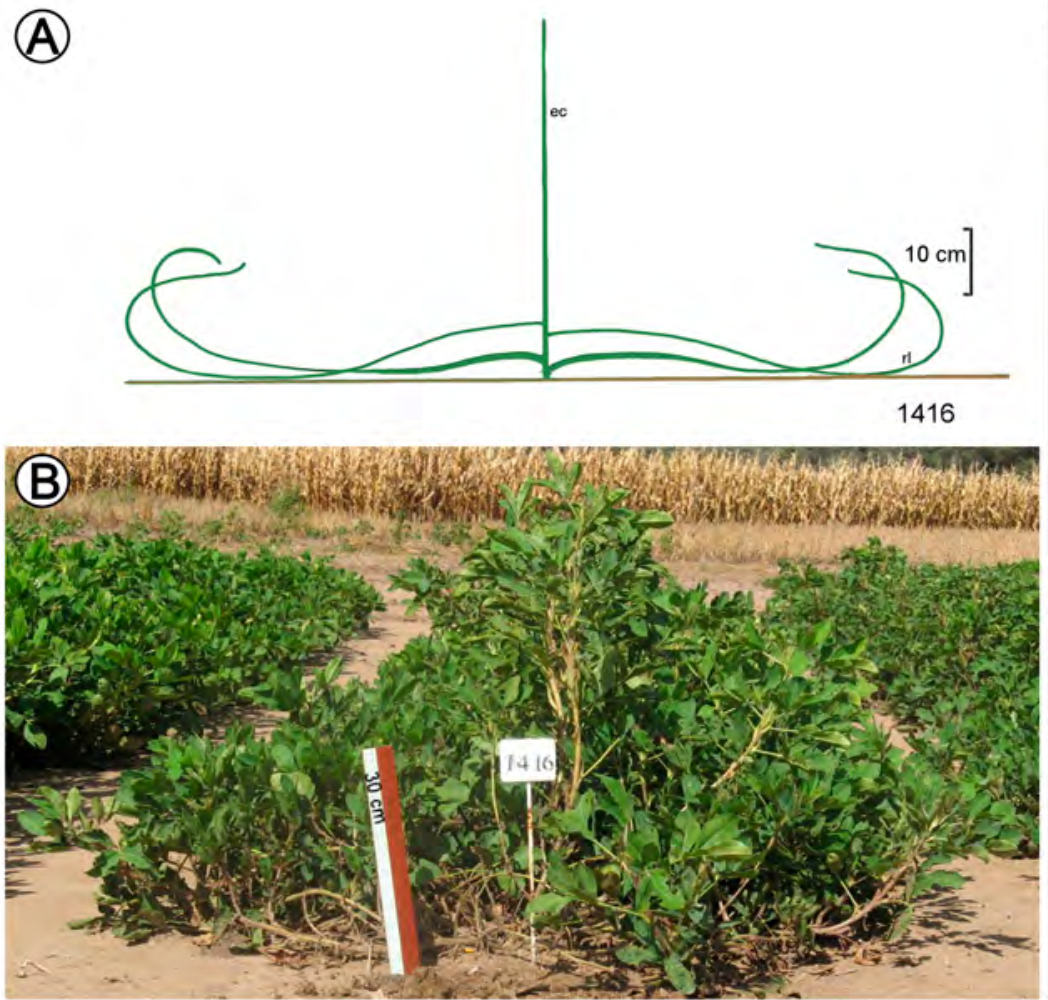

Fig. 47. Zaruma, 1416. A: Esquema de la planta. B: Planta. C: Fruto. D: Semillas.

Fig. 47. Zaruma, 1416. A: Plant outline. B: Plant. C: Fruit. D: Seeds.

Mdi.

US

DEIP 6471

US 682

(1)

US 683 (1)

97/98 1603

US 683 (2)

US
PI

91/2034

86/2662

86/2535

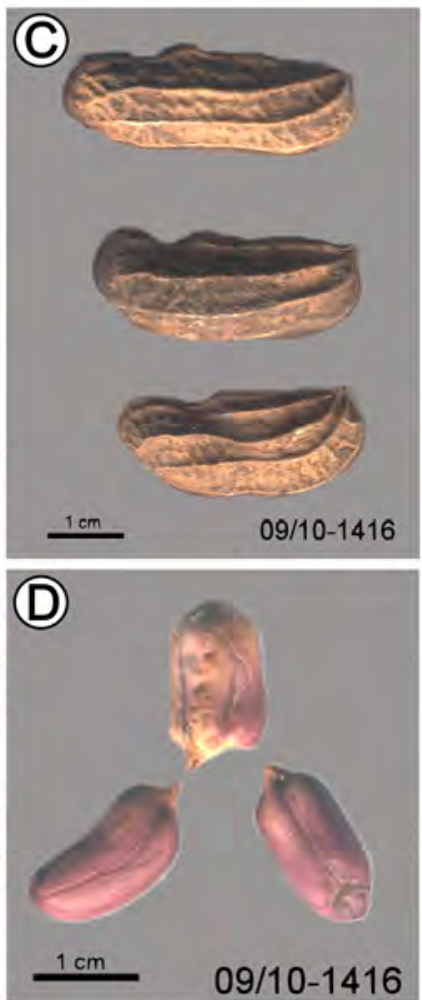

09/10-1416 
Mdi.

97/98 1604

$\begin{array}{ll} & \text { US } 699(2) \\ & \text { US } 699(2) \\ 97 / 981606 & \text { US } 700(2) \\ 97 / 981607 & \text { US } 700(3) \\ 97 / 981696(1) & \text { US } 700(4) \\ 97 / 981696(1) & \text { US } 700(2) \\ & \text { US } 700(2) \\ & \text { US } 701(1) \\ & \text { US } 701(2)\end{array}$

97/98 1608

US 701

US 702 (2)

US 703 (2)

US 703 (2)

97/98 1610

US 703 (2)

97/98 1611

US 703 (3)

US 704 (1)

97/98 1612

US 704 (1)

97/98 1613

97/98 1614

97/98 1615

$97 / 981615$

97/98 1616(1)

97/98 1617 (2)

$\begin{array}{ll} & \text { US } 709 \\ & \text { US } 711(1) \\ & \text { US } 714(2) \\ & \text { US } 715(2) \\ & \text { US } 717(2) \\ & \text { US } 717(1) \\ & \text { US } 717(2) \\ 97 / 981618 & \text { US } 717(2) \\ 97 / 981619(1) & \text { US } 717(1) \\ & \text { US } 719(1) \\ & \text { US } 719 \\ & \text { US } 720(3) \\ & \text { US } 722 \\ & \text { US } 722\end{array}$

97/98 1621(2)
US 704 (3)

US 704 (4)

US 701 (1)

US 705 (3)

US 706 (2)

US 706 (1)

US 707 (2)

$$
\text { US } 707 \text { (1) }
$$

US 722

US 724 (2)
PI

PI 497587

86/2538

$86 / 2547$

86/2550

PI 497616

PI 497617

PI 497615

PI 497615

86/2555

$86 / 2559$

PI 497618

$86 / 2561$

$86 / 2563$

$86 / 2563$

PI 497621

PI 497622

86/2566

PI 497623

PI 497625

PI 497626

$86 / 2571$

PI 497629

$86 / 2578$

PI 497630

$86 / 2584$

PI 497632

86/2586

$86 / 2587$

$86 / 2588$

$86 / 2592$

$86 / 2594$

86/2595

86/2868

86/2869

PI 497643

86/2599

PI 497646

$86 / 2602$

$86 / 2609$

$86 / 2610$

PI 497649

86/2612

\section{Procedencia}

El Oro, Piñas

El Oro, Piñas

El Oro, Piñas

El Oro, Piñas

El Oro, Piñas

El Oro, Piñas

El Oro, Zaruma

El Oro, Zaruma

El Oro, Portovelo

El Oro, Portovelo

El Oro, Pindo-Bado Ancho

Loja, Loja

Loja, Catacocha

Loja, Catacocha

Loja, Catacocha

Loja, Catacocha

Loja, Yamana

Loja, Casanga

Loja, Macará 
Mdi.

97/98 1622 (1)

US

97/98 1623 (1)

97/98 1624

97/98 1625

97/98 1626

97/98 1627

97/98 1628

97/98 1629

97/98 $1630(1)$

98/99 2661

98/99 2662

98/99 2663

98/99 2671

98/99 2673

98/99 2675

98/99 2676

98/99 2680

98/99 2682

98/99 2684

98/99 2685

98/99 2689

98/99 2699

98/99 2700

98/99 2704

98/99 2705

98/99 2728

98/99 2738

98/99 2750

98/99 2752

98/99 2757

98/99 2758
PI

PI 497651

US 725

$86 / 2614$

US 725 (1)

US 725 (2)

US 728 (3)

US 728 (1)

US 728 (3)

US 729 (1)

$86 / 2625$

US 729 (1)

US 729 (3)

US 730 (3)

$86 / 2628$

US 730 (1)

$86 / 2632$

US 730 (3)

US 730 (4)

WC 984

WC 1379

WC 1382

WWT 1348 Grif 12555

WWT 1352 Grif 12564

WWT 1354 Grif 12568

WWT 1356 Grif 12575

WWT 1363 Grif 12584

WWT 1366 Grif 12589

WWT 1366 Grif 12591

WWT 1369 Grif 12594

WTS 18 Grif 13802

WTS 91 Grif 13872

WTS 92 Grif

13873

WTS 106 Grif 13884

WTS 107 Grif 13885

WWT 1344 Grif 12544

WTS 6 Grif 13797

WWT 1348 Grif 12558

WWT 1352 Grif $12566^{a}$

WWT 1352 Grif 12566

WWT 1354 Grif 12570

PI 497652

PI 497653

PI 497656

PI 497658

PI 497659

PI 497661

PI 497664

PI 497665

PI 390428

PI 390432

PI 390433

\section{Procedencia}

Loja, Macará

Loja, Yurusali

Loja, Chaguarpamba

El Oro, Balzas

Morona Santiago Macas, 1078 m s.n.m.

Zamora, Chinchipe, El Pangui, 885 m s.n.m.

Zamora, Chinchipe, Yanzatza, 900 m s.n.m.

Loja, Sacapinga, 1140 m s.n.m.

El Oro, Zaruma, 1265 m s.n.m.

El Oro, Zaruma,1265 m s.n.m.

Pichincha, Chacapata, 1110 m s.n.m.

Los Ríos, Quinsaloma, 320 m s.n.m.

Cañar, La Troncal, 200 m s.n.m.

Morona-Santiago,Sinai, 1290 m s.n.m.

Morona-Santiago, Sinai, 1290 m s.n.m.

Pastaza, Puyo, 987 m s.n.m.

Imbabura, Santa Rosa, 1050 m s.n.m.

Morona-Santiago, Macas, 1078 m s.n.m.

Zamora, Chinchipe, El Pangui, 885 m s.n.m.

Zamora, Chinchipe, Yanzatza, 900 m s.n.m. 


\section{Zaruma negro}

Planta abierta, ramas de posición variable. Flor con alas anaranjadas, siempre con mancha morada, estandarte anaranjado violáceo, brote violáceo. Frutos por lo común menores de $4 \mathrm{~cm}$ long. 1,5-2 cm diám., con carena y pico. Granos negros.

2009/10 1412 WTS 110 Grif 13889 Morona Santiago, San José, 1250 m s.n.m.
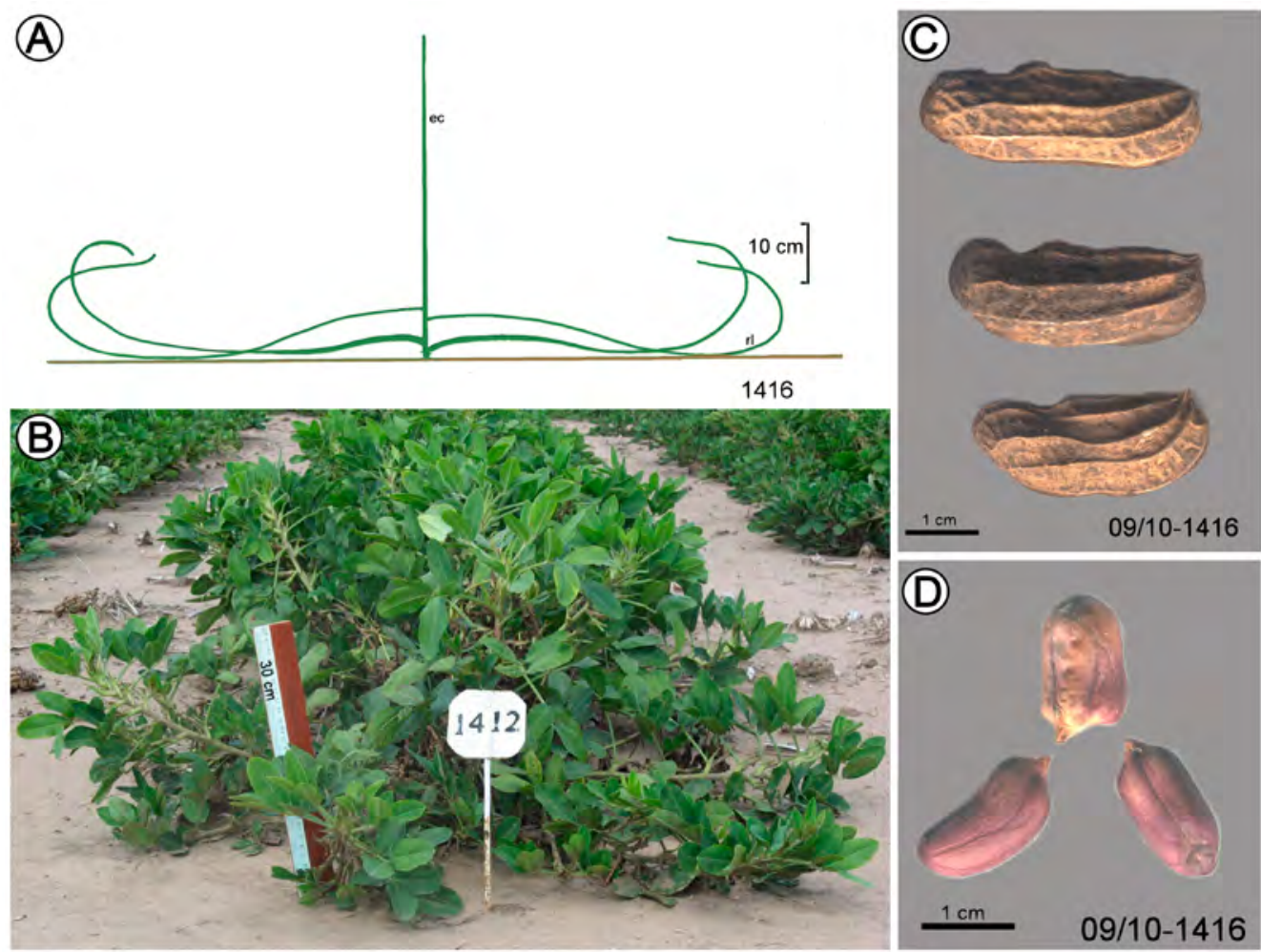

Fig. 48. Zaruma negro, 1412. A: Esquema de la planta. B: Planta. C: Fruto. D: Semillas.

Fig. 48. Zaruma negro, 1412. A: Plant outline. B: Plant. C: Fruit. D: Seeds.

$\begin{array}{ll}\begin{array}{l}\text { Mdi. } \\ \text { 98/99 2701 }\end{array} & \text { US } \\ \text { 98/99 2702 } & \text { WTS 94 Grif 13875 } \\ \text { 98/99 2719 } & \text { WTS 97 Grif 13877 } \\ & \text { WTS105 Grif 13883 } \\ \text { 98/99 2723 } & \text { WWT 1330 Grif 12521 } \\ \text { 98/99 2724 } & \text { WWT 1330 Grif 12522 } \\ \text { 98/99 2725 } & \text { WWT 1333 Grif 12529 } \\ 98 / 99 \text { 2733 } & \text { WWT 1349 Grif 12559 } \\ \text { 97/98 1623 (2) } & \text { US 725 (1) } \\ \text { 98/99 2674 } & \text { WWT 1352 Grif 12564 }\end{array}$

PI

\section{Procedencia}

Morona Santiago, Macas, 1040 m s.n.m.

Sucumbios, Shushufindi, 370 m s.n.m.

Morona Santiago, San Antonio, $1150 \mathrm{~m}$ s.n.m.

Sucumbios, Shushufindi, 382 m s.n.m.

Napo, Loreto, 695 m s.n.m.

Morona Santiago, Sucúa, 890 m s.n.m.

PI 497652

Zamora, El Pangui, 885 m s.n.m. 


\section{Zaruma pálido algo violáceo}

Planta erecta, ramas sinuosas, eje central aparente, tallo morado. Ramas $n+2$ reproductivas gruesas, hasta $15 \mathrm{~cm}$ long., con hojitas hacia el ápice. Brote violáceo. Pecíolo algo violáceo. Estípulas con cerdas. Estandarte anaranjado, con aro; alas con mancha morada. Clavos violáceos.

Cajas con costillas longitudinales sobresalientes, con jorobas, con carena pequeña y con pico breve (se siente al tacto). Granos pálidos, con tinte morado.
2009/10 1343
US 711(2)
BPZHa
Loja, Loja
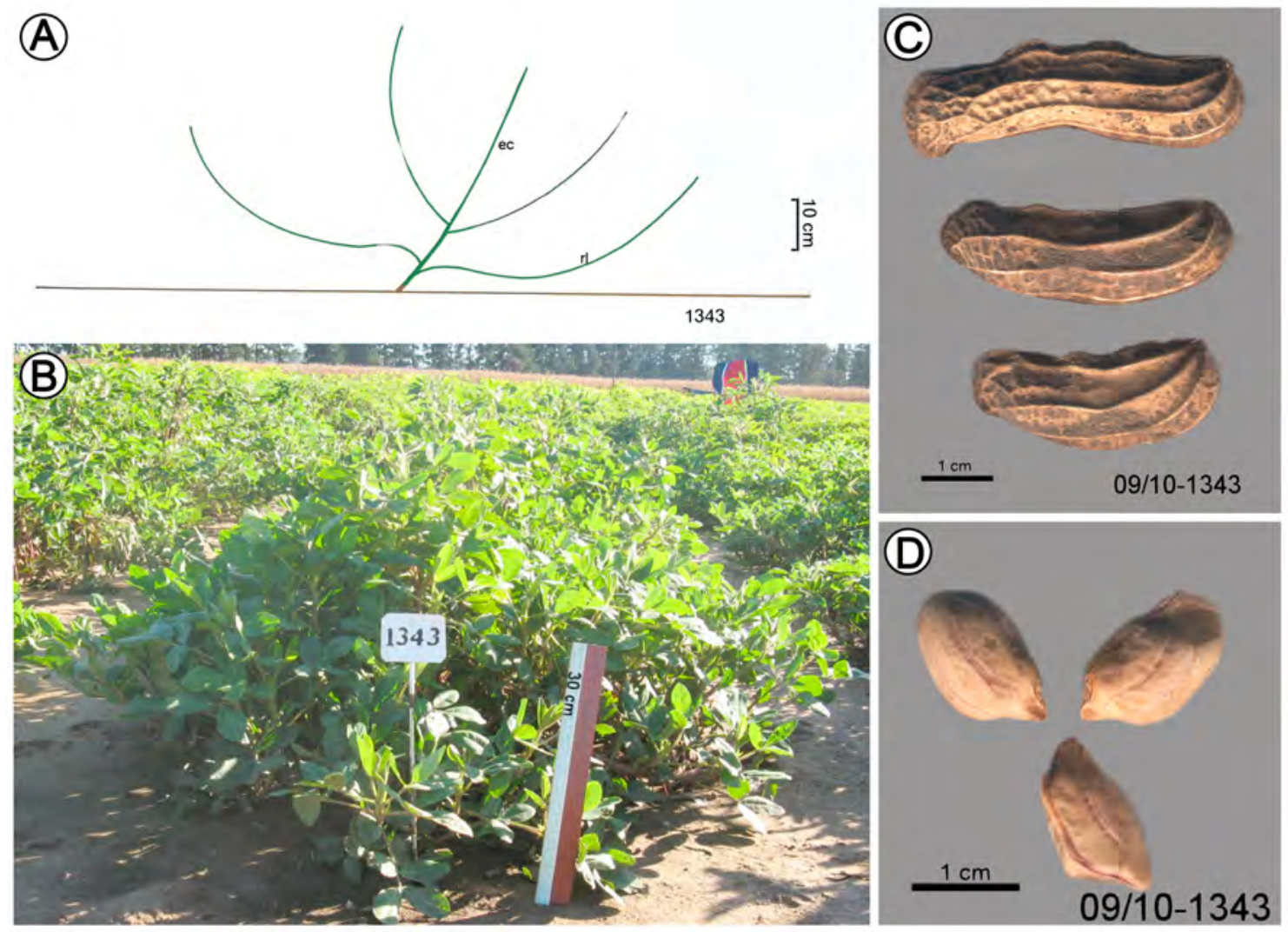

Fig. 49. Zaruma pálido algo violáceo, 1343. A: Esquema de la planta. B: Planta. C: Fruto. D: Semillas. Fig. 49. Zaruma pálido algo violáceo, 1343. A: Plant outline. B: Plant. C: Fruit. D: Seeds. 


\section{Zaruma pálido}

Planta erecta, poco ramificada, ramas sinuosas, eje central alto, bien aparente, ramas secundarias postradas; $n+1$ con muy pocas ramitas; $n+2$, casi rastreras. Tallo verde. Brote verde. Estípulas verdes, con cerdas. Estandarte casi sin aro basal; alas amarillas. Clavo vinoso. Cajas similares a las del Zaruma negro sin pico.

\section{9/10 1409 WTS 96 Grif 13876 Morona Santiago, Sucúa, 940 m s.n.m.}
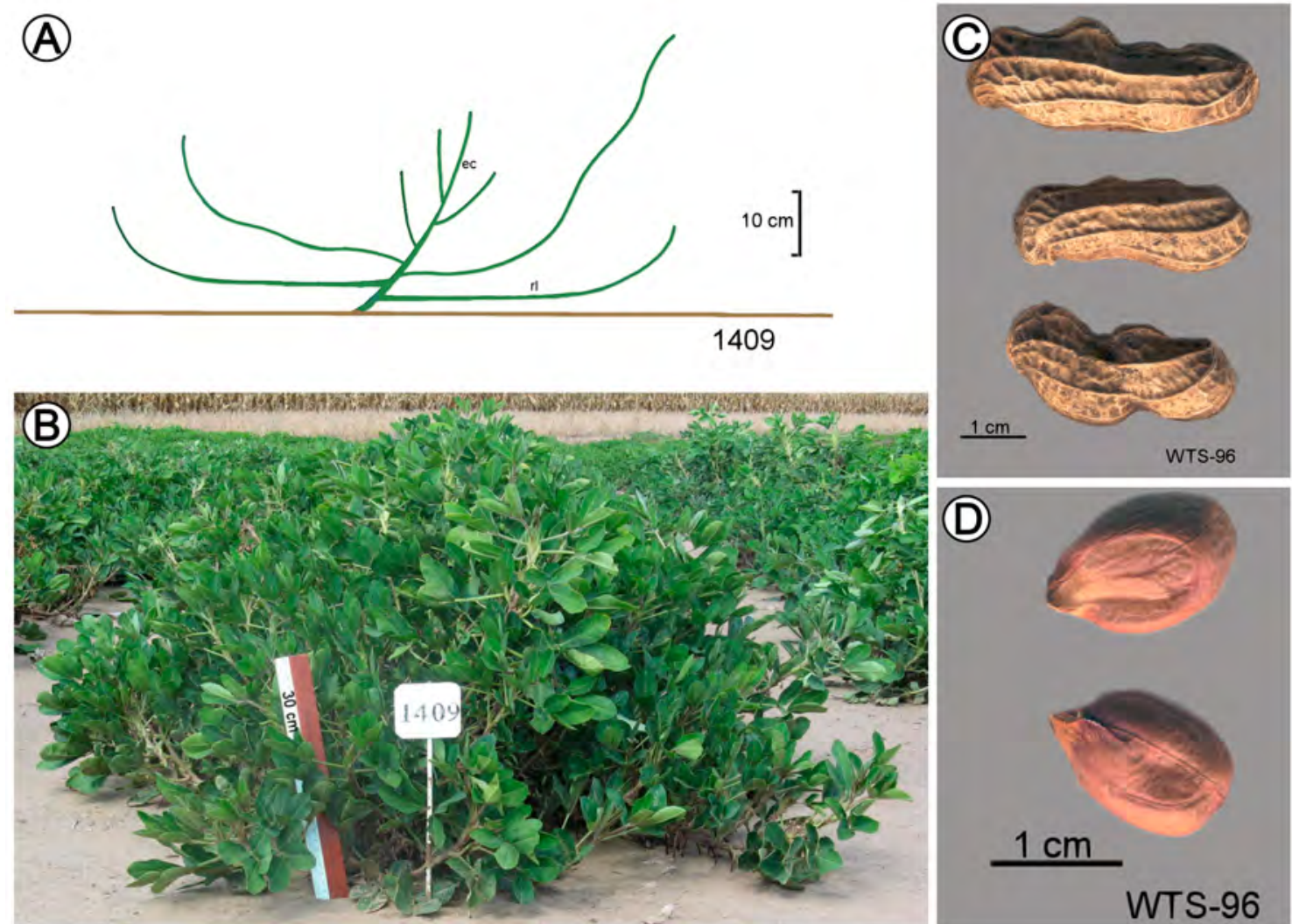

Fig. 50. Zaruma pálido, 1409. A: Esquema de la planta. B: Planta. C: Fruto. D: Semillas. Fig. 50. Zaruma pálido, 1409. A: Plant out line. B: Plant. C: Fruit. D: Seeds.

Mdi.

US

$97 / 981671$
US $683(3)$

US $683(3)$

US 699 (4)

US 702 (2)

US 703 (3)

US 704 (2)

US 705 (2)

US 706 (3)
PI

86/2646

$86 / 2647$

$86 / 2648$

$86 / 2649$

$86 / 2650$

$86 / 2651$

86/2652

\section{Procedencia}

Quito

\section{PI 497586}

El Oro, Piñas

El Oro, Piñas

El Oro, Piñas

El Oro, Zaruma

El Oro, Zaruma

El Oro, Portovelo 
A. Krapovickas et al., Las razas de maní de Ecuador

Mdi.

97/98 1672

97/98 1673

97/98 1674

97/98 1675

97/98 1676

98/99 2706

98/99 2707

98/99 2708

98/99 2709

98/98 2710

98/99 2711
US

US 706 (2)

US 707 (2)

US 717 (2)

US 719 (3)

US 728 (1)

$86 / 2654$

US 728 (2)

US 729 (3)

$86 / 2655$

US 729 (2)

US 730 (2)

$86 / 2657$

WWT 1329 Grif 12519

WWT 1331 Grif 12524

WWT 1342 Grif 12536

WWT 1345 Grif 12551-1

WWT 1345 Grif 12552

WWT 1389 Grif 12579
PI

PI 497631

PI 497633

PI 497644

Loja, Catacocha

Loja, Yurusali

PI 497657

PI 497660

Loja, Chaguarpamba

El Oro, Balzas

Sucumbios, Shushufindi, $370 \mathrm{~m}$ s.n.m.

Sucumbios, Shushufindi, $370 \mathrm{~m}$ s.n.m.

Pastaza, Puyo, 987 m s.n.m.

Pastaza, Conguqui, 975 m s.n.m.

Loja, San Antonio, 1220 m s.n.m. 


\section{Zaruma rosado}

Planta abierta, poco ramificada, eje central alto, bien aparente, ramas postradas. Tallos sinuosos, violáceo claros. Brote verde. Estípulas algo moradas, con cerdas. Estandarte con aro marcado; alas amarillas. Cajas en general tipo Zaruma, sin pico, con granos rosados.
2009/10 1342
US 704 (2)
BPZHa
El Oro, Zaruma

(A)
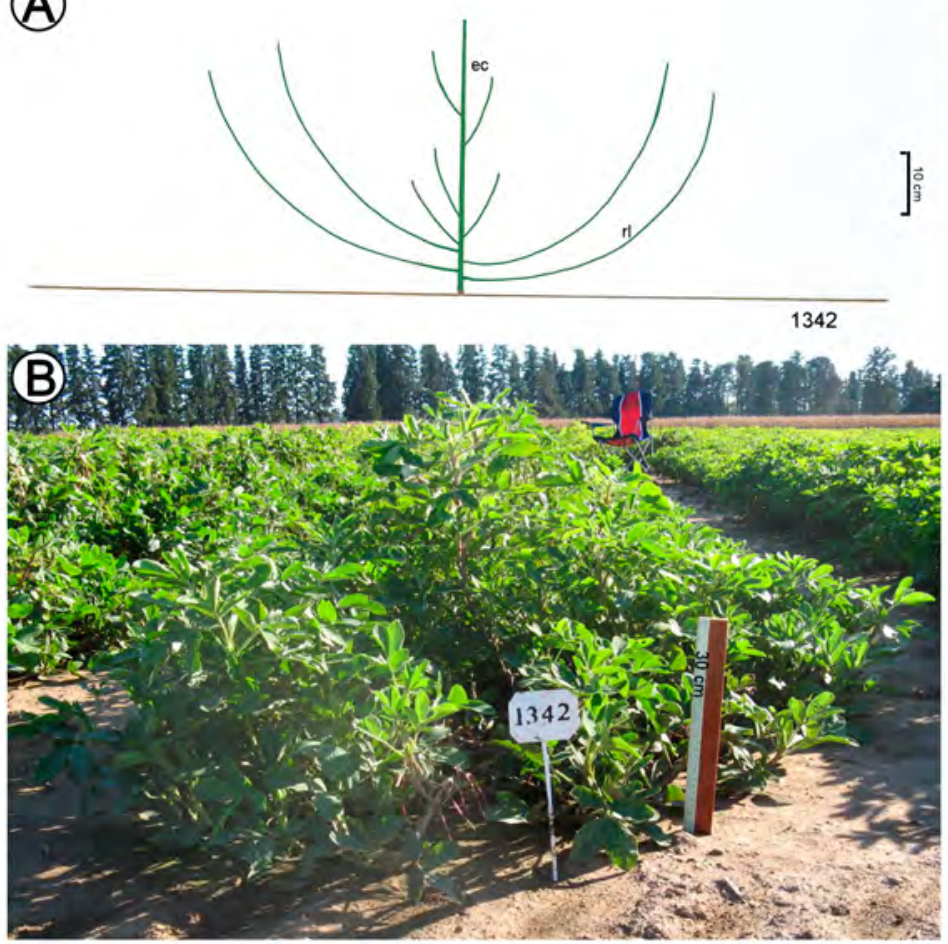

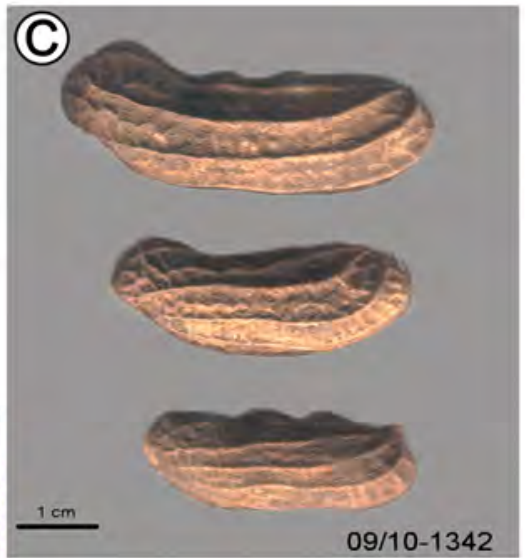

(D)

$1 \mathrm{~cm}$

Fig. 51. Zaruma rosado, 1342. A: Esquema de la planta. B: Planta. C: Fruto. D: Semillas.

Fig. 51. Zaruma rosado, 1342. A: Plant outline. B: Plant. C: Fruit. D: Seeds.

Mdi.

US

US 700 (2)

US 704 (3)

97/98 1670

US 704 (2)
PI

$86 / 2658$

$86 / 2659$
Procedencia

El Oro, Piñas

El Oro, Zaruma

PI 497624 


\section{Zaruma colorado}

Planta similar a las de Zaruma rosado, pero algo más ramificada y más compacta y con el eje central más aparente. Tallo verde con algo de violáceo. Estandarte con aro; alas amarillas. Cajas similares a las de Zaruma rosado pero con granos colorados.

(A)
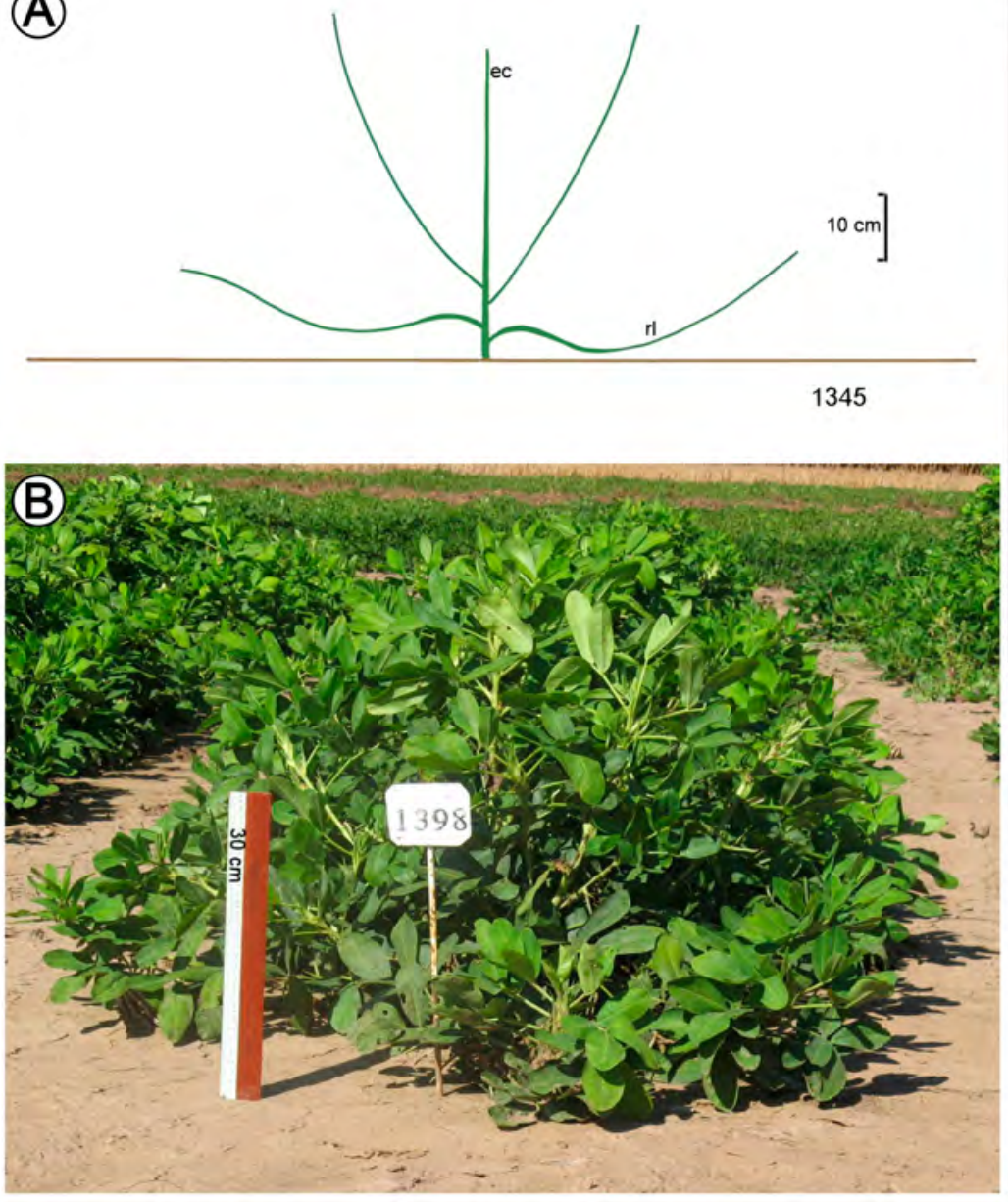
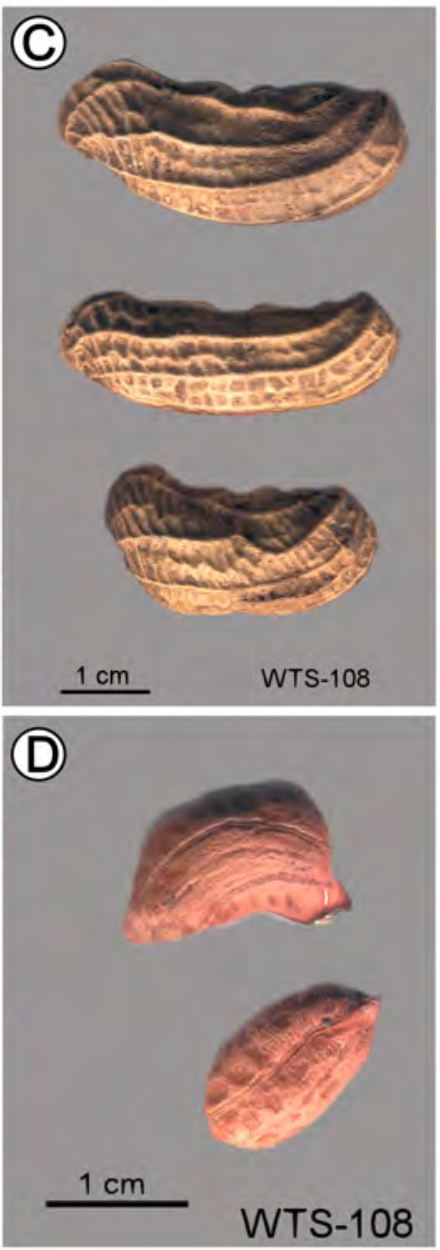

Fig. 52. Zaruma colorado, 1345. A: Esquema de la planta. 1398. B: Planta. C: Fruto. D: Semillas. Fig. 52. Zaruma colorado, 1345. A: Plant outline. B: Plant. C: Fruit. D: Seeds.

Mdi.

2009/10 1345
US

US 705 (2)

$86 / 2660$

Procedencia

El Oro, Zaruma 


\section{Huasquillo negro}

Planta poco ramificada, eje central muy aparente, ramas secundarias dísticas, sinuosas, casi rastreras, con ramas $n+2$ horizontales. Tallo morado. Brote violáceo. Estípulas con cerdas; pecíolo violáceo. Estandarte morado, con aro; alas con mancha morada. Clavos morados. Cajas largas, angostas, con jorobas y algo de pico. Granos negros, largos.

\section{9/10 1423 \\ WWT 1368 Grif 12593 El Oro, Zaruma}

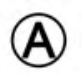

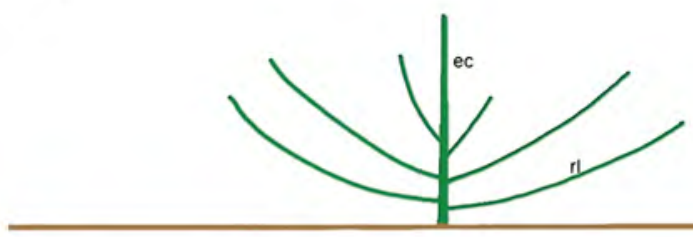

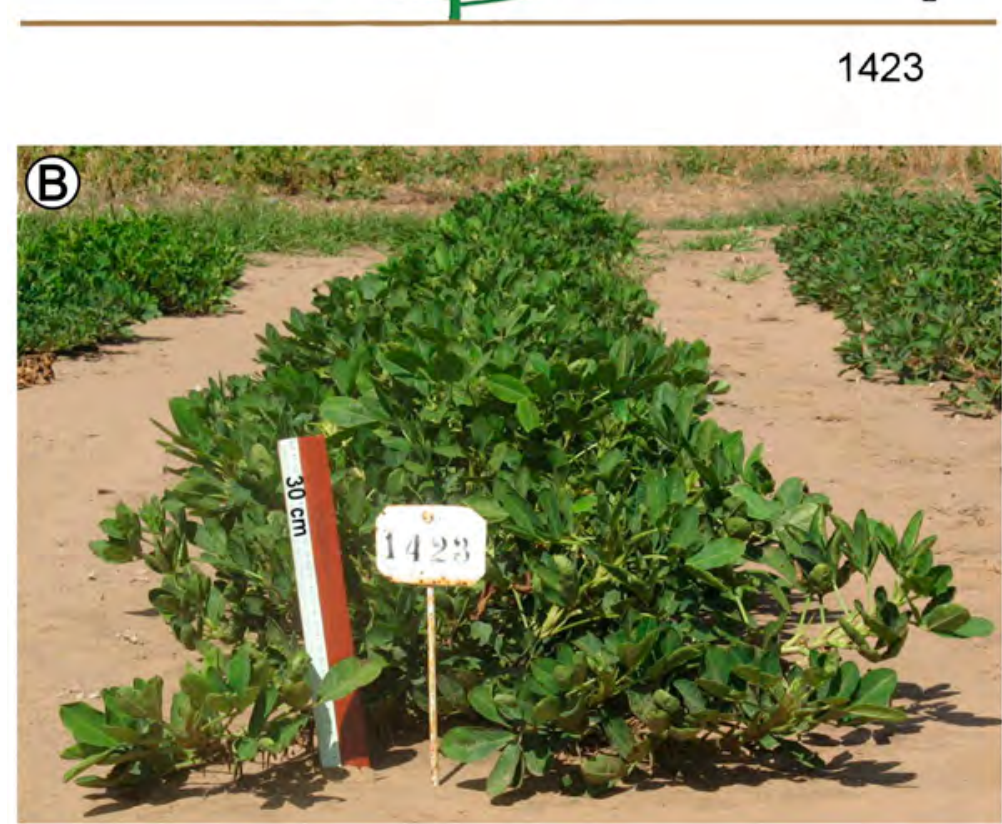

\section{(C)}

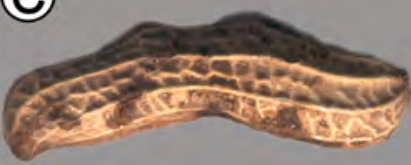

$0 \mathrm{~cm}]$

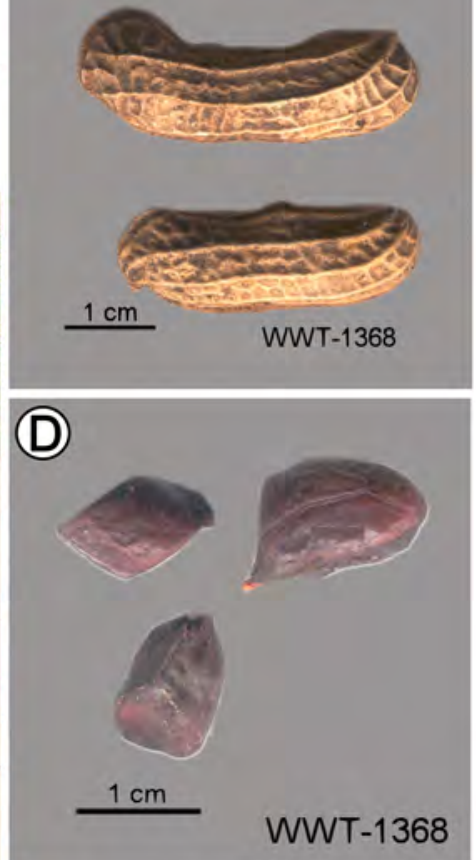

Fig. 53. Huasquillo negro, 1423. A: Esquema de la planta. B: Planta. C: Fruto. D: Semillas.

Fig. 53. Huasquillo negro, 1423. A: Plant out line. B: Plant. C: Fruit. D: Seeds.

Mdi.

US

US 682

US 702 (2)

US 703 (1)

97/98 1685

$97 / 981616$ (2)

97/98 1617 (1)
US 703 (1)

US 706 (1)

US 706 (1)

US 707 (1)

\section{PI}

86/2662 (2)

$86 / 2633$

$86 / 2634$

$86 / 2640$

PI 497620

PI 497630

PI 497632

\section{Procedencia}

Pichincha, Sangolquí

El Oro, Piñas

El Oro, Portovelo 
A. Krapovickas et al., Las razas de maní de Ecuador

Mdi.

US

US 708

$86 / 2638$

97/98 1686

98/99 2715

97/98 1700

98/99 2756
US 708

US 711 (1)

US 713

$86 / 2642$

US 714 (2)

$86 / 2644$

US 729 (2)

$86 / 2645$

WWT 1365 Grif 12587

US 730 (1)

WWT 1366 Grif 12590
PI

Procedencia

El Oro, El Pindo-Bajo Ancho

PI 4997634

Loja, Loja

Loja, Catacocha

Loja, Catacocha

Loja, Chaguarpamba

El Oro, Portovelo, 775 m s.n.m.

PI 497662

El Oro, Zaruma 


\section{Huasquillo pálido}

Planta abierta, eje central muy aparente, ramas rastreras, sinuosas. Tallo verde. Estípulas con cerdas. Estandarte sin aro. Clavos violáceo claro.

Cajas alargadas, con jorobas y algo de pico. Conteniendo granos alargados de color pálido, tendiente a salmón.
2009/10 1346
US 706 (3) BPZHa
El Oro, Portovelo

(A)
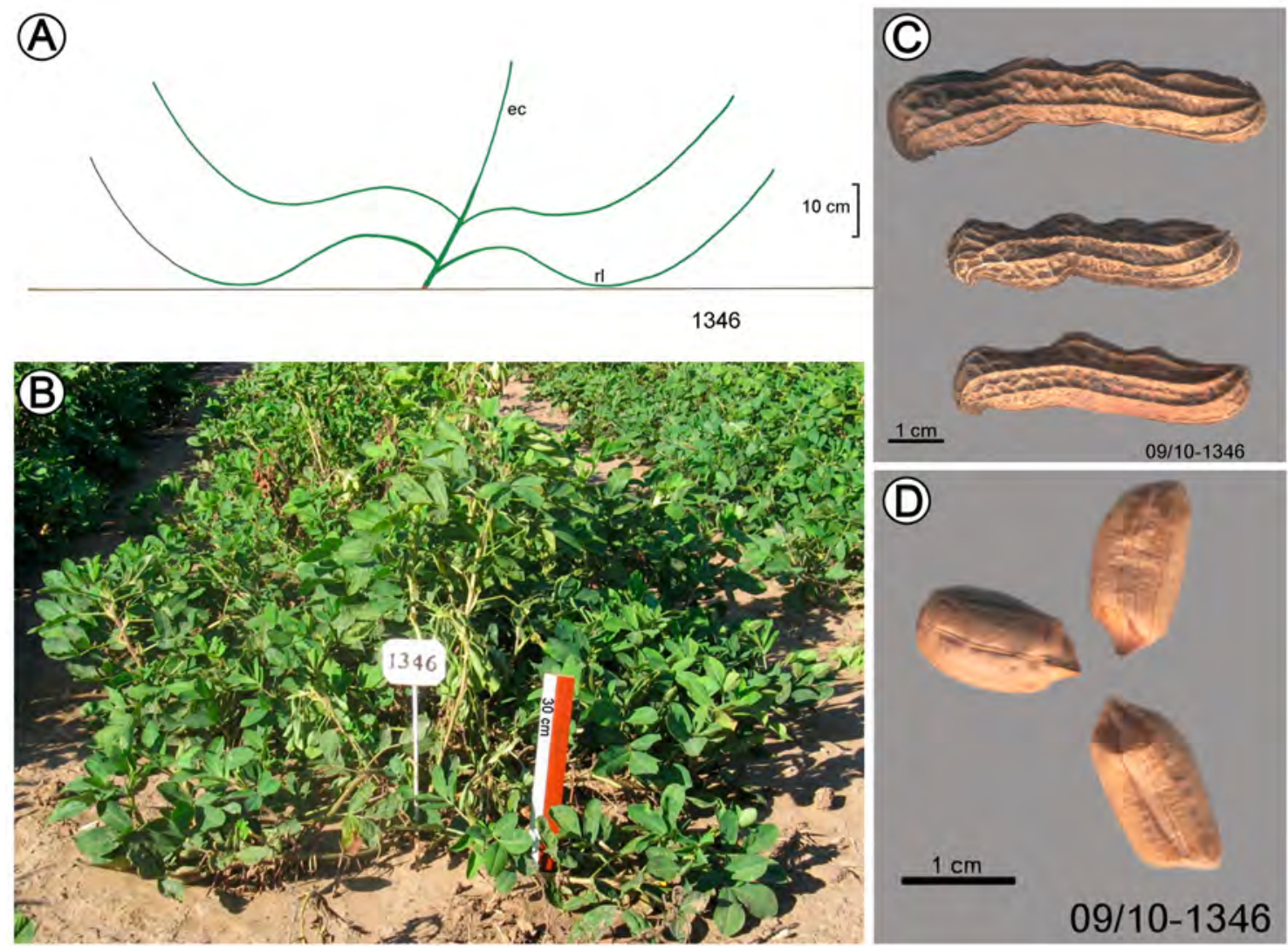

Fig. 54. Huasquillo pálido, 1346. A: Esquema de la plata. B: Planta. C: Fruto. D: Semillas.

Fig. 54. Huasquillo pálido, 1346. A: Plant outline. B: Plant. C: Fruit. D: Seeds. 


\section{Huasquillo punta clara}

Planta abierta con ramas ramas casi rastreras. Frutos hasta $7 \mathrm{~cm}$ de long. y menos de 1,5 cm de diám., con pico marcado. Granos violáceos con punta clara.

(A)
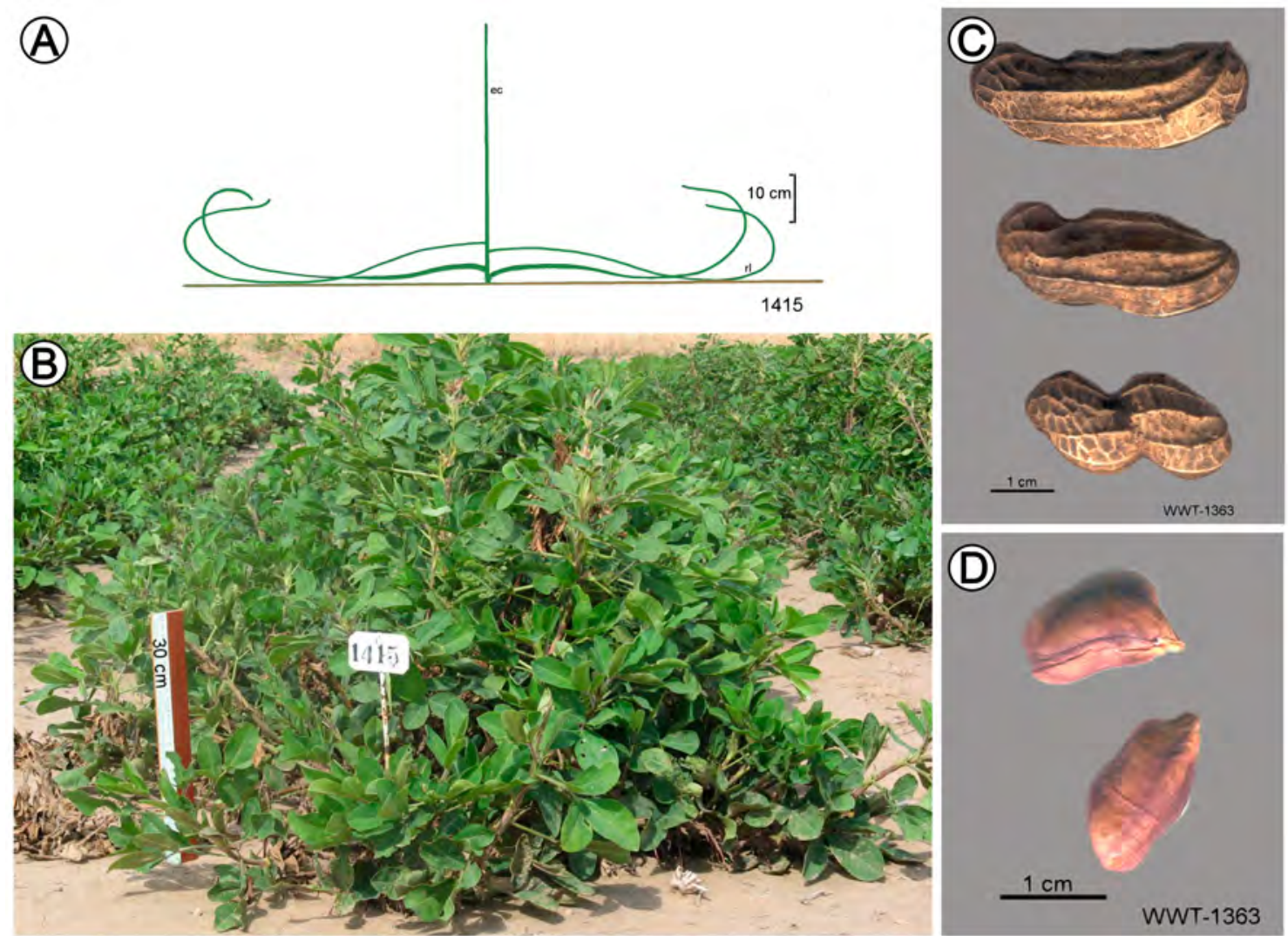

Fig. 55. Huasquillo punta clara, 1415. A: Esquema de la planta. B: Planta. C: Fruto. D: Semillas. Fig. 55. Huasquilllo punta clara, 1415. A: Plant outline. B: Plant. C: Fruit. D: Seeds.

Mdi.

98/99 2681
US

WWT1 363 Grif 12585

\section{Procedencia}

Loja, El Trapiche, 770 m s.n.m.

\section{Agradecimientos}

Queremos expresar nuestro agradecimiento a las autoridades de la Estación Experimental INTA Manfredi, Córdoba. A la Fundación Maní Argentino, por su apoyo económico. A la Ing. Agr. (Dra.) M. Gabriela López por la elaboración de fotos. A la Lic. Cecilia Puigbó y a la Ing. Agr. (Dra.) Carolina Peichoto, por sus correcciones y su colaboración para culminar el trabajo. A la Lic. Mariela Nuñez Florentín por la edición de las láminas. 


\section{ANEXO}

Listado cronológico de las colecciones de maní de Ecuador

1948 Provincia El Oro

$\begin{array}{llllllll}\text { Cat. } & \text { RCM } & \text { Catal. } & \text { DEIP } & \text { Procedencia } & \text { Leg. } & \text { Variedad } & \text { Número herbario CTES } \\ 1959 & 73 / 74 & & & & & & \\ 412 & 608 & 1403 & 6471 & \text { Zaruma } & \text { P. A. Romero } & \text { aeq } & 33756\end{array}$

1975 Coleccionista Eduardo Calero

Mdi. PI

97/98 1703
PI 405132

\section{Procedencia}

Tarapoto

1976 Coleccionista Joe Blakeslee

Mdi.

US

2009/10 1404

98/99 2720

98/99 2644

98/99 2645
$\mathrm{N}^{\circ} 1 \quad$ PI 407451

$\mathrm{N}^{\circ} 2 \quad$ PI 407452

$\mathrm{N}^{\circ} 3$ PI 407453

$\mathrm{N}^{\circ} 4 \quad$ PI 407454

\section{Procedencia}

Orellana, cerca de Limoncocha

Orellana, cerca de Limoncocha

Orellana, cerca de Limoncocha

Orellana, cerca de Limoncocha

1983 Coleccionistas, Donald Banks, José R. Pietrarelli, Hebert Zurita, Charles Simpson, Franco Valenzuela, Luis Haro.

\begin{tabular}{|c|c|c|c|c|c|c|c|}
\hline US & RCM & Col. & Procedencia & Nombre original & Denominación Actual & Variedad & No CTES \\
\hline \multicolumn{8}{|c|}{ Provincia de Pichincha } \\
\hline 681 & 2665 & BPZVa & Sangolquí & & Negro criollo & per & 39919 \\
\hline 682 & 2666 & BPZVa & Sangolquí & & Negro criollo & per & 39912 \\
\hline 682 & 2716 & BPZVa & Sangolquí & & Catalán & per & 39813 \\
\hline 682 & $2662-1$ & BPZVa & Sangolquí & & Zaruma & aeq & \\
\hline 682 & $2662-2$ & BPZVa & Sangolquí & & Huaquillo & aeq & \\
\hline $683-1$ & 2535 & $\mathrm{BPZ}$ & Quito & & Zaruma & aeq & 39821 \\
\hline $683-3$ & 2646 & $\mathrm{BPZ}$ & Quito & & Zaruma pálido & aeq & 39892 \\
\hline 684 & 2732 & $\mathrm{BPZ}$ & Quito & & Rosita & fast & 39950 \\
\hline 685 & 2733 & $\mathrm{BPZ}$ & Quito & Rosita & Rosita & fast & 39953 \\
\hline $686-2$ & 2745 & $\mathrm{BPZ}$ & Quito & Pepón & Overo compacto & hyp & 39973 \\
\hline $686-1$ & 2756 & $\mathrm{BPZ}$ & Quito & Pepón & Pepón rastrero & hyp & 39988 \\
\hline $686-1$ & 2748 & $\mathrm{BPZ}$ & Quito & Pepón & Pepón cojín & hyp & 39984 \\
\hline $687-2$ & 2761 & $\mathrm{BPZ}$ & Quito & Higuerilla & Higuerilla & hyp & 39978 \\
\hline $687-1$ & 2746 & $\mathrm{BPZ}$ & Quito & Higuerilla & Overo compacto & hyp & 39974 \\
\hline $687-1$ & 2762 & $\mathrm{BPZ}$ & Quito & Higuerilla & Overo rastrero & hyp & 40619 \\
\hline $687-2$ & 2760 & $\mathrm{BPZ}$ & Quito & Higuerilla & Cojin pequeño colorado & hyp & 39977 \\
\hline 688 & 2667 & $\mathrm{BPZ}$ & Quito & & Negro criollo & per & 39920 \\
\hline \multicolumn{8}{|c|}{ Provincia de Guayas } \\
\hline 689 & 2669 & BPZ & E. E. Boliche & cultivar Boliche & Negro criollo & per & 39929 \\
\hline
\end{tabular}


A. Krapovickas et al., Las razas de maní de Ecuador

\begin{tabular}{|c|c|c|c|c|c|c|c|}
\hline US & RCM & Col. & Procedencia & Nombre original & Denominación Actual & Variedad & $\mathrm{N}^{\circ}$ CTES \\
\hline 690 & 2763 & $\mathrm{BPZ}$ & E. E. Boliche & $\begin{array}{l}\text { cultivar Santa } \\
\text { Rosa }\end{array}$ & cultivar Santa Rosa & hyp & 39979 \\
\hline 691 & 2670 & $\mathrm{BPZ}$ & E. E. Boliche & $\begin{array}{l}\text { cultivar Rojo } \\
\text { del Oriente }\end{array}$ & $\begin{array}{l}\text { Cultivar Rojo del } \\
\text { Oriente }\end{array}$ & per & 39930 \\
\hline 692 & 2757 & ВРZНа & Pedro Carbo & Pepón & Pepón rastrero & hyp & 40617 \\
\hline 692 & 2750 & ВРZНа & Pedro Carbo & Pepón & Pepón cojín & hyp & 39969 \\
\hline $693-1$ & 2743 & ВРZНа & Pedro Carbo & Charapotó & Rosita & fast & 39959 \\
\hline $693-1$ & 2671 & ВРZНа & Pedro Carbo & Charapotó & Negro criollo & per & 39921 \\
\hline $693-1$ & 2704 & ВРZНа & Pedro Carbo & Charapotó & Tingo María & per & 39891 \\
\hline $693-6$ & 2744 & ВРZНа & Pedro Carbo & Charapotó & Overo enano & hyp & 39975 \\
\hline $693-4$ & 2758 & ВРZНа & Pedro Carbo & Charapotó & Pepón rastrero & hyp & 40618 \\
\hline $693-4$ & 2751 & ВРZНа & Pedro Carbo & Charapotó & Pepón cojín & hyp & 39970 \\
\hline 694 & 2764 & ВРZНа & Pedro Carbo & Rosita & Higuerilla & hyp & 39980 \\
\hline 694 & 2765 & ВРZНа & Pedro Carbo & Rosita & Colorado rastrero & hyp & 39992 \\
\hline $695-1$ & 2759 & ВРZНа & Pedro Carbo & Pepón & Pepón rastrero & hyp & 39991 \\
\hline $695-1$ & 2754 & ВРZНа & Pedro Carbo & Pepón & Pepón cojín & hyp & 39971 \\
\hline $695-2$ & 2752 & ВРZНа & Pedro Carbo & Pepón & $\begin{array}{l}\text { Folíolos plegados } \\
\text { salmón }\end{array}$ & hyp & \\
\hline $695-2$ & $2752-1$ & ВРZНа & Pedro Carbo & Pepón & $\begin{array}{l}\text { Folíolos plegados } \\
\text { colorado }\end{array}$ & hyp & 41844 \\
\hline $695-3$ & $2767-1$ & ВРZНа & Pedro Carbo & Pepón & Higuerilla & hyp & 39987 \\
\hline $695-3$ & 2676 & ВРZНа & Pedro Carbo & Pepón & Negro criollo & per & $\begin{array}{l}\text { Negro } \\
\text { criollo }\end{array}$ \\
\hline $695-2$ & 2735 & ВРZНа & Pedro Carbo & Pepón & Rosita & fast & 39955 \\
\hline 696 & 2768 & ВРZНа & Bachiller & & Cojín negro & hyp & 39981 \\
\hline $697-1$ & 2736 & ВРZНа & Bachiller & Rosita & Rosita & fast & 39951 \\
\hline $697-2$ & 2739 & ВРZНа & Bachiller & Rosita & Rosita pálido & fast & 39961 \\
\hline $698-3$ & $2713-1$ & ВРZНа & $\begin{array}{l}\text { Lomas de } \\
\text { Sargentillo }\end{array}$ & Rosita & $\begin{array}{l}\text { Rastrero } \\
\text { salmón }\end{array}$ & hyp & 41835 \\
\hline $698-1$ & 2737 & ВРZНа & $\begin{array}{l}\text { Lomas de } \\
\text { Sargentillo }\end{array}$ & Rosita & Rosita & fast & 39952 \\
\hline $698-2$ & 2740 & ВРZНа & $\begin{array}{l}\text { Lomas de } \\
\text { Sargentillo }\end{array}$ & Rosita & Rosita pálido & fast & 39962 \\
\hline $698-3$ & $2742-1$ & ВРZНа & $\begin{array}{l}\text { Lomas de } \\
\text { Sargentillo }\end{array}$ & Rosita & Rosita sin pico & fast & 41837 \\
\hline $698-3$ & $2742-2$ & ВРZНа & $\begin{array}{l}\text { Lomas de } \\
\text { Sargentillo }\end{array}$ & Rosita & $\begin{array}{l}\text { Color caja } \\
\text { grande }\end{array}$ & fast & 41838 \\
\hline $698-3$ & $2742-3$ & ВРZНа & $\begin{array}{l}\text { Lomas de } \\
\text { Sargentillo }\end{array}$ & Rosita & $\begin{array}{l}\text { Colorado } \\
\text { pequeño }\end{array}$ & fast & 41839 \\
\hline $698-3$ & $2742-5$ & ВРZНа & $\begin{array}{l}\text { Lomas de } \\
\text { Sargentillo }\end{array}$ & Rosita & $\begin{array}{l}\text { Pálido de } \\
\text { Sargentillo }\end{array}$ & fast & 41841 \\
\hline $698-3$ & $2866-2$ & ВРZНа & $\begin{array}{l}\text { Lomas de } \\
\text { Sargentillo }\end{array}$ & Rosita & Colorado precoz & fast & 41849 \\
\hline $698-3$ & 2867 & ВРZНа & $\begin{array}{l}\text { Lomas de } \\
\text { Sargentillo }\end{array}$ & Rosita & Negro planta compacta & fast & \\
\hline
\end{tabular}




\begin{tabular}{|c|c|c|c|c|c|c|c|}
\hline US & RCM & Col. & Procedencia & Nombre original & Denominación Actual & Variedad & $\mathbf{N}^{0}$ CTES \\
\hline $698-3$ & 2677 & ВРZНа & $\begin{array}{l}\text { Lomas de } \\
\text { Sargentillo }\end{array}$ & Rosita & Negro criollo & per & 39932 \\
\hline $698-3$ & 2678 & ВPZHa & $\begin{array}{l}\text { Lomas de } \\
\text { Sargentillo }\end{array}$ & Rosita & Negro criollo & per & 39966 \\
\hline $698-3$ & $2876-1$ & & & & & & \\
\hline $698-3$ & $2876-2$ & & & & & & \\
\hline \multicolumn{8}{|c|}{ Provincia El Oro } \\
\hline $699-1$ & 2680 & ВРZНа & Piña & & Negro criollo & per & 39883 \\
\hline $699-1$ & 2547 & ВPZНа & Piña & & Zaruma & aeq & 39846 \\
\hline $699-4$ & 2647 & ВРZНа & Piña & & Zaruma pálido & aeq & 39893 \\
\hline $700-2$ & 2550 & ВРZНа & Piña & & Zaruma & aeq & 39889 \\
\hline $700-2$ & 2658 & ВPZНа & Piña & & Zaruma rosado & aeq & 39909 \\
\hline $700-1$ & 2682 & ВРZНа & Piña & & Negro criollo & per & 39884 \\
\hline $700-1$ & 2555 & ВРZНа & Piña & & Zaruma & aeq & \\
\hline $700-2$ & 2741 & ВРZНа & Piña & & Colorado de Piñas & fast & 39958 \\
\hline $702-2$ & 2561 & ВPZНа & Piña & & Zaruma & aeq & 40606 \\
\hline $702-2$ & 2648 & ВРZНа & Piña & & Zaruma pálido & aeq & 39894 \\
\hline $702-2$ & 2633 & ВРZНа & Piña & & Huasquillo & aeq & 39815 \\
\hline $702-1$ & 2683 & ВРZНа & Piña & & Negro criollo & per & 39866 \\
\hline $703-2$ & 2563 & ВРZНа & Piña & Charapotó & Zaruma & aeq & \\
\hline $703-3$ & 2649 & ВРZНа & Piña & Charapotó & Zaruma pálido & aeq & 39895 \\
\hline $703-1$ & 2634 & ВPZНа & Piña & Charapotó & Huasquillo & aeq & 39857 \\
\hline $704-1$ & 2566 & ВРZНа & Zaruma & & Zaruma & aeq & 39834 \\
\hline $704-2$ & 2050 & ВРZНа & Zaruma & & Zaruma pálido & aeq & 39896 \\
\hline $704-3$ & 2659 & ВРZНа & Zaruma & & Zaruma rosado & aeq & 39908 \\
\hline $705-1$ & 2571 & ВPZНа & Zaruma & & Zaruma & aeq & 39816 \\
\hline $705-2$ & 2651 & ВРZНа & Zaruma & & Zaruma pálido & aeq & 39903 \\
\hline $705-2$ & 2660 & ВРZНа & Zaruma & & Zaruma colorado & aeq & 39906 \\
\hline $706-2$ & 2578 & ВРZНа & Portovelo & & Zaruma & aeq & \\
\hline $706-3$ & 2652 & ВРZНа & Portovelo & & Zaruma pálido & aeq & 39893 \\
\hline $706-1$ & 2640 & ВРZHа & Portovelo & & Huasquillo & aeq & 39897 \\
\hline $706-2$ & 2684 & ВPZНа & Portovelo & & Negro criollo & per & 39882 \\
\hline $707-2$ & 2584 & ВРZНа & Portovelo & & Zaruma & aeq & 39824 \\
\hline 708 & 2638 & ВРZНа & $\begin{array}{l}\text { El Pindo, } \\
\text { Bado Ancho }\end{array}$ & Huasquillo & Huasquillo & aeq & 39859 \\
\hline 709 & 2586 & ВРZНа & $\begin{array}{l}\text { El Pindo, } \\
\text { Bado Ancho }\end{array}$ & Balón & Zaruma & aeq & 40610 \\
\hline 709 & 2686 & ВРZНа & $\begin{array}{l}\text { El Pindo, } \\
\text { Bado Ancho }\end{array}$ & Balón & Negro criollo & per & 39817 \\
\hline 710 & 2688 & ВРZНа & Ambocos & $\begin{array}{l}\text { Caturro } \\
\text { Balón }\end{array}$ & Negro criollo & per & 39935 \\
\hline \multicolumn{8}{|c|}{ Provincia Loja } \\
\hline $711-1$ & 2706 & ВРZНа & Loja & Criolla & Zapotepamba & fast & 39914 \\
\hline $711-1$ & 2587 & ВPZНа & Loja & Criolla & Zaruma & aeq & 39849 \\
\hline
\end{tabular}


A. Krapovickas et al., Las razas de maní de Ecuador

\begin{tabular}{|c|c|c|c|c|c|c|c|}
\hline US & RCM & Col. & Procedencia & Nombre original & Denominación Actual & Variedad & $\mathrm{N}^{\circ}$ CTES \\
\hline $711-2$ & 2653 & ВРZНа & Loja & Criolla & Zaruma pálido-violáceo & aeq & 39904 \\
\hline $711-1$ & 2641 & ВРZНа & Loja & Criolla & Huasquillo & aeq & 39860 \\
\hline $711-2$ & 2664 & ВРZНа & Loja & Criolla & Criolla? & per & 40613 \\
\hline $711-1$ & 2689 & ВРZНа & Loja & Criolla & Negro criollo & per & 39869 \\
\hline $711-2$ & 2714 & ВРZНа & Loja & Criolla & Morado de Cotacocha & per & \\
\hline 712 & 2707 & ВРZНа & Catacocha & Charapotó & Zapotepamba & fast & 39910 \\
\hline 713 & 2717 & ВРZНа & Catacocha & & Catalán & per & 39878 \\
\hline 713 & 2642 & ВРZНа & Catacocha & & Huasquillo & aeq & 39861 \\
\hline $714-2$ & 2588 & ВРZНа & Catacocha & & Zaruma & aeq & 39825 \\
\hline $714-2$ & 2644 & ВРZНа & Catacocha & & Huasquillo & aeq & 39862 \\
\hline $714-2$ & 2722 & ВРZНа & Catacocha & & Catalán & per & 39937 \\
\hline $714-2$ & 2715 & ВРZНа & Catacocha & & Verde de Catacocha & per & 39874 \\
\hline $715-1$ & 2725 & ВРZНа & Catacocha & & Catalán & per & 39876 \\
\hline $715-2$ & 2592 & ВРZНа & Catacocha & & Zaruma & aeq & 39837 \\
\hline 716 & 2710 & ВРZНа & Catacocha & & Zapotepamba & fast & 39911 \\
\hline $717-2$ & 2594 & ВРZНа & Catacocha & & Zaruma & aeq & 39844 \\
\hline $717-2$ & 2595 & ВРZНа & Catacocha & & Zaruma & aeq & 39838 \\
\hline $717-1$ & 2692 & ВРZНа & Catacocha & & Negro criollo & per & 39925 \\
\hline $717-2$ & 2694 & ВРZНа & Catacocha & & Criolla & per & 39983 \\
\hline $717-2$ & 2714 & ВРZНа & Catacocha & & Morado de Cartacocha & per & 39965 \\
\hline 718 & 2727 & ВРZНа & Catacocha & & Catalán & per & 39939 \\
\hline 719 & 2695 & ВРZНа & Catacocha & & Negro criollo & per & 39817 \\
\hline $719-1$ & 2599 & ВРZНа & Catacocha & & Zaruma & aeq & 39828 \\
\hline $719-3$ & 2654 & ВРZHа & Catacocha & & $\begin{array}{l}\text { Zaruma } \\
\text { pálido }\end{array}$ & aeq & 39899 \\
\hline $720-3$ & 2602 & ВРZНа & Yamana & Criolla & Zaruma & aeq & 39826 \\
\hline 721 & 2728 & ВРZНа & Casanga & Catalán & Catalán & per & 39942 \\
\hline 722 & 2729 & ВPZНа & Casanga & Catalán & Catalán & per & 39943 \\
\hline 722 & 2663 & ВРZНа & Casanga & Catalán & Catalán & per & 40612 \\
\hline 722 & 2609 & ВРZНа & Casanga & Criolla & Zaruma & aeq & \\
\hline 722 & 2610 & ВРZНа & Casanga & Criolla & Zaruma & aeq & \\
\hline 723 & 2711 & ВРZНа & Casanga & Zapotepamba & Zapotepamba & fast & 39915 \\
\hline $724-2$ & 2612 & ВРZНа & Macará & Criolla & Zaruma & aeq & 39841 \\
\hline 724 & 2699 & ВРZНа & Macará & Criolla & Negro criollo & per & 39918 \\
\hline 725 & 2614 & ВРZНа & Macará & Criolla & Zaruma & aeq & 39818 \\
\hline 726 & 2730 & ВРZНа & Macará & Criolla & Catalán & per & 39926 \\
\hline 727 & 2701 & ВРZНа & Macará & Criolla & Negro criollo & per & 39820 \\
\hline $728-3$ & 2616 & ВРZНа & Yurusali & Criolla & Zaruma & aeq & 39819 \\
\hline $728-1$ & 2655 & ВРZНа & Yurusali & Criolla & $\begin{array}{l}\text { Zaruma } \\
\text { pálido }\end{array}$ & aeq & 39900 \\
\hline $729-1$ & 2625 & ВРZНа & Chaguarpamba & Criolla & Zaruma & aeq & 39843 \\
\hline $729-3$ & 2656 & ВРZHа & Chaguarpamba & Criolla & $\begin{array}{l}\text { Zaruma } \\
\text { pálido }\end{array}$ & aeq & 39901 \\
\hline
\end{tabular}




\begin{tabular}{|c|c|c|c|c|c|c|c|}
\hline US & RCM & Col. & Procedencia & Nombre original & Denominación Actual & Variedad & $\mathrm{N}^{\circ}$ CTES \\
\hline $729-2$ & 2645 & ВРZНа & Chaguarpamba & Criolla & Huasquillo & aeq & 40611 \\
\hline \multicolumn{8}{|c|}{ Provincia El Oro } \\
\hline $730-3$ & 2628 & ВРZНа & Balsas & Criolla & Zaruma & aeq & 39830 \\
\hline $730-1$ & 2632 & ВPZНа & Balsas & Criolla & Zaruma & aeq & \\
\hline $730-2$ & 2657 & ВРZНа & Balsas & Criolla & $\begin{array}{l}\text { Zaruma } \\
\text { pálido }\end{array}$ & aeq & 39902 \\
\hline \multicolumn{8}{|c|}{ Provincia Guayas } \\
\hline $731-1$ & 2747 & ВРZНа & Guayaquil & & Overo compacto & hyp & 39976 \\
\hline $731-2$ & 2738 & ВРZНа & Guayaquil & & Rosita & fast & 39956 \\
\hline \multicolumn{8}{|c|}{ Provincia Pichincha } \\
\hline 732 & 2769 & BPVa & San Antonio & & Medio mundo & hirs & 40620 \\
\hline 733 & 2770 & BPVa & Runicucho & & Medio mundo & hirs & 39995 \\
\hline
\end{tabular}

Abreviaturas: aeq: var. aequatoriana, Cat.: Catálogo, Col.: Coleccionistas, fast: var. fastigiata, GRIF: Registro de colecciones de Williams, hirs: var. hirsuta, hyp.: var. hypogaea; Mdi.: Manfredi, per: var. peruviana, PI: Plant Introductions, RCM: Registro Córdoba Manfredi, US: Número bajo el cual fue introducido a los Estados Unidos de Norteamérica.

En 1995, se realizó una nueva expedición, integrada por David E. Williams (IPGRIAméricas), Karen A. Williams (USDAARS) y Cesar Tapia (INIAP-DENAREF) de Quito, Ecuador. Realizaron colecciones de muestras en Quito, Lago Agrio, Coca, Puerto Misahualli, Puyo, Macas, Gualaquisa, Loja, Zaruma, Crucita, con la sigla de coleccionistas WWT.

En 1996, se realizó un nuevo viaje, a cargo de Karen Williams, Charles Simpson, Texas A \& M, University, Stephenville y Cesar Tapia (DENAREF), Quito, Ecuador, con la sigla WTS, enriqueciendo las colecciones de Manfredi. El detalle de ambos viajes figura a continuación de las descripciones de las razas.

\section{Bibliografía}

BANKs, D. C. (1983). The collections of Arachis hypogaea germplasm, from Ecuador. Technical Report to the IBPGR 3-24.

Gregory, W. C. (1977). The collection of peanut germplasm 1976-1977. Technical Report to the IBPGR. MSS 118 pp.
KrapoVICKAS, A. \& V. A. RigONI. (1960). La nomenclatura de las subespecies y variedades de Arachis hypogaea $\mathrm{L}$. Revista de Investigaciones Agropecuarias 14: 197-228.

Krapovickas, A. \& Gregory, C. (1994). Taxonomía del género Arachis (Leguminosae). Bonplandia 8: 1-186. https://doi.org/10.30972/bon.160158

Krapovickas, A.,Vanni, R. O., Williams, D. E., Williams, K. A. \& SÁnchez, R. (2001). Los maníes de Guatemala y sus relaciones con México y Ecuador. III Simpósio de Recursos Genéticos para América Latina y el Caribe, Londrina, Paraná. Brasil, pp. 5662.

Pietrarelli, J.R. \& Krapovickas, A. (1990). Catálogo semianalítico de los maníes cultivados (Arachis hypogaea L.) originarios de la región andina (Bolivia, Perú, Ecuador), conservados en la estación Experimental Agropecuaria de Manfredi (Provincia de Córdoba) R. Argentina. INTA Manfredi, 32 pp.

Williams, D. E., Williams, K. \& Tapia, C. (1995). Collections of germoplasm of landraces and other peanut varieties grown in Ecuador. Technical Report to de IPGRI-Americas, $27 \mathrm{pp}$.

Williams, K. A., TAPiA, C. \& Simpson, C. (1996). Complete the collections of germplasm of representative landraces and other peanut varieties grown in Ecuador. Technical Report USDA-ARS, 45 pp. 